\title{
III. Nonkonformes Verhalten der Zeugen Jehovas und staatliche Repression
}

\section{Die Verschärfung des Konfliktes: Wahlenthaltung, Verweigerung von Beflaggung, „Hitler-Gruß“ und Eingliederung in die NS-Massenorganisationen}

Neben dem Vorgehen gegen die Bibelforschervereinigung als Organisation gab es von Anfang an auch Repressionen gegen die einzelnen Gläubigen. Die Forderungen, die der ,neue Staat“ und die ihn tragende Partei auf allen Ebenen des öffentlichen Lebens stellten, waren unvereinbar mit den Glaubensgrundsätzen der Zeugen Jehovas und den ihnen obliegenden Verpflichtungen zur unbedingten und ausnahmslosen Befolgung aller biblischen Weisungen.

Den ersten offenen Konflikt brachten die Reichstagswahlen vom 5. März 1933. Bei den vorangegangenen freien Wahlen bestand für die Zeugen Jehovas kein Problem darin, gemäß ihrer Glaubensüberzeugung, die ihnen Neutralität in politischen Fragen gebot, dem Aufruf zur Wahl keine Folge zu leisten. Mit der Wahl vom 5. März 1933 veränderte sich jedoch der Charakter von Wahlen in Deutschland gründlich. Die Nationalsozialisten wollten eine starke Mehrheit für ihren fünf Wochen zuvor an die Spitze einer Koalitionsregierung berufenen Reichskanzler und „Führer“ Adolf Hitler erzwingen. Deshalb versuchten SA-Trupps und andere Parteiformationen die Bevölkerung zur Stimmabgabe für die Liste 1 (NSDAP) zu nötigen. Jene Wahlschlepper erschienen an den Haustüren, forderten zur Wahlbeteiligung auf und beabsichtigten, möglichst jeden zum Wahllokal zu bringen. Wer sich diesem Ansinnen verweigerte, galt als verdächtig beziehungsweise als nicht bereit, sich zum „,neuen Staat“ und seinen Reichskanzler zu bekennen. Auf diese Weise wurden Regimegegner ausgemacht, selbst wenn diese sich selbst gar nicht als solche empfanden. So war für die Nationalsozialisten auch die religiös begründete Wahlenthaltung der Zeugen Jehovas ein offenkundiger Beweis für deren vermeintliche Feindschaft beziehungsweise Unzuverlässigkeit in bezug auf den Hitler-Staat.

Die Motive der Zeugen Jehovas bewegten sich jedoch in einer anderen Sphäre. Sie begründeten ihre Entscheidung ausschließlich religiös: „Wir beteiligen uns nicht an der Wahl, weil wir unseren König Christus ein für allemal gewählt haben und ihm folgen werden, wohin er geht. Wir kämpfen für ihn und mit ihm, weil wir ihn lieben, achten und kennen! Warum will man uns unbedingt an der Wahlurne haben?"1

Die Wahl eines anderen als Adolf Hitler - und sei es auch König Christus - war aber eine Vorstellung, die dem Selbstverständnis des nationalsozialistisch beherrschten Staates fundamental widersprach. Die schrankenlose Ausschließlichkeit der nationalsozialistischen Ideologie bildete deshalb selbst schon einen wichtigen Grund für die Verfolgung der Zeugen Jehovas im „Dritten Reich“.

1 Aus einer während des „Dritten Reiches“ im Untergrund kursierenden Bibelforscherschrift mit dem Titel „Unser Kampf und Hitlers ,Mein Kampf““, zit. nach Steinberg, Essen, S. 162. 
War es bei den auch bereits unter dem Eindruck des beginnenden Terrors veranstalteten Wahlen vom 5. März gegenüber den Zeugen Jehovas noch zumeist bei psychischem Druck geblieben, so kam es bei der mit einer Reichstagswahl verbundenen Volksabstimmung am 12. November 1933 über den Austritt des Deutschen Reiches aus dem Völkerbund sowie bei den folgenden Scheinwahlen des Einparteienstaates zu massiven Übergriffen. Bei den Zeugen Jehovas - wie auch bei anderen, die sich aus politischen Gründen der Wahlbeteiligung entzogen - drangen SA-Leute in die Wohnungen ein, beschimpften und bedrohten sie. Die Betroffenen wurden mit Gewalt zu den Wahllokalen geschleppt. Verweigerten sie weiterhin die Stimmabgabe, so setzten sie sich der Gefahr schwerer Mißhandlungen aus.

Obgleich es auch im nationalsozialistischen Deutschland de jure keine Wahlpflicht gab ${ }^{2}$, herrschte de facto ausnahmslos Wahlzwang. Die Berufung der Zeugen Jehovas auf die nach dem Gesetz jedem Bürger freigestellte Teilnahme erwies sich als zwecklos. Die Vertreter der politischen Polizei sahen diesbezüglich auch ohne rechtliche Grundlage eine den „Volksgenossen“ auferlegte Pflicht als gegeben an. In einem Bericht des Geheimen Staatspolizeiamtes über das Verhalten der Zeugen Jehovas bei den Wahlen vom 12. November 1933 heißt es beispielsweise: „Ehemalige Mitglieder der Sekte, die durch den Wahlschlepperdienst zur Beteiligung an der Wahl aufgefordert wurden, weigerten sich mit aller Entschiedenheit, ihrer Wahlpflicht zu genügen, und zwar unter Berufung darauf, daß die Bibel nach Auslegung der Sekte ihnen verbiete, sich an der Wahlhandlung zu beteiligen." ${ }^{3}$ Für die Gestapo bewies die Wahlverweigerung, ,daß die angeblich religiöse Überzeugung der Internationalen Bibelforscher [...] sich mit den Staatsbürgerpflichten im nationalsozialistischen Staat schlechterdings nicht vereinigen läßt"4 . Der Leiter der Bayerischen Politischen Polizei, Reinhard Heydrich, der die von den Bibelforschern praktizierte Nicht-Beteiligung an der Novemberwahl auf eine ihnen erteilte „Anweisung“ meinte zurückführen zu können, hielt es sogar für geboten, gegen die Verantwortlichen gegebenenfalls mit Schutzhaftmaßnahmen vorzugehen, da - wie er in einem Runderlaß vom 27. Dezember 1933 ausführte - ,derartige Vorkommnisse“ geeignet seien, „die Bevölkerung zu erregen und die öffentliche Ruhe und Ordnung zu stören"5.

Mancherorts sahen sich die Zeugen Jehovas nach den Wahlen vom 12. November dem öffentlichen beziehungsweise parteilich dekretierten Zorn ausgesetzt. So wurden sie beispielsweise von SA-Trupps, die ihnen verhöhnende Plakate mit Aufschriften wie „Wir sind Landesverräter, wir haben nicht gewählt“ umgehängt hatten, zum Gespött der Öffentlichkeit durch die Straßen getrieben ${ }^{6}$. In der sächsischen Kleinstadt Oschatz wurde ein Bibelforscher auf einem von SA-Trommlern eskortierten Pferdefuhrwerk zweieinhalb Stunden lang durch den Ort gefahren und

\footnotetext{
2 Wenn es sich bei der Frage der Wahlteilnahme auch „um ein nationales Gebot ersten Ranges“ handele, wie 1935 der Rechtswissenschaftler Werner Weber befand, so könne doch das in den Wahlen bekundete „Bekenntnis zu Führer und Volk“ nur dann seinen Sinn erfüllen, sofern es „aus freiem Entschluß“ erwachse (Weber, Dienst- und Leistungspflichten, S. 5ff.).

3 BA, R 58/1068, BI. 172, Geheimes Staatspolizeiamt, Mitteilungen Nr. 4, 10.3.1934.

4 Ebenda.

5 IfZ, MA 554, 936374, BPP, RdErl. vom 27.12.1933.

$6 \mathrm{Vgl}$. Zürcher, Kreuzzug, S. 126ff.
} 
in Sprechchören als „Lump“ und „Vaterlandsverräter“ verschrien”. In dem vor den Toren Stettins gelegenen Pölitz stellte man für drei Wochen auf dem Marktplatz eine „Schandtafel“ auf, die auf einer „Liste der Volksverräter“ die Namen von den ortsansässigen Bibelforschern aufführte, die die Wahlteilnahme verweigert hatten ${ }^{8}$.

In einigen Fällen blieb es nicht bei derartigen Schikanen. Ein oder zwei Tage nach der Novemberwahl wurde das abseits gelegene Gehöft der in der Nähe von Schwäbisch-Gmünd wohnhaften Landwirtseheleute Uhlmann, die der mehrfachen Aufforderung zur Teilnahme an den Wahlen nicht nachgekommen waren, ,,von unbekannter Hand" angezündet. Stall, Scheune und Wohnhaus brannten vollständig aus; die wirtschaftliche Existenz der Familie war damit weitgehend zerstört. Im Verlauf des eingeleiteten Ermittlungsverfahrens wurde aber der Geschädigte selbst der Brandstiftung beschuldigt und in Untersuchungshaft genommen; erst als sich herausstellte, daß der Hof nicht versichert war, wurde der Vorwurf des Versicherungsbetruges fallengelassen. Weitere Ermittlungen erfolgten nicht; das Verfahren wurde ergebnislos eingestellt ${ }^{9}$. Noch schwerwiegendere Folgen hatte ein Vorfall, der sich in Bochum am Wahltag zugetragen hatte. Der 52jährige Berginvalide Rudolf Nicolaus war durch einen SA-Trupp gewaltsam aus der Wohnung geholt und zu dem in der Johanniterstraße 8 gelegenen SA-Heim verschleppt worden. Von den Folgen der ihm dort mit Gummiknüppeln zugefügten Mißhandlungen konnte der an einer Steinstaublunge erkrankte Mann sich nicht mehr erholen; er starb nach einigen Monaten ${ }^{10}$.

$\mathrm{Zu}$ ähnlichen Verkommnissen kam es auch bei den „Volksabstimmungen“ und „Wahlen“ der folgenden Jahre. Oftmals marschierten größere Gruppen von Parteianhängern noch am Wahlabend zu Haus oder Wohnung der Zeugen Jehovas. An einen derartigen „Volksauflauf“ hat eine seinerzeit in Leutenbach (Kreis Waiblingen) wohnhafte Zeugin Jehovas folgende Erinnerungen: „Tatsächlich kam dann nach der Wahl, bei Nacht eine Rotte und schrie vor unserem Haus im Sprechchor, wir Volksverräter sollten herauskommen. Wir blieben aber hinter verschlossenen Türen und Fensterläden einfach ruhig, wenn sie auch Steine gegen die Fensterläden warfen. Dann beschmierten sie die ganze Hauswand mit der Aufschrift: ,Volksverräter. Ich habe Deutschland verraten! “"11

7 Vgl. Jahrbuch 1974, S. $115 f$.

8 Vgl. Pommern 1934/35/Quellen, S. 410-413.

9 EB Elise Kühnle, 23.11.1987. Auf dieses Ereignis hat auch der ehemalige württembergische Landesvorsitzende des Kommunistischen Jugendverbandes Deutschlands und Widerstandskämpfer Friedrich Schlotterbeck in seinem unmittelbar nach Kriegsende abgefaßten Erlebnisbericht „Je dunkler die Nacht ... Erinnerungen eines deutschen Arbeiters 1933-1945“ Bezug genommen (vgl. Schlotterbeck, Erinnerungen, S. 297-299). Als der 1933 erstmals verhaftete Schlotterbeck während des Krieges erneut untertauchen mußte, erinnerte er sich des Bibelforschers Karl Uhlmann, mit dem er zusammen im KZ Welzheim inhaftiert war, und suchte dessen in einem abgelegenen Waldtal in der Nähe des schwäbischen Dorfes Haselbach befindliches Anwesen auf, um sich dort zu verbergen: „SA-Leute hatten sein Haus angezündet, die Feuerwehr durfte nicht löschen, und das Haus durfte nicht wieder aufgebaut werden. Jetzt wohnte er in der Ruine." (Ebenda, S. 298)

10 Vgl. Zürcher, Kreuzzug, S. 114, 171.

11 EB Minna Knöller, 8.6.1984. 
Die Zeugen Jehovas versuchten, an Wahltagen den Schwierigkeiten so weit wie möglich auszuweichen ${ }^{12}$. Viele von ihnen gingen frühmorgens aus dem Haus, verbargen sich tagsüber außerhalb von Ortschaften und kehrten erst nach Dunkelheit, nachdem die Wahllokale geschlossen waren, wieder zu ihrer Wohnung zurück. Andere Zeugen Jehovas, vor allem jene, die sich in der Verbotszeit von der Betätigung im Verkündigungswerk zurückgezogen hatten, beugten sich dem Druck und beteiligten sich an den Wahlen; Berichten zufolge machten einige die Wahlzettel ungültig, beispielsweise durch Aufschriften wie „Etwas Verabscheuungswürdiges ist jeder, der euch erwählt (Jes 41: 24)“. Es gab aber auch Zeugen Jehovas, wenngleich wohl nur eine kleine Minderheit, die ihre Verweigerungshaltung ganz aufgaben, etwa mit dem Argument, daß eine Abstimmung wie jene, die am 10. April 1938 über die „Eingliederung“ Österreichs stattfand, keine mit dem „biblischen Neutralitätsgebot" in Konflikt stehende Stellungnahme zu einer im eigentlichen Sinne politischen Entscheidung fordere.

Vielfach waren Zeugen Jehovas die einzigen im Ort, die nicht zur ,Wahl“ gingen. Gerade in kleinen Dörfern waren sie dabei starken Nötigungen ausgesetzt, da sie allein die Absicht der örtlichen Parteiführer, bei den Wahlen mit HundertProzent-Ergebnissen aufzuwarten, zunichte machten. Andererseits gab es gerade dann, wenn sie seit langem in ihrem sozialen Umfeld eingebunden und in vornationalsozialistischer Zeit ein akzeptiertes Mitglied der Dorfgemeinschaft waren, auch Personen, selbst solche mit Parteiabzeichen, die ihrerseits mögliche Konflikte zu vermeiden versuchten. Von ihnen wurde beispielsweise der Rat gegeben, sich pro forma zu beteiligen und einfach den leeren Zettel einzuwerfen; die Sache mit dem Ergebnis werde man schon zu organisieren wissen. Eine derartige Taktik, die der Glaubensüberzeugung der Zeugen Jehovas wie dem Wahlresultat Rechnung zu tragen versuchte, war hingegen nicht die Sache jener, die vor Gott und der Welt ein aufrichtiges Bekenntnis abzulegen entschlossen waren.

Die Verfolgungsinstanzen kannten hinsichtlich der Wahlverweigerung keine Nachsicht. Sie sahen in der Entscheidung der Zeugen Jehovas ,politische Momente", die deren „Gefährlichkeit" unterstrichen. Berichtete die Staatspolizeistelle Kassel anläßlich der Volksabstimmung vom 19. August 1934, mit der sich Hitler nach dem Tode Hindenburgs die Übernahme des Reichspräsidentenamtes bestätigen ließ, daß die Bibelforscher ,an verschiedenen Orten trotz guten Zuredens nicht dazu zu bewegen [waren], sich an der Wahl zu beteiligen" 13 , so war in den späteren Jahren der Euphemismus der nüchternen Prosa gewichen. Im Jahreslagebericht 1938 des Sicherheitshauptamtes des Reichsführers-SS wurde beispielsweise vermerkt, daß sich unter den 700 in Schutzhaft genommenen Bibelforschern zahlreiche Personen befanden, ,die am 10.4.1938 in aller Öffentlichkeit die Teilnahme an der Wahl verweigert und gegen den Führer gehetzt hatten"14.

12 Die folgende Darstellung stützt sich auf: EB Liesel Baroni, 8.6.1984; EB Hanna Bläse, Juni 1984; EB Hedwig Ehmann, 3.5.1984; EB Bruno Knöller, 23.11.1987; EB Gustav Widmaier, Juni 1984; EB Karl-Heinz Zietlow, 25.1.1986.

13 Staatspolizeistelle Kassel, Lagebericht für den Monat August 1934 vom 5.9.1934, Die Lageberichte der Geheimen Staatspolizei über die Provinz Hessen-Nassau, S. 154.

14 Jahreslagebericht 1938 des Sicherheitshauptamtes, BA, R 58/1094, B1. 76. 
Noch stärker als die Wahlfrage führte die Verweigerung des „Hitler-Grußes“ zu schweren Konflikten mit dem NS-Staat. Einem Menschen das nach biblischem Verständnis allein Gott vorbehaltene „Heil“ zuzusprechen, berührte eine zentrale Frage christlicher Identität. Für die Zeugen Jehovas begründete der Gebrauch des Wortes „Heil“ eine religiöse Formel, die von der Berufung auf Gott untrennbar war. Dabei bezogen sie sich zum einen auf das Gelöbnis gegenüber dem einen und einzigen Gott, so wie es im „Vater unser“ mit den Worten „Geheiligt werde Dein Name“ bekräftigt wird, und zum anderen auf die ausschließliche Zuschreibung des Heils auf den „Erlöser“ und „Heilsbringer“, von der es im Zeugnis der Apostelgeschichte heißt: „Und es ist in keinem anderen [als Christus] das Heil; denn es ist auch kein anderer Name unter dem Himmel für die Menschen gegeben, durch den wir gerettet werden sollen.“ 15 Der „Hitler-Gruß“ bedeutete demgegenüber, daß einem Menschen ,heilbringende“ Kraft zugeschrieben wurde. Nach Überzeugung der Zeugen Jehovas stellte dieser auf den „Führer“ zu leistende Heilsgruß damit sowohl eine Gotteslästerung als auch eine nach der Bibel verbotene Menschenverherrlichung dar. Für sie war der Ausspruch „Heil Hitler“ deshalb mehr als der Ausdruck eines politischen Bekenntnisses zum Regime und Huldigung eines Personenkultes; für bekennende Zeugen Jehovas war der „Hitler-Gruß“ gleichbedeutend mit der Verleugnung Christi.

Die Nationalsozialisten waren nicht im geringsten bereit, auf derartige religiöse Erwägungen Rücksicht zu nehmen. Sie forderten von jedem „Volksgenossen“ die dem „Führer“ auf diese Weise zu bekundende Ehrenbezeigung. Auch für sie war der Gruß mehr als nur eine Formalie, aber auch mehr als die Ritualisierung des Führerprinzips. Der „Hitler-Gruß“ war zugleich ein mit Bedacht eingeführtes Mittel zur Gewissenskontrolle und ein Instrument der Herrschaftssicherung, da er den eigenen Anhängern das Gefühl der Selbstbestätigung vermittelte, während er Gegner oftmals in ihrer Integrität zu erschüttern vermochte ${ }^{16}$.

Die unbeugsame Haltung vieler Zeugen Jehovas in der Grußfrage zog schwere Folgen nach sich. Neben willkürlichen Mißhandlungen und Provokationen durch SA-Trupps kam es bereits 1933 zu Festnahmen wegen der Verweigerung des GruBes. Beispielsweise wurde in Hamburg ein Bibelforscher, der auf einer Feier die Hand zum Gruß nicht erhoben hatte, von der Staatspolizei verhaftet und im Stadthaus, dem Hamburger Gestapo-Quartier, geschlagen, als er sich „unbelehrbar“ zeigte $^{17}$. Zu Beginn des „Dritten Reiches“ kamen die Betroffenen meistens nach

15 Apg 4, 12 .

16 Der Psychologe Bruno Bettelheim hat darauf hingewiesen, daß der Grußzwang nicht nur eine fortwährende öffentliche Loyalitätsbekundung jedes einzelnen zum „neuen Staat" einforderte, sondern auch darauf abzielte, die Integrität der Regimegegner zu brechen, indem ihnen durch die tagtägliche Nötigung, gegen ihre eigene Überzeugung handeln zu müssen, die Selbstachtung genommen werden sollte: „Jedesmal, wenn er in der Öffentlichkeit grüßen mußte, war das für ihn ein Erlebnis, das seine Integration erschütterte und schwächte. Um es genauer auszudrükken: wenn ihn die Situation zum Grüßen zwang, fühlte er sich sofort als Verräter an seinen tiefsten Überzeugungen. [...] So mußte also ein Antinazi viele Male am Tag zum Märtyrer werden oder seine Selbstachtung aufgeben." (Bettelheim, Aufstand, S. 313, vgl. ausführlicher Bettelheim, Die psychische Korruption, S. 332ff.)

17 EB Alfred Knegendorf, 29.1.1985; VVN, Komiteeakten K 14. 
mehreren Stunden oder einigen Tagen wieder aus der Polizeihaft frei ${ }^{18}$. Das änderte sich im Zusammenhang mit der verstärkten Verfolgung der Zeugen Jehovas seit 1934/35. Zuweilen wurden nun sogar Einweisungen in die Konzentrationslager nur mit der Verweigerung des „Deutschen Grußes“ begründet. Auf einem Schutzhaftbefehl aus dem Jahre 1936 ist dazu lediglich vermerkt: „Durch sein Verhalten hat er das Ärgernis der Bevölkerung in hohem Maße erregt."19 Im Jahre 1937 wurde ein gerade verheiratetes Paar von der Gestapo verhaftet, weil es bei der vor dem Standesamt in Görlitz vollzogenen Trauung der Aufforderung des Standesbeamten nach Erweisung des „Deutschen Grußes“ nicht nachgekommen war ${ }^{20}$. In Düsseldorf erfolgte Mitte 1939 die Festnahme eines Zeugen Jehovas, der von Beruf Symphoniker war, deshalb, weil er zu Beginn einer Opernaufführung den „Hitler-Gruß“ des Orchesterwarts nicht erwidert hatte. Erst nach über fünf Jahren KZ-Haft in Sachsenhausen und Neuengamme kam er wieder frei ${ }^{21}$.

Trotz derartiger Konsequenzen ließen sich viele Zeugen Jehovas nicht von ihrer Glaubensüberzeugung abbringen. In einem Haftprüfungsbericht, den der Kommandant des Frauen-KZ Moringen am 7. März 1935 abfaßte, heißt es über die Bibelforscherin Rosina G., sie müsse als ,unbelehrbar“ gelten, denn sie habe erklärt, „daß sie lieber 10 Jahre im Werkhaus säße, als mit dem Wort ,Heil“ den Namen ,Hitler“ zu verbinden“ 22 .

In dem Weltanschauungsstaat, der ein öffentliches Bekenntnis zu seinen Grundsätzen und Zielen verlangte, war kein Raum für ,Neutralität“. Die zunehmend totale Erfassung der Bevölkerung in den Parteigliederungen und den Massenorganisationen, aber auch etwa der Aufbau des Blockwartwesens führten zu einem System gesellschaftlicher Kontrolle, das jede dem Regime nicht gefällige Haltung zu registrieren suchte. Von der Nicht-Teilnahme an Veranstaltungen und Umzügen, von der Ablehnung eines Beitrages für eine der zahlreichen von den Nationalsozialisten durchgeführten Haus- oder Straßensammlungen oder von der Verweigerung des Fahnenaushanges wurde genau Notiz genommen. Der Eifer der bestellten oder selbsternannten Überwacher wurde im Blick auf die Zeugen Jehovas noch dadurch bestärkt, daß diese ihre Haltung häufig offen demonstrierten und sich dann, ungeachtet der möglichen Folgen, auch nicht scheuten, ihre Meinung frei heraus zu sagen. So hatte ein Bibelforscher aus Wewelsfleth bei Glückstadt, der bei einem vom Absingen der erste Strophe des Deutschlandliedes und des Horst-WesselLiedes begleiteten Stapellauf beide Hände tief in die Hosentasche gesteckt hatte, anstatt wie die anderen Belegschaftsmitglieder das Schiff mit erhobener Hand zu grüßen, auf Vorhaltungen provokant erwidert: ,... die zweite [richtig: die dritte]

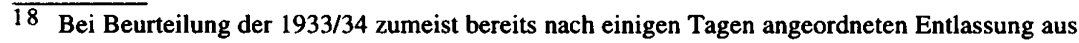
der Polizeihaft ist auch zu berücksichtigen, daß die anfangs großteils noch improvisierten Verfolgungsmaßnahmen stärker auf die Abschreckung und eine dadurch bewirkte „Umstellung“ zielten - wofür ein kurzer rigoroser Zugriff durchaus ausreichend sein konnte - als auf eine längere Inhaftnahme bzw. auf eine dauernde Absonderung von der „Volksgemeinschaft".

DCB, Bezirksamt Schongau, Schutzhaftbefehl vom 7.2.1936.

20 EB Paul Scholz, 6.6.1984.

21 UaP Günther Schwarberg, Tagebuch von Ernst Schneider.

22 Zit. nach Zipfel, Kirchenkampf, S. 185. 
Strophe wagt ihr wohl nicht mehr zu singen, von wegen Einigkeit und Recht und Freiheit." 23

Ebenso wie den „Hitler-Gruß“ empfanden die Zeugen Jehovas auch das Grüßen der Fahne als einen Akt der Anbetung und damit als heidnischen Götzendienst. Sich vor einem Symbol des Staates zu verbeugen, war für sie ausgeschlossen. Sie beriefen sich dabei auf das Beispiel der ersten Christen, die sich geweigert hatten, das Standbild des Kaisers zu grüßen, und verwiesen darauf, daß sie mit ihrer Haltung schließlich ,nicht gegen das Gesetz“ verstießen ${ }^{24}$. Den Justizorganen galt jedoch bereits der Nicht-Besitz einer Hakenkeuzfahne als hinreichender Beweis für eine in Gerichtsverfahren entscheidungsrelevante NS-Gegnerschaft ${ }^{25}$. So traten neben die willkürlichen Schikanen und Mißhandlungen, die oft im Zusammenhang mit gezielten Provokationen standen, etwa wenn SA-Trupps Zeugen Jehovas stellten und sie ultimativ aufforderten, die mitgeführte Fahne zu grüßen ${ }^{26}$, auch justitielle Folgen. Eine Bibelforscherin aus Knittelfeld (Steiermark) mußte beispielsweise Ende der dreißiger Jahre aufgrund eines Gerichtsbeschlusses ihre an der Straßenfront gelegene Wohnung räumen, weil sie sich beharrlich geweigert hatte, eine Hakenkreuzfahne hinauszuhängen ${ }^{27}$.

Wenn die Justiz einen möglichen Anknüpfungspunkt fand, konnte es sogar zu einer Strafverfolgung derartiger Verweigerungshaltungen kommen. Am 21. November 1940 verurteilte das Sondergericht St. Pölten einen Bibelforscher aus Hofstaat (Niederösterreich), der sich geweigert hatte, für das Winterhilfswerk zu spenden, zu 15 Monaten Gefängnis. Das Gericht stützte sein Urteil auf das Heimtückegesetz $^{28}$, da jener Leopold Höflinger zu den SA-Männern mit der Sammelbüchse gesagt hatte: „Nein, für oder zum Leuteerschießen gebe ich nichts her." 29 War eine juristische Handhabe nicht möglich, so regelte die Gestapo derartige Fälle im eigenen Zuständigkeitsbereich. Für den Kaufmann Martin Heinel aus dem westfälischen Eickhorst, der im Sommer 1940 bei einer Sammlung für die Winternothilfe erklärt hatte, daß er wohl etwas geben würde, ,wenn er genau wüßte, daß für dieses Geld keine Kriegswaffen gekauft würden", folgte auf die Festnahme eine annähend fünfjährige KZ-Haft in Dachau, Buchenwald und Natzweiler ${ }^{30}$.

Auch die Zuflucht zu gewissen Schutztaktiken, etwa stets mit zwei Taschen zum Einkaufen zu gehen, um nicht in die Verlegenheit zu kommen, den Arm heben zu müssen, oder das Taschentuch vor die Nase zu halten, wenn jemand auf der Straße

23 Zit. nach Möller, Steinburg, S. 214.

24 Vgl. die bei Steinberg, Essen, S. 162, abgedruckte Bibelforscherschrift „Unser Kampf und Hitlers ,Mein Kampf“".

25 Vgl. Richterbriefe, S. 48.

26 Vgl. Zürcher, Kreuzzug, S. 112; VVN HH, Komiteeakten F 9 und L 6.

27 Vgl. Jahrbuch 1989, S. 101.

28 Gesetz gegen heimtückische Angriffe auf Staat und Partei und zum Schutz der Parteiuniformen vom 20.12.1934, RGBl. 1934 I, S. 1269. Nach § 2 wurde mit Gefängnis bestraft, ,wer öffentlich gehässige, hetzerische oder von niedriger Gesinnung zeugende Äußerungen [...] macht, die geeignet sind, das Vertrauen des Volkes zur politischen Führung zu untergraben“.

29 Gestapo Wien, Tagesrapport Nr. 4 v. 10.-12.1.1941, Mitterrutzner, Niederösterreich, S. 293; vgl. auch ebenda, S. 276. Höflinger wurde nach Strafverbüßung in das KZ Dachau überstellt.

$30 \mathrm{Vgl}$. Struckmeier, Heinel, S. 162f. 
mit der Sammeldose erschien ${ }^{31}$, konnte nicht verhindern, daß jeder einzelne sich immer wieder Situationen ausgesetzt sah, in denen er nicht ausweichen konnte, sondern sich entscheiden mußte. Dies war beispielsweise dann der Fall, wenn Zeugen Jehovas wegen eines noch nicht vollzogenen Beitrittes zu einer der Massenorganisationen, in denen die Nationalsozialisten die ganze Bevölkerung zu erfassen suchten, zur Rede gestellt wurden. Für die Bibelforscher, die eine Mitarbeit in „weltlichen Organisationen" auch während der Weimarer Republik weitgehend abgelehnt hatten, entstand hier ein weiteres Problem, da die angestrebte Eingliederung aller jeweils in Frage kommenden Bevölkerungsgruppen bei Organisationen wie der „Hitlerjugend“ oder der „Deutschen Arbeitsfront“ faktisch die Zwangsmitgliedschaft bedeutete. Als getaufte und „Gott geweihte“ Zeugen Jehovas war für sie die Bindung an das ,christliche Neutralitätsgebot" $z$ wingend. Ihre noch nicht getauften Kinder in die „Hitlerjugend“ zu schicken, kam für sie vor allem aus drei Gründen nicht in Frage, die in einer Flugschrift wie folgt beschrieben wurden: 1.) „Die HJ ist ein Verein, in welchem politische Sachen besprochen und ausgeführt werden“; 2.) „Bei der HJ grüßt man mit ,Heil Hitler““; 3.) „Dann die vormilitärischen Übungen ... "32

Die weitaus meisten Zeugen Jehovas widerstanden den Nötigungen zum Beitritt beziehungsweise zur Betätigung in Organisationen wie der NS-Volkswohlfahrt oder dem Reichsluftschutzbund. Da bei der NS-Volkswohlfahrt (NSV) ${ }^{33}$ ebenso wie bei der NS-Frauenschaft oder anderen der Partei angeschlossenen Verbänden keine Beitrittspflicht bestand, zogen die Ablehnungen nicht unmittelbar administrative Maßnahmen nach sich; für die Nationalsozialisten unterstrichen sie jedoch den mangelnden Willen der Bibelforscher, sich von ihrer "Irrlehre" freizumachen und sich in die „Volksgemeinschaft" einzufügen.

Wenn ihnen Posten als Luftschutzwarte angetragen wurden und sie dies zurückwiesen, konnte es hingegen zu schwereren Belastungen kommen. Denn für die Nationalsozialisten war die Luftschutzkampagne ein wesentliches Moment der Militarisierung der Bevölkerung. Im 1935 erschienenen „Luftschutz-Leitfaden“ wurde verkündet: „Luftschutz ist praktischer Dienst an der Volksgemeinschaft. Niemand darf sich ihm entziehen. "34 Im gleichen Jahr wies die Bayerische Politische Polizei die ihr unterstellten Dienststellen an, „umgehend zu berichten, ob Fälle bekannt geworden sind, daß Anhänger der, Internationalen Vereinigung Ernster Bibelforscher' ihre Teilnahme am Heeresdienst, Luftschutzdienst, NSV usw. verweigert haben“35. Zwei Jahre später ordnete die Münchener Staatspolizeileitstelle an, daß Bibelforscher, die nach Aufforderung den Dienst beim Reichsluftschutzbund

31 Vgl. Kühl, Friedrichstadt, S. 183f.

32 Aus einer 1940/41 in Österreich kursierenden Bibelforscher-Flugschrift mit dem Titel „Meine Gründe, weshalb ich mich weigere, den H.J.-Dienst mitzumachen“, abgedruckt in: Neugebauer, Wien, S. $176 \mathrm{f}$.

33 Gegen Ende der dreißiger Jahre waren in der NSV über zehn Millionen (!) Mitglieder eingeschrieben. Vgl. Zimmermann, J. F., NS-Volkswohlfahrt.

34 Teetzmann, Luftschutz-Leitfaden, S. 98. Im Jahre 1939 zählte der Reichsluftschutzbund 13,5 Millionen Mitglieder, d. h. ein Viertel der erwachsenen deutschen Bevölkerung.

35 BHStA, Reichsstatthalter 638, BPP, RdErl. vom 24.5.1935. 
verweigerten, in Schutzhaft zu nehmen seien ${ }^{36}$. Nach Kriegsbeginn wurde mit der „Wehrkraftschutzverordnung“37 die Strafbarkeit begründet. Der ministerielle Gesetzeskommentar betonte ausdrücklich, daß unter den Begriff der „Wehrfeindlichkeit" auch die Ablehnung „,der Erfüllung der Luftschutzpflichten“38 falle.

Neben Schutz- oder Strafhaft konnten auch andere Folgen treten. So meldeten die im Auftrag des Exilvorstandes der SPD herausgegebenen ,Deutschland-Berichte" im September 1936, daß in einem schlesischen Betrieb zwei Bibelforscher entlassen worden seien, weil sie sich geweigert hatten, dem Luftschutz des Betriebs beizutreten: „Dies wurde als Staatsfeindlichkeit und Sabotage ausgelegt.“39

Bei der Ablehnung der Betätigung im Luftschutzbund kam für die Zeugen Jehovas neben dem ,Neutralitätsgebot“ noch ein anderes Moment ihrer Glaubensüberzeugung zum Tragen. So bekundeten sie, daß sie sich in Fragen des Luftschutzes ganz auf Gott verlassen würden und Jehova der einzige Schutz für den Menschen sei: „Ein Christ wird keinen Anteil nehmen an einer Luftschutzorganisation für den Fall eines Krieges, weil eine solche Organisation mehr oder weniger mit militärischen Einrichtungen verbunden ist und weil er dadurch stillschweigend zugeben würde, daß er von einer solchen Organisation Heil und Rettung erwarte. “40

Am nachhaltigsten stellte sich die Frage der Mitgliedschaft im Blick auf die als „Organisation des gesamten werktätigen deutschen Volkes“ geschaffene „Deutsche Arbeitsfront" (DAF) 41 . Die Mitgliedschaft in der DAF, die zunächst die Angehörigen der aufgelösten Gewerkschaften, später auch der Handwerker- und Unternehmervereinigungen umfaßte, wurde faktisch schon bald zu einer Voraussetzung für jedes gewerbliche Beschäftigungsverhältnis. Teilweise wurden die Arbeiter und Angestellten einfach vom Betrieb aus als Mitglieder der DAF geführt; die Beiträge wurden vom Lohn einbehalten. Die Zeugen Jehovas lehnten die Zugehörigkeit zur Arbeitsfront, die unter Führung des Stabsleiters der Politischen Organisation der NSDAP und späteren (ab 1936) Reichsorganisationsleiters Dr. Robert Ley ein der Partei angeschlossener, rechtlich aber selbständiger Verband mit analogem Aufbau war, ebenfalls aufgrund ihres Bekenntnisses zur ,Neutralität“ ab; auch eine reine Nennmitgliedschaft über den Betrieb kam für sie vom Grundsatz her nicht in Frage. Der Nicht-Beitritt zur Arbeitsfront führte in zahlreichen Fällen zu Entlassungen, und ohne Nachweis der Mitgliedschaft blieb die Suche nach einem neuen Arbeits-

$\overline{36}$ BA, R 58/264, Bl. 306, Staatspolizeileitstelle München, RdErl. vom 19.5.1937. Imberger, Widerstand, S. 368, berichtet von mehreren Fällen, in denen schleswig-holsteinische Zeugen Jehovas bereits nach Erlaß des Luftschutzgesetzes vom 26.5.1935 in Schutzhaft genommen und für einige Monate in Konzentrationslager eingewiesen wurden.

37 VOSchdW vom 25.11.1939, RGB1. 1939 I, S. 2319; siehe auch S. $345 f$.

38 Deutsches Strafrecht, Band 1, S. 172. Nach Zipfel hat das SG Berlin in einem Fall der Ablehnung des Beitritts zum Luftschutzbund eine Strafe von sechs Monaten Gefängnis wegen „Verächtlichmachung des Luftschutzes“ verhängt (vgl. Zipfel, Kirchenkampf, S. 196, Anm. 48). Diese Verurteilung aus der Zeit 1936/37 deutet darauf hin, daß auch bereits vor Kriegsbeginn unter Berufung auf das Heimtückegesetz - die Verweigerung der Betätigung im RLB mit juristischen Mitteln verfolgt wurde.

39 Deutschland-Berichte 3 (1936), S. 1177.

40 DCB, Mitteilungsblatt der deutschen Verbreitungsstelle des W.T., September 1942, zitiert in der Anklageschrift des Oberreichsanwaltes beim VGH, $8 \mathrm{~J}$ 131/43, vom 3.8.1943.

41 Vgl. zur DAF, der 1938 bei formell freiwilliger Mitgliedschaft 20 Millionen Erwerbstätige angehörten, Mason, Sozialpolitik, S. 100ff.; Mai, Arbeitsfront, S. $212 \mathrm{ff}$. 
platz oftmals vergeblich. Neben den zu gewärtigenden beruflichen und sozialen Schwierigkeiten konnten bei Verweigerung der DAF-Mitgliedschaft noch weitere Gefährdungen treten. So wurde beispielsweise der Bibelforscher Franz P. am 13. Oktober 1936 von der Hamburger Gestapo verhaftet, nachdem er auf die Aufforderung, der Arbeitsfront beizutreten, eine Erklärung abgegeben hatte, daß er sich dazu aus Glaubensgründen nicht imstande sehe ${ }^{42}$. Erst nach über zwei Jahren, am 12. Dezember 1938, wurde er aus der KZ-Haft entlassen.

Aus Sorge um die Zukunft ihrer Familien beim drohenden Verlust des Arbeitsplatzes und damit des wirtschaftlichen Auskommens war ein Teil der Zeugen Jehovas bereit, sich in die „Deutsche Arbeitsfront“ einreihen zu lassen und ihr beizutreten. Für sie stellte - wenn auch unter Gewissensqualen - eine DAF-Mitgliedschaft noch das am ehesten mögliche Zugeständnis an den nationalsozialistischen Staat dar. Während die Zahl der Bibelforscher, die in Partei-Gliederungen oder andere der NSDAP angeschlossene Verbände wie der NS-Volkswohlfahrt, der NSFrauenschaft oder der NS-Kriegsopferversorgung eintraten ${ }^{43}$, äußerst niedrig gewesen zu sein scheint ${ }^{44}$, liegen die Zahlen für die Zugehörigkeit zur Arbeitsfront höher, auch wenn sie insgesamt vergleichsweise gering blieben. Dies veranschaulicht das Beispiel der Hamburger Zeugen Jehovas. ${ }^{45}$ Hier konnten zu 169 Personen Angaben über deren Mitgliedschaften im „Dritten Reich“ ermittelt werden:

Tabelle 2: $\quad$ Mitgliedschaft von Hamburger Zeugen Jehovas in NS-Gliederungen

\begin{tabular}{lrr}
\hline & absolut & in \% \\
\hline Keine Mitgliedschaft & 146 & 86,4 \\
NSDAP & 0 & 0 \\
Nationalsozialistische Volkswohlfahrt & 1 & 0,6 \\
Reichsluftschutzbund & 2 & 1,2 \\
Deutsche Arbeitsfront & 20 & 11,8 \\
Summe & 169 & 100,0
\end{tabular}

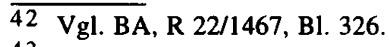

43 Gerhard Hetzer hat in seiner Studie über Augsburg von einzelnen Zeugen Jehovas berichtet, die gewisse Affinitäten und teilweise sogar offene Unterstützung für den Nationalsozialismus zeigten, so z. B. von einem seit 1922 der IBV angehörenden Werkmeister, der drei Jahre später zu den Ältesten der Augsburger Bibelforschergemeinde zählte und im Sommer 1927 der NSDAP beigetreten war. Hetzer weiß außerdem davon zu berichten, daß einigen Hinweisen in GestapoVernehmungsprotokollen zufolge der ,Stürmer" in Bibelforscherkreisen ,,als Lektüre geschätzt wurde“. Auch seien Kinder einiger Bibelforscher mit Duldung ihrer Eltern frühzeitig zur Stamm-HJ gestoßen (Hetzer, Augsburg, S. 639). Diese unvermittelt angeführten Beispiele, bei denen auch die Frage nach der Aussagequalität quellenkritisch zu diskutieren sein dürfte, erweisen sich aufs Ganze gesehen als sehr seltene, im individuellen Bereich anzusiedelnde Ausnahmen, denen ein Erklärungswert für das Gesamtphänomen abgesprochen werden muß.

44 In den eingesehenen Gnadenheften (StA M, SLG HH) finden sich zuweilen Hinweise auf Mitgliedschaften in NS-Gliederungen, beispielsweise in der Nationalsozialistischen Betriebszellenorganisation oder der NS-Frauenschaft. Auch wurde von den Bittstellern auf die Mitgliedschaft der eigenen Kinder in der HJ oder auf die von Verwandten in der NSDAP aufmerksam gemacht. $\mathrm{Zu}$ bedenken ist dabei, daß diese Gesuche in einer Extremsituation abgefaßt wurden, die von Verzweiflung geprägt und von der Suche nach möglichen „Entlastungen“ bestimmt war. 
Die in einem hohen Grade konsequente Versagung gegenüber den Forderungen des nationalsozialistischen Weltanschauungsstaates und die unbeugsame Haltung vieler Zeugen Jehovas waren für die Nationalsozialisten ihrerseits (neben anderen Gründen wie der ideologischen Verwerfung der Bibelforscherlehre und der Reaktion auf die Fortführung der IBV in der Illegalität) Grund genug für die große Härte, mit der sie diese kleine Glaubensgemeinschaft verfolgten.

\section{Instrumente der Verfolgung: Die Entrechtung und die Vernichtung der wirtschaftlichen Existenz}

Neben der Bekämpfung der Zeugen Jehovas durch Gestapo und Strafgerichte unter Anwendung der „klassischen“ Mittel zur Ausschaltung tatsächlicher oder vermeintlicher Oppositioneller - der Einweisung in Konzentrationslager und Gefängnisse zählten in gleicher Weise auch gezielte Maßnahmen zur wirtschaftlichen Existenzvernichtung zum Verfolgungsinstrumentarium des NS-Regimes. ${ }^{46}$

Am offensichtlich zielstrebigsten wurde ihre Entfernung aus dem öffentlichen Dienst betrieben. Diejenigen Zeugen Jehovas, die als Post- und Bahnbedienstete, Arbeiter, Angestellte und Beamte der kommunalen oder staatlichen Verwaltung arbeiteten, wurden fast ausnahmslos entlassen. Sie waren bei ihren Kollegen und Vorgesetzten zumeist als ausgesprochen gewissenhafte und mit den geforderten „Beamtentugenden“ ausgestattete Bedienstete bekannt; sie galten allgemeinhin als strebsam, ehrlich und untertänig. Trotzdem gingen die nationalsozialistisch geführten Behörden gnadenlos gegen die betreffenden Personen vor. Dienstentfernungen wurden in der Regel wegen der Nicht-Erweisung des „Hitler-Grußes“ oder der Weigerung zur Ableistung des Beamteneides ausgesprochen ${ }^{47}$; die Rechtsgrundlage bildete in den meisten Fällen das von den Nationalsozialisten zur Legalisierung

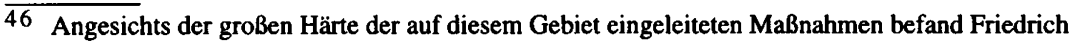
Zipfel, daß die Zeugen Jehovas ,,innerhalb des nationalsozialistischen Ausnahmestaates unter einem speziellen Ausnahmerecht“ standen, das ihnen ,jede Existenzmöglichkeit abschneiden sollte" (Zipfel, Kirchenkampf, S. 192). Die Rechtsprechung in Entschädigungsangelegenheiten sah das jedoch zuweilen ganz anders. So verneinte die Wiedergutmachungskammer Bielefeld in einem Urteil vom 28.6.1950, daß die Bibelforscher in ihrer "Gesamtheit einer Verfolgung im Sinne des Art. 1 REG [Rückerstattungsgesetz] ausgesetzt“ gewesen waren. Zwar habe ihnen die nationalsozialistische Regierung die religiöse Betätigung untersagt, und im Falle der Zuwiderhandlung seien sie strafrechtlich bestraft worden, aber „die damalige Regierung“ habe nicht beabsichtigt, , die Ernsten Bibelforscher aus dem wirtschaftlichen Leben Deutschlands auszuschließen“. Mit der anschließenden Aussage entfernte sich die Wiedergutmachungskammer dann gänzlich von den tatsächlichen Begebenheiten: „Den Angehörigen dieser Vereinigung ist in wirtschaftlicher Beziehung nichts geschehen." (RzW 1 [1949/50], S. 409)

47 Manfred Koch hat in seiner Arbeit über die IBV in Mannheim die Feststellung getroffen, daß erst dann Dienststrafverfahren eingeleitet oder Entlassungen ausgesprochen wurden, ,wenn die Zeugen Jehovas in Haft genommen wurden" (Koch, M., Die kleinen Glaubensgemeinschaften, S. 428). Wenn dies auch in vielen Fällen zutreffend ist, so ist diese Aussage auf den Gesamtzusammenhang bezogen nicht aufrechtzuerhalten. Vielmehr stand zumeist die Entlassung am Anfang der Verfolgungsmaßnahmen. Es ist jedoch richtig, daß eine Verurteilung wegen Betätigung für die verbotene IBV bei den (noch) im öffentlichen Dienst Beschäftigten die Dienstentlassung regelmäßig nach sich zog. 
der Massenentlassungen von Regimegegnern und jüdischen Bürgern geschaffene „Gesetz zur Wiederherstellung des Berufsbeamtentums“.

Die ersten Schwierigkeiten entstanden kurz nach Anordnung der Grußpflicht. Mit Erlaß vom 20. Juli 1933 hatte für Preußen der Minister des Innern verfügt, daß im Dienst und innerhalb der dienstlichen Gebäude durch Erheben des rechten Armes der „Deutsche Gruß“ zu erweisen sei48. Damit wurde die vom „neuen Staat“ geforderte besondere Ehrenbezeigung für alle Bediensteten der öffentlichen Verwaltung verbindlich gemacht; die Nicht-Erweisung des „Deutschen Grußes“ stellte fürderhin eine Dienstpflichtverletzung dar. Wenngleich das Erheben des rechten Armes zum sichtbaren Zeichen der Unterordnung und Einfügung in die veränderten Verhältnisse wurde, so bedeutete es nach dem Verständnis vieler Zeugen Jehovas noch nicht eine für sie gänzlich ausgeschlossene Handlungsweise, da das wortlose Verrichten des Grußes keine ausdrückliche Zuschreibung des allein Gott zukommenden „Heils“ an den „Führer“ der nationalsozialistischen Bewegung beinhaltete.

Zur Art der Grußerweisung waren über die genannte Anordnung hinaus keine weiteren Verfügungen getroffen worden. Die Verwaltungsspitzen konnten allem Anschein nach zu keinem Einvernehmen über die Frage gelangen, „ob der deutsche Gruß unter allen Umständen mit den Worten ,Heil Hitler' geleistet werden müs-

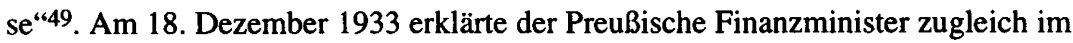
Namen des Ministerpräsidenten und sämtlicher Staatsminister, daß es ,freigestellt“ sei, ,zu dieser Grußbezeugung die Worte ,Heil Hitler“ oder ,Heil' oder gar nichts zu sagen. Andere Worte sind aber gleichzeitig mit dem deutschen Gruß nicht zu sagen." 50

Auf der Erlaßebene - die Behördenchefs vieler Verwaltungseinrichtungen hatten es allerdings schon zuvor für notwendig gehalten, für ihren Zuständigkeitsbereich eigene, zum Teil präzisere Dienstanweisungen zu erteilen - blieb es bei dieser Regelung bis Anfang 1935. Mit Erlaß vom 22. Januar 1935 beseitigte der Reichsund Preußische Minister des Innern die bisherige Freistellung zur Art der Grußerweisung und verfügte, ,,daß fortan die Beamten, Behördenangestellten und -arbeiter den deutschen Gruß im Dienst und innerhalb der dienstlichen Gebäude und Anlagen durch Erheben des rechten - im Falle körperlicher Behinderung des linken Armes und durch den gleichzeitigen deutlichen Ausspruch ,Heil Hitler“" ${ }^{\prime 51}$ auszuführen hätten.

Damit wurde den im Staatsdienst beschäftigten Zeugen Jehovas die letzte Möglichkeit genommen, diese „Grußklippe“ geschickt zu umgehen. Fortan stellte auch das Verhalten derjenigen, die bisher durch wortloses Erheben des Armes den

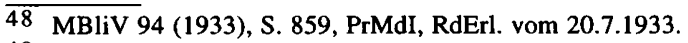

49 ZBB 7 (1936/37), S. 259, Reichsdisziplinarhof, F 47/35, Urteil vom 4.6.1935. Nach den Ausführungen des RDH bestand im Jahre 1933 über diese Frage selbst bei den höchsten Reichsressorts keine Einigung.

50 MBliV 94 (1933), S. 1487, RdErl. des Preußischen Finanzministers zugleich im Namen des Ministerpräsidenten und sämtlicher Staatsminister vom 18.12.1933. Elf Tage später erließ der RMdI „mit Rücksicht auf die inzwischen aufgetretenen Zweifel über die Art des deutschen Grußes“ eine Anordnung gleichen Wortlautes. Vgl. Lehberger, Umbau, S. 20.

51 DJ 97 (1935), S. 213, RuPrMdI, Erlaß vom 22.1.1935. 
„Deutschen Gruß“ entrichtet hatten, ein Dienstvergehen dar: Der nationalsozialistische Staat forderte das unmißverständliche Bekenntnis zu seinem „Führer“.

Die Zeugen Jehovas wurden in Gesprächen mit ihren Vorgesetzten vor die Alternative gestellt, entweder den vorgeschriebenen Gruß zukünftig zu leisten oder entlassen zu werden. Oftmals wurden sie auch von den Dienstherren zur Abgabe einer schriftlichen Erklärung über ihre Haltung in dieser Frage aufgefordert. Zumindest in Magdeburg kursierte Ende 1934 unter den Bibelforschern eine Stellungnahme mit Argumenten gegen die Grußpflicht, die zur entsprechenden Vorlage bei den Dienststellen bestimmt schien. Ihr einleitender Satz lautete: „Ich erkläre unserer Behörde (Gemeinde) offenkundig, daß ich mich innerhalb und außerhalb des Amtsgebäudes dem Hitlergruß gegenüber ablehnend verhalten muß und für immer verhalten werde. Einem wahren Christen geziemt es nicht, irgendetwas zu tun, was der Huldigung eines Menschen gleichkommt." 52

Ebenso wie es den Zeugen Jehovas aufgrund ihres Glaubens nicht möglich war, den „Hitler-Gruß“ zu entrichten, kam für sie auch eine Ableistung des mit dem „Gesetz über die Vereidigung der Beamten und der Soldaten der Wehrmacht" vom 20. August 1934 eingeführten neuen Diensteides nicht in Frage, dessen Eidesformel lautete: „Ich schwöre: Ich werde dem Führer des Deutschen Reiches und Volkes Adolf Hitler treu und gehorsam sein, die Gesetze beachten und meine Amtspflichten gewissenhaft erfüllen, so wahr mir Gott helfe. "53 Auch hier war die Nichterfüllung gleichbedeutend mit der Dienstentfernung. $\$ 57 \mathrm{der}-$ allerdings erst verhältnismäßig spät erlassenen - Neufassung des „Beamtengesetzes“ bestimmte unzweideutig: „Wer sich weigert, den gesetzlich vorgeschriebenen Treueid zu leisten, ist zu entlassen. "54

Die juristische Handhabe zur Dienstentfernung von Beamten, die der Bibelforschervereinigung angehörten, bildete in den meisten Fällen jedoch das am 7. April 1933 verkündete „Gesetz zur Wiederherstellung des Berufsbeamtentums“"55. Unter Bezugnahme auf diese auch als „Berufsbeamtengesetz“ (BBG) bezeichnete Rechtsgrundlage für die politischen Massenentlassungen zu Beginn des „Dritten Reiches“ verfügte das Reichsinnenministerium am 11. Juni 1934 eine grundsätzliche Regelung hinsichtlich der Anwendbarkeit des BBG auf die Zeugen Jehovas. Der Staats-

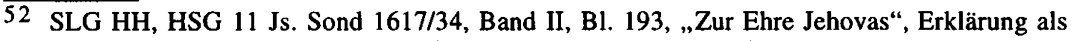
Anlage zum Schreiben der Staatspolizeistelle Magdeburg vom 16.1.1935.

53 RGB1. 1934 I, S. 785. Zum Beamteneid bzw. zur Vereidigung der Beamten im „Dritten Reich" auf die Person Hitlers vgl. Bauernfeind, Eid und Frieden, S. 38-43.

54 Deutsches Beamtengesetz vom 26.1.1937, RGBI. 1937 I, S. 41. Auch vor Erlaß der Neufassung des Beamtengesetzes wurde unter Berufung auf ministerielle Anordnungen und nach entsprechender Auslegung des geltenden Beamtenrechtes ebenso verfahren.

Die nach § 4 Abs. 2 mögliche Leistung einer Beteuerungsformel an Stelle des Eides für Mitglieder solcher Religionsgesellschaften, denen dies gesetzlich gestattet worden war, betraf ausschließlich die Glaubensgemeinschaft der Mennoniten, deren religiösen Bedenken (biblisches Schwurverbot, vgl. Mt 5, 33.34) gegen die Eidesleistung auf gleiche Weise schon in vornationalsozialistischer Zeit Rechnung getragen worden war. Dieses ,Zugeständnis“ währte jedoch nicht lange. Mit Schreiben vom 15.12.1938 ordnete Martin Bormann an, ,in Zukunft [...] irgendwelche Ausnahmen bei der Eidesleistung durch Mennoniten nicht mehr zuzulassen“" (BA, Sammlung Schumacher/267 II, Der Stellvertreter des Führers, RdS Nr.2/1939 vom 15.12.1938).

55 RGB1. 1933 I, S. 175. 
sekretär im Innenministerium Hans Pfundtner befand zwar, daß die Bibelforscher nicht zu den im „Gesetz zur Wiederherstellung des Berufsbeamtentums“ beziehungsweise seinen „Durchführungsverordnungen“ genannten „Parteibuchbeamten“ oder zu den Beamten, die sich im kommunistischen Sinne betätigt haben, gezählt werden könnten ${ }^{56}$, gleichwohl erklärte er die Zugehörigkeit zur IBV zu einer Dienstpflichtverletzung, die eine Entfernung aus dem Staatsdienst erfordere:

„Wenn auch in den Kreisen der Bibelforscher Anhänger ehemaliger kommunistischer und marxistischer Parteien und Organisationen Aufnahme gefunden haben und die Bibelforscher mit ihren gegen den Staat gerichteten Tendenzen dem Kommunismus - wenn auch vielleicht ungewollt Vorschub leisten, so wird man sie doch als ,kommunistische Hilfsorganisation' im Sinne des BBG nicht bezeichnen können. Andererseits sind die Bibelforscher zweifellos jenen staatsfeindlichen Vereinigungen zuzurechnen. Darum stellt auch die Zugehörigkeit eines Beamten zu der Internationalen Bibelforscher-Vereinigung eine Verletzung der ihm obliegenden Dienstpflicht und seines Treueides dar, die die Einleitung eines Dienststrafverfahrens mit dem Ziele auf Dienstentlassung rechtfertigt, umso mehr, wenn er beharlich die Erweisung des deutschen Grußes verweigert. Derartige Beamte bieten nicht die Gewähr, daß sie jederzeit rückhaltlos für den nationalen Staat eintreten. “57

Staatssekretär Pfundtner wies die Landesregierungen und obersten Reichsbehörden an, „das Weitere zu veranlassen“, und fügte ferner hinzu, daß ihm von ,etwaigen Dienststrafurteilen“ in dieser Sache Kenntnis zu geben sei. In den Ländern wurden entsprechende Überprüfungen eingeleitet; beispielsweise verfügte der Regierungspräsident in Hildesheim am 31. August 1934, daß sämtliche Lehrer und Lehrerinnen der Volks- und Mittelschulen seines Bezirks binnen drei Wochen eine Erklärung zu unterzeichnen hatten, in der sie versichern mußten, nicht der Internationalen Bibelforschervereinigung oder einer ihrer Nebenorganisationen anzugehören ${ }^{58}$. Nachdem bereits im Jahre 1933 zahlreiche Entlassungen von in Behördendiensten stehenden Arbeitern und Angestellten wegen Grußverweigerung und IBV-Zugehörigkeit vorgenommen worden waren, kam es infolge des ministeriellen

56 Die 3. DVO zum Gesetz zur Wiederherstellung des Berufsbeamtentums vom 6.5.1933 (RGBl. 1933 I, S. 245) bestimmte, daß außer den zu entlassenden „Parteibuchbeamten“ und Beamten "nichtarischer Abstammung" auch „politisch unzuverlässige Beamte“ zur Entlassung kommen können.

57 RMdI, Anordnung vom 11.6.1934, Akten der Reichskanzlei, Teil I: 1933/34, Band 2, S. 1321f. Nach Renate Lichtenegger wurde der Erlaß später ,auch auf solche Beamte ausgedehnt, die selbst keine IBV-Angehörigen waren, deren Gattinnen jedoch der Bibelforscherorganisation angehörten" (Lichtenegger, Bibelforscher, S. 182). Die Existenz einer derartigen Verfügung, die Renate Lichtenegger nicht belegen kann und die es allem Anschein nach auch nicht gegeben hat, wurde von ihr vermutlich daraus abgeleitet, daß in Ehescheidungsverfahren die Zugehörigkeit einer Beamtenfrau zur IBV als eine für den Ehemann unzumutbare und materielle Schwierigkeiten heraufbeschwörende Untergrabung seiner Stellung im öffentlichen Leben gewertet wurde (vgl. JW 66 [1937], S. 1308). In derartigen Fällen wurden Behördenbedienstete zur Trennung von ihren sich zu dem Bibelforscherglauben bekennenden Ehepartnern genötigt, ihnen alle erdenklichen Schwierigkeiten im Beruf bereitet und jede Aufstiegsmöglichkeit genommen; Dienstentlassungen aus diesem Grunde sind aber, soweit bekannt, nicht vorgekommen.

58 Amtliches Schulblatt für den Regierungsbezirk Hildesheim, 31 (1934), S. 211. 
Erlasses nun vermehrt auch zu Dienstentlassungen von Beamten, die der Bibelforschervereinigung angehörten ${ }^{59}$.

Die Betroffenen versuchten gegen die Entscheidungen anzugehen und legten Rechtsmittel ein. Viele Dienststrafverfahren kamen vor dem als Berufungsinstanz zu den Disziplinarkammern urteilenden Reichsdisziplinarhof in Leipzig zur Verhandlung. Reichsgerichtspräsident Dr. Erwin Bumke teilte in einer im Juni 1937 im Reichsjustizministerium abgehaltenen Besprechung mit, daß es ,wohl kaum eine Sitzung" gegeben habe, ,in der nicht ein oder zwei Bibelforscher vor uns erschienen sind " 60 . Seine Eindrücke von den Angeschuldigten faßte Bumke in die Worte: „Es war immer dasselbe Bild eines älteren Beamten, der nie Anstoß erregt hatte. Diese Leute nehmen die Entlassung glatt in Kauf." Wenn es sich im allgemeinen auch um eher ,harmlose“ Personen gehandelt habe, so könne er doch nur von einem einzigen Fall berichten, in dem der Betreffende infolge des Gerichtsverfahrens seine Haltung aufzugeben bereit gewesen sei und zu erkennen gegeben habe, daß er nunmehr gewillt sei, den Eid auf den ,Führer“ $\mathrm{zu}$ leisten.

Nur wer erklärte, sich zukünftig den Forderungen des NS-Staates ohne Abstriche fügen zu wollen, durfte nach Meinung der Disziplinarrichter im Dienst verbleiben. In diesem Sinne gestalteten sie ihre Spruchpraxis über Zeugen Jehovas. Im Fall eines Postschaffners aus Bad Warmbrunn (Schlesien), der seit dem 1. Mai 1927 in einem unkündbaren Beschäftigungsverhältnis stand und gegen den durch Verfügung des Reichspostministers vom 25. Oktober 1934 ein Disziplinarverfahren eingeleitet worden war, entschied die Reichsdisziplinarkammer Liegnitz mit Urteil vom 21. Dezember 1934 auf Dienstentlassung, da der Angeschuldigte sich „trotz wiederholter Belehrungen“ geweigert habe, den ihm auferlegten ,neuen Diensteid in der vorgeschriebenen neuen Form" zu leisten ${ }^{61}$. Der Postschaffner hatte dem Disziplinargericht gegenüber darauf verwiesen, daß er seinen Beamtenpflichten durch den von ihm 1922 bei Eintritt in den Postdienst geleisteten Eid bereits Genüge getan habe und daß ihm aus Gründen des Glaubens die Leistung des ,in religiöser Form" gefaßten neuen Eides nicht möglich sei. Für das Gericht hingegen war es ,selbstverständlich“, daß der ,auf eine neue staatspolitische Grundlage gestellte Staat“ auch eine erneute Vereidigung verlangen könne, da die Beamten nunmehr ,unter den veränderten Umständen“ ihre Dienstpflichten zu erfüllen hätten. Mit seiner Weigerung setze sich der Postbeamte deshalb ,in bewußten Gegensatz zum heutigen Staat". Daran änderte nach Ansicht der Richter auch die Berufung auf Glaubensgründe nichts; sie sahen in der Nicht-Erbringung des Eides nur die Verneinung der „elementaren Grundlagen“, auf denen der „,neue Staat“ fuße: „Der nationalsozialistische Staat ist auf den Grundsatz des Führertums und der Treue

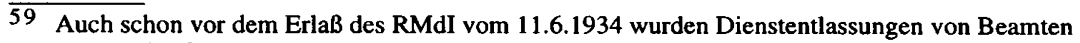
wegen Grußverweigerung und IBV-Zugehörigkeit verfügt. So wurden beispielsweise in Friedrichstadt ein städtischer Wächter und ein Justizwachtmeister Ende 1933 zwangspensioniert (vgl. Kühl, Friedrichstadt, S. 176). Für Hamburg sind für das Jahr 1933 drei Entlassungen von Beamten belegbar (ein Rathausdiener und zwei Bedienstete der Gesundheits- bzw. Sozialverwaltung). Vgl. VVN HH, Komiteeakten B 27, S. 3.

60 BA, R 22/4277, BI. 187, Protokoll der Besprechung mit den OLG-Präsidenten und Generalstaatsanwälten im RJM am 18.6.1937.

61 BA, Z Sg. 134/28, o. B1. (zu Heinrich H.), Reichsdisziplinarkammer Liegnitz, Pr.L.6/34/5, Urteil vom 21.12.1934. 
von Führer und Gefolgschaft aufgebaut. Daher lehnt der Angeschuldigte, wenn er sich weigert, dem Führer die Treue zu geloben, dadurch gerade das ab, was der neue Staat von allen Volksgenossen verlangt und was er erst recht von seinen Beamten verlangen muß.“

Obwohl die Disziplinarkammer anerkannte, daß der Postschaffner ,,bisher ein ruhiger und zuverlässiger Beamter gewesen ist, der immer seine Pflicht erfüllte“, wurde selbst eine auch nur übergangsweise Zahlung des Ruhegehaltes abgelehnt ${ }^{62}$, da ein Beamter nicht beanspruchen könne, ,daß Staat und Volk, von denen er sich selbst abwendet, ihm noch Ruhegehalt zukommen“ lassen.

Der Zeuge Jehovas, der sich ausdrücklich zur Abgabe einer schriftlichen „Versicherung an Eides Statt" bereit erklärte, legte Beschwerde ein und rief den Reichsdisziplinarhof an. Dieser bestätigte in einer Entscheidung vom 6. Mai 1935 das Urteil der Vorinstanz, da die Liegnitzer Kammer zu Recht die Eidesverweigerung als ,schwere Amtspflichtverletzung“ eingestuft habe. Die religiösen Vorbehalte wertete der Gerichtshof als „Einzelbedenken“ aus „persönlichen Beweggründen“, die unberücksichtigt bleiben müßten, da Beamte verpflichtet seien, „sich ohne Rücksicht auf Sondererwägungen in das große Ganze einzuordnen“63. Das Urteil der Vorinstanz wurde lediglich unter Verweis auf die bisher tadelsfreie Dienstführung, den geleisteten Kriegsdienst und in Anbetracht von drei zu versorgenden Kindern insofern abgeändert, daß drei Viertel des gesetzlichen Ruhegehaltes auf zwei Jahre belassen wurden.

Ein halbes Jahr später gestand der Reichsdisziplinarhof in einem ähnlich gelagerten Fall einem im Dienst der Reichsfinanzverwaltung stehenden Steuerinspektor ausdrücklich $\mathrm{zu}$, daß „seine Weigerung auf rein religiösen Gründen“ beruhe ${ }^{64}$. Auf die Entscheidung des Gerichts hatte diese Feststellung aber keinen Einfluß; die Entlassung des am 27. August 1934 von seiner Dienststelle, dem Finanzamt in Tuttlingen, vergeblich zur Leistung des Eides aufgeforderten und nach seiner Weigerung noch am gleichen Tag seines Arbeitsplatzes verwiesenen Steuerinspektors wurde aufrechterhalten.

In dem Fall eines Hamburger Postinspektors, der vor seiner am 22. Februar 1935 erfolgten Entlassung 43 Dienstjahre ohne Beanstandungen tätig gewesen war, erklärte der Reichsdisziplinarhof ebenfalls die Entfernung aus dem Dienst für rechtens, obwohl der Postbeamte im August des Vorjahres den Eid geleistet hatte und bereit war, den rechten Arm zum Gruß zu erheben ${ }^{65}$. Da er aber aufgrund seines Glaubens nicht mit den Worten „Heil Hitler" grüßen konnte, sah der Leipziger Gerichtshof auch hier eine „schwere Dienstverfehlung“ als gegeben an.

62 Die 3. DVO zum BBG sah vor, daß im Fall einer Dienstentlassung von ,politisch unzuverlässigen Beamten“ dreiviertel des gesetzlichen Ruhegeldes gewährt werden sollten (RGBl. 1933 I, S. 245).

63 ZBB 7 (1936/37), S. 176, Reichsdisziplinarhof, F 25/35, Urteil vom 6.5.1935.

64 UaP J. E. Straßer (Sammlung zur historischen Dokumentation), Reichsdisziplinarhof, F 74/35, Urteil vom 29.10.1935.

65 Reichsdisziplinarhof, F 212/35, Schriftwechsel zu diesem Gerichtsverfahren in: SLG HH, HSG 11 Js. Sond. 1617/34, Band II, BI. 193; SLG HH, HSG 11 Js. Sond. 127/35. In diesem Fall erkannte der RDH auf Belassung der halben Ruhegehaltsbezüge für fünf Jahre. 
Ein seit 1922 der IBV angehörender Postschaffner zeigte ein weiteres Zugeständnis, indem er der staatlichen Erwartungshaltung insofern entgegenzukommen meinte, als er den Gruß mit erhobenem Arm und dem Ausspruch „Heil“ leistete66. Dem Reichsdisziplinarhof fehlte aber „das Bekenntnis zum Führer“, das nach Meinung der Richter ,zu den vornehmsten Pflichten eines Beamten im Dritten Reiche“" gehöre. Da durch die Verweigerung des Grußes zwangsläufig „der Verdacht erweckt“" werde, daß der betreffende Beamte ,nicht auf dem Boden des Dritten Reiches“ stünde, sei es ,unmöglich einen solchen Beamten im Dienste zu belassen".

$\mathrm{Zu}$ einem anderen, eine Ausnahme darstellenden Urteilsspruch führte ein Verfahren, das gegen einen in der Finanzverwaltung tätigen Obersekretär angestrengt worden war. In der am 4. Juni 1935 ergangenen Entscheidung stellte der Reichsdisziplinarhof fest, daß die Zugehörigkeit zur IBV vor deren Verbot nicht als Dienstvergehen gewertet werden könne. Doch auch für die Zeit seit Erlaß des Verbotes gelte, daß in dem alleinigen Bekenntnis zu den religiösen Anschauungen der Bibelforscher noch kein vorwerfbares Dienstvergehen zu erblicken sei. Dieses liege erst dann vor, wenn die innere Gesinnung durch Handlungen oder Unterlassungen nach außen trete. In den Urteilsgründen heißt es dementsprechend, daß der ,Angeschuldigte sich dadurch, daß er sich nach dem Verbot der Internationalen Bibelforscher-Vereinigung noch zu deren Lehren insoweit bekannt hat, als er sich die Nachprüfung jedes staatlichen Gesetzes auf seine Gültigkeit auf Grund der Lehren der Bibel vorbehalten hat, unter den gegebenen Umständen keines Dienstvergehens schuldig gemacht" 67 habe.

Mit der Auffassung, daß das „Bekenntnis zu einer bestimmten Anschauung“ keine Entfernung aus dem Dienst rechtfertige, hielt der Reichsdisziplinarhof noch - und immerhin im Gegensatz zu den Vorstellungen nationalsozialistischer Juristen, denen zufolge die subjektive Gesinnung mindestens ebenso wie die objektive Handlung bei der Beurteilung von Pflichtverletzungen zu berücksichtigen war - an Rechtsprinzipien aus vornationalsozialistischer Zeit fest. Doch gleichzeitig unterstrich der Leipziger Disziplinarhof auch, daß sowohl in der dem Obersekretär vorgeworfenen nicht vorschriftsgemäßen, nämlich auf das Erheben des rechten Armes sich beschränkenden Erweisung des „Deutschen Grußes“, als auch in der Ablehnung des Beitrittes zur NS-Volkswohlfahrt und der Nicht-Teilnahme an den Fachschaftsveranstaltungen schwere Dienstverfehlungen zu sehen seien. Dies insbesondere, weil der dadurch entstehende Verdacht eines ,grundsätzlichen Widerstandes gegen die vom neuen Staate und der ihm eng verbundenen NSDAP getroffenen Einrichtungen" so nicht ausgeräumt werden könne. Da aber der Obersekretär in der Verhandlung Besserung gelobte und sich zur Befolgung der ihm aufgetragenen „Dienstpflichten“ bereit erklärte - der Urteilstext vermerkt dazu, der Angeschuldigte „sei dem Zug der Zeit gefolgt und wolle sich bemühen, ein Nationalsozialist zu sein" -, hob der Disziplinarhof die Entscheidung der Vorinstanz auf und hielt unter

66 ZBB 7 (1936/37), S. 104, Reichsdisziplinarhof, F 199/35, Urteil vom 11.2.1936.

67 ZBB 7 (1936/37), S. 258-260 (259), Reichsdisziplinarhof, F 47/35, Urteil vom 4.6.1935. 
ausdrücklicher Betonung der „,bisherigen im ganzen tadelfreien dienstlichen Führung des Angeschuldigten“ eine Verwarnung für ausreichend.

Die Zahl der Verfahren, in denen auf Belassung im Dienst entschieden wurde, ist ausgesprochen gering, obwohl es durchaus - wie bei den meisten anderen Gerichtsbarkeiten, die in Bibelforscherangelegenheiten urteilten - vorkommen konnte, daß Richter den ihnen auch im NS-Staat verbliebenen Ermessensspielraum einmal im Sinne des Angeschuldigten nutzten und ein bemerkenswert „mildes“ Urteil fällten. Ein solches Urteil erging im Fall eines 35jährigen Altonaer Postbeamten, der sich geweigert hatte, dem Postschutz beizutreten ${ }^{68}$. Daraufhin hatte die Reichspostdirektion am 24. März 1936 ein Disziplinarverfahren gegen ihn mit der Begründung eingeleitet, daß der Briefzusteller ,die Lehre der Internationalen Bibelforscher vertritt und dieses auch im Dienste zeigt“. Die Reichsdisziplinarkammer in Schleswig hielt demgegenüber eine Entlassung für nicht erforderlich und entschied am 8. Juni 1936 auf Weiterbeschäftigung. Nunmehr legte zum einen die Staatsanwaltschaft im Auftrage des Reichspostministers Berufung ein, zum anderen wurde ein weiteres Disziplinarverfahren eingeleitet, ,weil M. am 29.3.36 seiner Wahlpflicht nicht genügt hat". Doch die Reichspostdirektion scheiterte auch dieses Mal mit ihrem Ansinnen - und das, obwohl der Angeschuldigte sich zur Zeit des Verfahrens einen Monat lang in Gestapo-Haft befand und gleichzeitig gegen ihn ein Strafverfahren wegen Zuwiderhandlung gegen das IBV-Verbot lief ${ }^{69}$. Zwar wurde dem Postbeamten jeder Aufstieg untersagt, aber nach anderthalbjähriger Suspension konnte der Altonaer Zeuge Jehovas Ende November 1937 wieder die Arbeit in seinem Zustellbezirk aufnehmen.

Doch in der Regel kannten die Disziplinarrichter im NS-Staat keine Nachsicht mit den Zeugen Jehovas. Dabei scheuten sie sich auch nicht, über die im NSBeamtenrecht geforderten Loyalitätsbekundungen hinaus noch weitere Beweise für die ,nationale Zuverlässigkeit“ einzufordern. So bestätigte das Preußische Oberverwaltungsgericht im November 1936 die Dienstentlassung eines sich seit $1931 \mathrm{zu}$ den Bibelforschern bekennenden Polizeibeamten, weil dieser in seinen Einlassungen ein demonstratives Desinteresse an den Zielen der Staatsführung zu erkennen gegeben habe ${ }^{70}$. Zwar stellte auch für das Oberverwaltungsgericht die innere Einstellung eines Beamten, insofern sie nicht nach außen in Erscheinung trete, für sich allein kein Dienstvergehen dar, in diesem Fall handelte es sich aber nach Meinung des Gerichts angesichts der den Belangen des Staates gegenüber gezeigten Interesselosigkeit um ein ,pflichtwidriges Unterlassen“. Denn der Polizeibeamte habe es vorsätzlich unterlassen, ,,sich auch nur mit den wichtigsten Grundsätzen des nationalsozialistischen Staates und der NSDAP vertraut zu machen". Zum Beleg konnten die Richter auf eine Erklärung des Angeschuldigten verweisen, in der dieser, vermutlich auf ihm vorgelegte Fragen antwortend, ausgeführt hatte:

68 Angaben nach VVN HH, Komiteeakten M 20; LA SH, Abt. 352 Altona Nr. 9201, B1. 46, Reichspostdirektion Hamburg, Schreiben vom 10.9.1936.

69 In der am 24.9.1936 vor dem Schleswig-Holsteinischen Sondergericht in Altona geführten Verhandlung erging „mangels ausreichender Beweise“ Freispruch (LA SH, Abt. 352 Altona Nr. 9201, Bl. 65-71). Zu dem Verfahren siehe S. 281-283.

70 DJ 99 (1937), S. 245, PrOVG, Urteil vom 17.11.1936; vgl. auch RVerwBl. 58 (1937), S. 245 . 
„Eine Zeitung halte ich nicht, da ich es nicht für nötig halte, daß ich mich mit den weltlichen Dingen beschäftige. Ich lese täglich in der Bibel, das ist meine geistige Speise. Auch mit den Dingen des Staates und der nat.-soz. Bewegung beschäftige ich mich nicht. Ich habe davon gehört, daß die Allgemeine Wehrpflicht eingeführt ist. [...] Ich habe nichts davon gehört, daß Mussolini Abessinien erobern will. Was für eine Regierung in Österreich am Ruder ist, weiß ich nicht. Ich bin nicht im Bilde darüber, ob diese mit dem Deutschen Reich in freundschaftlichen oder feindseligen Beziehungen steht. "71 Ein derartiger „Tiefstand an Kenntnissen“ war nach höchstrichterlicher Überzeugung mit den Beamtenpflichten nicht vereinbar ${ }^{72}$. Das Preußische Oberverwaltungsgericht hielt deshalb eine Entfernung des Beamten aus dem Dienst für gerechtfertigt.

Die gleiche Tendenz zeigte ein Urteil, das im Fall einer in öffentlichen Diensten stehenden Hebamme erging. Das Sächsische Oberverwaltungsgericht hielt in einer Entscheidung vom 4. Dezember 1936 ihre Entlassung aus dem Angestelltenverhältnis für rechtens, obgleich das Gericht selbst einräumen mußte, daß die Bibelforscherin eine ,dem Volke und Staate feindliche Haltung bisher noch nicht unmittelbar betätigt" habe ${ }^{73}$. Da die Hebamme sich aber, wie die Richter befanden, in keiner Weise für Volk und Staat betätige, vielmehr sich ,ausnahmslos der Teilnahme an allen Unternehmungen und Veranstaltungen" versage, offenbare diese Zurückhaltung eine Grundanschauung, die befürchten lasse, daß die Frau, ,falls eine Lage der Dinge eintreten sollte, in der ihr staatliche Maßnahmen mit ihren Auffassungen über die ,Bibel' oder die ,Gebote Jehovas' in Widerspruch stehend erscheinen sollten, auch grundsätzlich nicht davor zurückschrecken wird, sich gegen das Volk und seine Führung zu entscheiden“. Damit leitete das Sächsische Oberverwaltungsgericht nachteilige Rechtsfolgen aus einer Prognose zukünftigen Verhaltens ab, ein bezeichnendes Beispiel dafür, daß auch auf zivilrechtlichem Gebiet Rechtskonstrukte nationalsozialistischen Gesinnungsstrafrechtes Anwendung fanden.

Konkret wurde der Hebamme, an deren beruflicher Pflichtenerfüllung die Richter nichts auszusetzen hatten, zum Vorwurf gemacht, daß sie sich prinzipiell, und zwar seit mindestens zehn Jahren, an Wahlen und Volksabstimmungen nicht beteiligte. Dazu stellte das Gericht fest - und dies unterstreicht den Charakter politischer Gesinnungsjustiz nachdrücklich -, daß zwar ,ein solches Verhalten vor dem nationalsozialistischen Umbruch ohne weiteres zulässig“ gewesen sei, doch „für die Zeit seit 1933" stelle sich der Sachverhalt anders. Die Frau habe offensichtlich „den Sinn des Umbruchs und die Notwendigkeit politischer Stellungnahme" nicht erkannt. Sie zeige sich ,unbelehrbar“ und halte „starr“ an Anschauungen fest, ,die gegebenenfalls in einen ausgesprochenen Gegensatz zu der heutigen völkischen Lebensordnung treten können“. Nach Lage des Falles sah das Gericht somit einen wichtigen Kündigungsgrund für gegeben an.

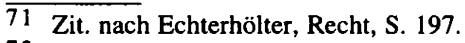

72 Beizupflichten ist Klaus J. Volkmann, der dem PrOVG bescheinigt, mit diesem Urteil „einen weitreichenden Eingriff in das forum internum" vorgenommen zu haben: „Eine Rechtspflicht zu allgemein-politischer Information, insbesondere zum Abonnieren einer Tageszeitung war weder für Beamte noch für die Allgemeinheit wirksam verkündet worden." (Volkmann, Rechtsprechung, S. 28)

73 JW 66 (1937), S. 1368, Sächsisches OVG, 101 I 35, Urteil vom 4.12.1936. 


\section{Entlassungen, Kündigungen, Tätigkeitsverbote}

Auch in der privaten Wirtschaft wurden Zeugen Jehovas aus den gleichen oder ähnlichen Gründen entlassen und ihrer beruflichen Existenzgrundlage beraubt. Der arbeitsrechtliche Kündigungsschutz galt für sie - wie für andere "Staatsfeinde“ nur noch in sehr eingeschränktem Maße. Bereits Anfang April 1933 waren die den Betriebsräten bei Kündigungen gesetzlich zustehenden Einspruchsrechte aufgehoben worden, wenn die Entlassung vom Arbeitgeber wegen des „Verdachts staatsfeindlicher Einstellung"74 ausgesprochen wurde. Nach Auflösung der Gewerkschaften und Schaffung der „Deutschen Arbeitsfront“ drangen in vielen Fällen deren Funktionäre auf eine Entfernung der Bibelforscher aus den Betrieben. Im Kündigungsschreiben eines Warenhauses hieß es ohne Umschweife: „Die Deutsche Arbeitsfront ist an uns herangetreten, Ihnen die Stellung in unserem Hause wegen staatsfeindlicher Einstellung zu kündigen. Wir sind unter den obwaltenden Verhältnissen gezwungen, dem Ersuchen Folge zu leisten, und sprechen Ihnen hiermit Ihre fristlose Entlassung zum heutigen Tage aus." "75 Insbesondere bei Nicht-Mitgliedschaft ${ }^{76}$ in der Arbeitsfront sahen ihre Repräsentanten den „Frieden der Betriebsgemeinschaft"77 gestört. Doch die Firmeninhaber folgten keineswegs immer derartigen Aufforderungen. Beispielsweise war im April 1936 der Leiter eines Chemnitzer Unternehmens nicht gewillt, sich den Pressionen der DAF zu beugen: „Der Chef erklärte, daß er einen solchen Mann für sein Magazin nicht wieder bekommt, der wüßte alles aus dem Kopf. Auch die Bemerkung des Vertrauensrates, daß wegen diesem einzigen Mann das Schild von der Arbeitsfront, Dieser Betrieb gehört geschlossen zur Arbeitsfront' nicht herausgehängt werden könnte, vermochte den Betriebsleiter nicht zu bewegen, den Bibelforscher zu entlassen."78

In derartigen Fällen versuchten die Parteianhänger sowohl verstärkt von außen auf die Firmenleitungen einzuwirken, als auch innerhalb der Betriebe die Belegschaftsmitglieder gegen die Bibelforscher aufzuhetzen. In einem rheinländischen Bergwerk wurden zum Beispiel Unterschriften unter eine Erklärung des Inhalts gesammelt, daß man mit diesen „Volksverrätern" nicht weiter zusammenarbeiten wolle. Im Anschluß kam es auf der Grube zur Kündigung von den vier dort be-

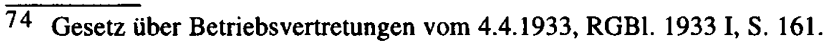

75 Zit. nach Zürcher, Kreuzzug, S. 89.

76 Das Vorgehen der DAF richtete sich nicht nur gegen die Zeugen Jehovas, die einen Beitritt abgelehnt hatten, sondern im Falle der Betätigung für die IBV auch gegen jene, die sich in die Arbeitsfront hatten einreihen lassen. So bedeutete eine gerichtliche Verurteilung in der Regel zugleich den Ausschluß aus der DAF. Wurde dies wohl auch ohne jedes Bedauern von den Betroffenen hingenommen, so drohte damit zugleich die Kündigung des Arbeitsverhältnisses, da die DAF nach einem Ausschluß ihrer Mitglieder auf eine Entlassung hinzuwirken versuchte.

77 Aus einer an einen Firmeninhaber gerichteten Aufforderung zur Entlassung des bei ihm beschäftigten Zeugen Jehovas, zit. nach Erwachet!, 22.6.1985, S. 10. Auch die für Fragen des "Arbeitsfriedens" im nationalsozialistischen Staat zuständigen „Treuhänder der Arbeit" scheinen in den Bibelforschern ein „störendes Element“ gesehen zu haben. So führte Reichstreuhänder Stiehler, der Treuhänder der Arbeit in Sachsen, im Juli 1935 das Auftreten von Betriebsstreitigkeiten und die Störung des Arbeitsfriedens auf „Vereinsmeier, besserwissende Eigenbrötler, unbelehrbare Sozialreformer", aber auch auf ,,konfessionelle Fanatiker" und „Sektierer" wie die „Ernsten Bibelforscher" zurück. Vgl. Deutschland-Berichte 2 (1935), S. 777. 
schäftigten Zeugen Jehovas ${ }^{79}$. Es gab aber auch Fälle, in denen Belegschaften es in ihrer großen Mehrheit verweigerten, gegen ihre Kollegen oder Kolleginnen Stellung zu beziehen ${ }^{80}$. Auch nach Entlassungen kam es zu Solidaritätsbekundungen; in einem schlesischen Betrieb veranstaltete die Belegschaft für die zwei gekündigten Bibelforscher eine Geldsammlung, um den Betroffenen über die Wochen hinwegzuhelfen, für die ihnen die Unterstützung gesperrt worden war ${ }^{81}$.

Entlassungsgründe waren neben der Ablehnung des Beitrittes zur DAF auch in der privaten Wirtschaft die Grußverweigerung sowie die Nicht-Teilnahme an den „Betriebsappellen“. Beispielsweise entließ die Hamburger Großwerft Blohm \& Voss am 28. Februar 1934 zwei den Zeugen Jehovas angehörende Werksfeuerwehrleute, weil sie sich weigerten, beim Betreten des Betriebsgeländes die Hand zum „Deutschen Gruß“ zu erheben ${ }^{82}$. Probleme entstanden für die Zeugen Jehovas regelmäßig anläßlich der Aufforderung zur Teilnahme an den Veranstaltungen zum „Tag der nationalen Arbeit" am 1. Mai, zu denen die Betriebe geschlossen hingeführt wurden. Laut einer Arbeitsgerichtsentscheidung bedeutete das Fernbleiben von den „Feierlichkeiten“ eine „schwere Verletzung der im Arbeitsvertrag begründeten Verpflichtung zum Gehorsam" 83 . In der NS-Presse wurde schließlich im Jahre 1936 die Entfernung der Bibelforscher aus sämtlichen deutschen Betrieben gefordert ${ }^{84}$.

Doch derartige Vorstellungen wurden nicht nur aufgrund des zunehmenden Arbeitskräftebedarfes nicht realisiert, sondern auch, weil in nicht wenigen Fällen Arbeitgeber zugunsten der bei ihnen beschäftigten Zeugen Jehovas intervenierten beziehungsweise sich bereit fanden, jene, die in anderen Betrieben entlassen worden waren, neu einzustellen und sie bei sich in Bereichen zu beschäftigen, in denen ihnen weniger Komplikationen drohten ${ }^{85}$. Wird dieses Engagement vor allem auch darauf zurückzuführen sein, daß sie die Arbeitskraft der als fleißig und gewissenhaft geltenden Zeugen Jehovas nicht missen oder sie nutzen wollten, so gibt es auch Beispiele dafür, daß jene Haltung vom Beistand für die wegen ihres Glaubens Verfolgten motiviert war. So bot der Direktor einer Weißenfelser Papierfabrik etli-

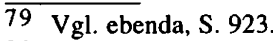

80 Vgl. Zürcher, Kreuzzug, S. 90.

81 Vgl. Deutschland-Berichte 3 (1936), S. 1177

82 Vgl. VVN HH, Komiteeakten K 37; Garbe, Gott mehr gehorchen, S. 201. Das Verfolgtenschicksal des Werksfeuerwehrmannes Karl Zietlow, der seit Anfang 1936 eine der vier Hamburger IBV-Gruppen leitete, $1938 \mathrm{zu}$ drei Jahren Gefängnis verurteilt wurde und Anfang Mai 1945 bei der „Evakuierung“ des KZ Neuengamme ums Leben kam, ist ebenda auf den Seiten 199 bis 207 in einer biographischen Skizze ausführlich geschildert. Nach dem Krieg war die Firma nicht bereit, der Witwe von Karl Zietlow für die Wiedergutmachung zu bescheinigen, daß ihr Mann wegen Verweigerung des „Hitler-Grußes“ entlassen worden war. Statt dessen versuchte die Firma, von ihrer Verantwortung abzulenken: „Herr Karl Zietlow mußte von uns entlassen werden, weil er sich beharrlich weigerte, auf Grund seiner inneren Überzeugung, den uns vom Amt für das Feuerlöschwesen gegebenen Vorschriften im Werkssicherheitsdienst voll zu entsprechen." (Bescheinigung der Fa. Blohm \& Voss vom 18.5.1946, Kopie im Besitz d. Verf.) Auch vier Jahre später war die Firma lediglich bereit, zu bestätigen: „Ihr verstorbener Ehemann mußte am 28.2.1934 entlassen werden, weil er sich weigerte, die für die Werksfeuerwehren vorgeschriebenen Bedingungen zu erfüllen." (Bescheinigung vom 11.12.1950)

83 Zit. nach Zürcher, Kreuzzug, S. 133.

84 Vgl. ebenda.

85 Vgl. Jahrbuch 1974, S. 126; Jahrbuch 1989, S. 115; VVN HH, Komiteeakten O 4. 
chen aus ihrer Stellung entlassenen Zeugen Jehovas unter Respektierung ihrer Grundsätze Beschäftigung, und der Elektromagnat Robert Bosch stellte sich schützend vor einen Bibelforscher, der am 3. Mai 1935 von der Stadtverwaltung in Heilbronn entlassen worden war und vier Jahre später bei der Firma Bosch im Arbeitsbereich Meßtechnik eine Anstellung gefunden hatte, als dieser auch an seiner neuen Arbeitsstelle wegen der Grußverweigerung in Konflikte geriet. Um die Situation zu entschärfen, nahm Bosch ihn aus der Firma und beschäftigte ihn fortan in seinem Privathaushalt ${ }^{86}$.

Viele Zeugen Jehovas, die entlassen worden waren und sich vergeblich um eine Neueinstellung bemühten, versuchten auf eine selbständige Tätigkeit auszuweichen. Aber auch in der Ausübung einer selbständigen Beschäftigung waren ihnen zahlreiche Beschränkungen auferlegt; oftmals wurde ihnen die Schaffung einer neuen Erwerbsgrundlage gänzlich verwehrt. So wurde beispielsweise im Fall jenes Steuerinspektors, dessen Dienstentlassung vom Reichsdisziplinarhof mit Urteil vom 29. Oktober 1935 für rechtens erklärt worden war ${ }^{87}$, diesem die Aufnahme einer Tätigkeit als Steuerberater durch Verfügung des Finanzamtes Tuttlingen vom 27. Januar 1936 ,wegen politischer Unzuverlässigkeit“ untersagt ${ }^{88}$. Dem Leiter der Hamburger IBV-Jugendgruppe, einem bereits 1933 entlassenen kaufmännischen Angestellten, gelang es trotz intensiven Bemühens nicht, sich im Handelsgewerbe selbständig zu machen, da die Genehmigung verwehrt wurde ${ }^{89}$. Einem Elektromonteur aus Dresden wurde nach seiner Entlassung sogar die Aufnahme einer freiberuflichen Tätigkeit als Lumpen- und Knochensammler untersagt, weil - wie es in einem Bescheid des Leipziger Gewerbeamtes vom 9. Januar 1937 heißt - „Tatsachen bekannt sind, die die Annahme rechtfertigen, daß Sie das beabsichtigte Gewerbe zu staatsfeindlichen Zwecken mißbrauchen werden“. Über die Art der „Tatsachen“ führt der Bescheid aus: „Für den Staat zeigen Sie kein Interesse und lehnen jede Mitgliedschaft zu irgend einer Organisation sowie auch zur DAF ab. [...] Dies sind Tatsachen, die Sie politisch nicht zuverlässig erscheinen lassen. “90

Die „Rechtsgrundlage“ für Entscheidungen wie die zuletzt genannte bot die Novelle zur Reichsgewerbeordnung (RGO) vom 3. Juli 1934, die bei der Neufassung des $\S 57$ die Versagung von Gewerbescheinen dann ermöglichte, wenn Tatsachen vorlagen, welche die Annahme rechtfertigten, daß der Nachsuchende sein Gewerbe zu staatsfeindlichen Zwecken mißbrauchen werde ${ }^{91}$. Einem Erlaß der Bayerischen Politischen Polizei vom 28. Januar 1936 zufolge war eine derartige Annahme bei Bibelforschern grundsätzlich vorauszusetzen:

86 EB Heinrich Markert, 5.6.1984. Zum in mehreren Fällen belegten Einsatz des 1942 verstorbenen Robert Bosch für NS-Verfolgte vgl. Treue, Widerstand von Unternehmern, S. 930f.

87 Siehe S. 170.

88 UaP J. E. Straßer (Sammlung zur historischen Dokumentation), Schreiben des betroffenen Steuerinspektors an die Landesdirektion der Finanzen vom 30.1.1947.

89 Vgl. VVN HH, Komiteeakten Z 4.

90 UaP J. E. Straßer (Sammlung zur historischen Dokumentation), Der Oberbürgermeister der Stadt Leipzig, Gewerbeamt, Bescheid vom 9.1.1937.

91 RGBI. 1934 I, S. 566. 
„Es ist bereits wiederholt die Wahrnehmung gemacht worden, daß gerade unter der Tarnung des Wandergewerbes die Ideen der Ernsten Bibelforscher in Wort und Schrift zur Verbreitung kommen, wobei bei Bekanntwerden derartiger Fälle die Feststellung des Täters mehr oder weniger große Schwierigkeiten bereitet. Anträge auf Ausstellung von Wandergewerbescheinen und Gewerbelegitimationskarten an Ernste Bibelforscher sind daher in Zukunft abzulehnen und die einschlägigen Dienststellen entsprechend anzuweisen. ${ }^{\text {(92 }}$

Auch bereits erteilte Genehmigungen von Gewerbescheinen wurden widerrufen ${ }^{93}$. Eine von einer Bibelforscherin wegen der Einziehung des Wandergewerbescheines angestrengte Klage wies der Bayerische Verwaltungsgerichtshof am 8. Mai 1936 ab, da die Beschwerdeführerin „vollständig auf dem Boden jener Vereinigung“" stehe und sich geweigert habe, ,zu erklären, daß sie sich nicht weiter für die Bibelforschersekte betätigen“ wolle ${ }^{94}$. Aus diesem Grunde müsse davon ausgegangen werden, „daß sie bei der Ausübung ihres Wandergewerbes bei ihren Kunden und sonstigen Volksgenossen ihre Gesinnung verbreiten" werde. Allein die Vermutung - irgendwelche Beweise für eine tatsächlich in der Ausübung ihres Gewerbes vorgenommene Einwirkung auf Dritte vermochte das Gericht nicht zu nennen - reichte für die Zurücknahme der Gewerbeerlaubnis wegen des Verdachts des „Mißbrauchs zu staatsfeindlichen Zwecken“ aus.

Im Unterschied zum Bayerischen Verwaltungsgerichtshof hatte das Preußische Oberverwaltungsgericht in einer Entscheidung vom 16. Januar 1936 keinen zwingenden Zusammenhang zwischen der Zugehörigkeit zu dem Kreise der Zeugen Jehovas und einer gewerblichen Unzuverlässigkeit gesehen. Eine solche Annahme, so befand das Obergericht, „,bedarf näherer Begründung “95. Ein halbes Jahr später unterstrich das Gericht diese zurückhaltendere Sicht und ergänzte, daß auch eine Bestrafung wegen Bibelforscherbetätigung nicht in allen Fällen die Versagung des Wandergewerbescheines rechtfertige ${ }^{96}$. In einer Entscheidung vom April 1938 erinnerte das Preußische Oberverwaltungsgericht die Verwaltungsbehörden an ihre Beweispflicht: „Nach dem Grundgedanken des Verbots kommt es nicht auf den Glauben an sich, sondern auf die damit verbundene und nach außen in Erscheinung tretende Betätigung an. Die verbotswidrige Betätigung muß nach den das Verwaltungsstreitverfahren beherrschenden Grundsätzen nachgewiesen werden. "97 $\mathrm{Da}$ aber für die Verwaltungsbehörden bereits mangelndes Interesse für den Staat oder die Nicht-Beteiligung an Wahlhandlungen als eine „,nach außen in Erscheinung

92 BHStA, Reichsstatthalter 638, BPP, RdErl. vom 28.1.1936.

93 Vgl. Der Hoheitsträger, Folge I, Januar 1938, S. 34; EB Bruno Knöller, 23.11.1987; VVN HH, Komiteeakten B 30. Gewerbescheine wurden unter Umständen auch staatspolizeilich eingezogen. So wurde einem Kaufmann für Manufakturwaren aus Hochdonn die Legitimationskarte von der Kieler Gestapo abgenommen, ,da der dringende Verdacht besteht, daß er auf seinen Geschäftsreisen weiterhin für die IBV wirbt" (SLG HH, SH SG 11 Son KMs 149/36, Bl. 140, Vermerk der Staatspolizeistelle Kiel vom 30.10.1936).

94 Reger 56 (1936), S. 533-535, Bayerischer Verwaltungsgerichtshof, 12 II 36, Urteil vom 8.5.1936.

95 PrOVG, III C 152.53, Urteil vom 16.1.1936, zit. nach Frege, Preußisches Oberverwaltungsgericht, S. 151.

96 PrOVG, III C 99.36, Urteil vom 13.8.1936, zit. nach ebenda.

97 PrOVG, Urteil vom 21.4.1938, zit. nach ebenda. 
tretende Betätigung" galt, war eine Argumentation wie die des Preußischen Oberverwaltungsgerichts letztlich nur sophistischer Natur.

Die Behörden verfügten neben der Nicht-Erteilung oder Einziehung von Gewerbescheinen auch die Aufhebung von Betriebsgenehmigungen. So wurde einem sich zum Bibelforscherglauben bekennenden Geschäftsmann, der sich an der Reichstagswahl vom 29. März 1936 nicht beteiligt hatte, folgender Bescheid zugestellt:

„Hierdurch untersage ich Ihnen die Herstellung und den Vertrieb von Fleischsalat und Mayonnaise auf Grund des $\S 20$ der Verordnung über Handelsbeschränkungen vom 13. Juli 1923, da Sie die für diesen Gewerbebetrieb erforderliche politische Zuverlässigkeit nicht besitzen. Nach den getroffenen Feststellungen haben Sie sich noch im Jahre 1936 für die Bestrebungen der verbotenen Internationalen Vereinigung Ernster Bibelforscher eingesetzt. “98

Der Fleischsalathersteller beschritt ergebnislos den Rechtsweg. Mit Urteil vom 28. Februar 1938 erklärte das Sächsische Oberverwaltungsgericht die Verfügung der Verwaltungsbehörde für rechtens, da unter dem in der genannten wirtschaftsrechtlichen Verordnung aus dem Jahre 1923 zugrunde gelegten Begriff der ,Zuverlässigkeit" nicht nur die gewerbliche, sondern - wie die in Diensten des NS-Staates stehenden Richter befanden - auch die politische Zuverlässigkeit zu verstehen sei ${ }^{99}$.

Dem Bibelforscherehepaar Marie und Rolf Appel aus Süderbrarup (Schleswig) wurde mit Bescheid vom 12. Mai 1941 der Betrieb einer Buchdruckerei für das gesamte Reichsgebiet untersagt. Die Frau - ihr Mann saß seit zwei Monaten in Berlin wegen Kriegsdienstverweigerung im Wehrmachtuntersuchungsgefängnis Alt Moabit ein - war gezwungen, die Druckerei weit unter Preis an die Schleswiger Nachrichten zu verkaufen ${ }^{100}$. Selbst Landwirten wurde die Existenzgrundlage entzogen; das Landeserbhofgericht in Celle erklärte mit Beschluß vom 4. Januar 1939 einen Zeugen Jehovas, der seit 1907 einen eigenen landwirtschaftlichen Betrieb bewirtschaftete, wegen fortgesetzter Nicht-Teilnahme an Wahlen - und unter Bezugnahme auf eine im Vorjahr wegen Betätigung für die IBV ausgesprochene Strafe von neun Monaten Gefängnis - für „nicht bauernfähig“101.

Neben die völlige Untersagung der Ausübung eines Gewerbes beziehungsweise eines Berufes konnten auch Teilbeschränkungen treten. So wurde 1935 einem 50jährigen Handwerksmeister nach der Verbüßung einer sechsmonatigen Haftstrafe wegen Betätigung für die IBV das Recht zum Unterrichten als Schneiderlehrer entzogen $^{102}$. Wirtschaftliche Einbußen erlitten als Selbständige tätige Zeugen Jehovas

$98 \quad$ Reger 58 (1938), S. 470, Verfügung vom 28.8.1937.

99 Reger 58 (1938), S. 470, Sächsisches OVG, Urteil vom 28.2.1938.

100 VVN HH, Komiteeakten A 12; das Schicksal der Familie Appel - neben dem Mann, der am 11.10.1941 unter dem Fallbeil des Zuchthauses Brandenburg starb, wurde auch ein Sohn im Oktober 1944 durch die SS hingerichtet - ist geschildert in: Verfolgung der Zeugen Jehovas in Kiel, S. 36-50; Philipsen, Für den Glauben in den Tod.

101 VVN HH, Komiteeakten S 55, Berufungsentscheid des Landeserbhofgerichtes in Celle vom 4.1.1939 (in Abschrift).

102 Vgl. VVN HH, Komiteeakten Sch 24. 
oft dadurch, daß ihr Geschäftsbetrieb boykottiert wurde ${ }^{103}$. Eine Bibelforscherin, die in Hamburg zusammen mit ihrem Mann, der zu den Exponenten der dortigen IBV-Gruppe zählte, ein gutgehendes Friseurgeschäft mit vier Angestellten führte, berichtete: „Unser Geschäft wurde seit 1933 fortwährend durch die Nazis boykottiert, so daß die Kunden Angst hatten, unser Geschäft zu betreten. Bis zur zweiten Verhaftung meines Mannes am 15. Dezember 1936 hatten wir durch die Boykottierung einen Schaden durch geringere Einnahmen von monatlich ca. 200 Mark. Durch unsere beiderseitige Inhaftierung und die fortgesetzte Boykottierung ist unser Geschäft vollständig zugrunde gegangen."104

Nicht immer waren die Auswirkungen derart ruinös. Gegenüber den Boykottkampagnen, deren Träger in der Regel die örtliche NS-Frauenschaft und die SA waren, verhielt sich die Bevölkerung eher reserviert, so daß die Schäden sich in Grenzen hielten. Bruno Knöller erinnert sich an die Geschehnisse um das elterliche Gemischtwarengeschäft in Simmozheim bei Pforzheim:

„Am Morgen des Wahltages kam die SA mit Karabinern, um meinen Eltern einen Schrecken einzujagen. Nun war es eine ,freie' Wahl, und unsere Eltern haben sich auf den Standpunkt gestellt, nicht zu gehen. [...] da war es von der Partei beschlossene Sache, das Geschäft zu boykottieren: Da Knöllers nicht zur Wahl gehen, werden sie boykottiert. Das wirkte dann drei, vier Wochen. Aber dann kamen die ersten bei Nacht und haben etwas gekauft, und dann kamen auch wieder einige von der Partei zu uns, und schließlich hieß es: ,Ja, wenn du kommst, dann kann ich auch wieder bei Tag etwas kaufen'. Das hat sich dann immer wieder eingespielt bis zur nächsten Wahl." 105

\section{Beschlagnahme, Ruhegeldentzug, Vermögensnachteile}

Unter Berufung auf das „Gesetz über die Einziehung volks- und staatsfeindlichen Vermögens" vom 14. Juli 1933 konnte auch das Eigentum von Bibelforschern konfisziert werden ${ }^{106}$. Betrafen derartige Einziehungen in erster Linie auch das „Vermögen" der IBV-Gruppen, beispielsweise Erlöse aus dem Verkauf von Büchern und Broschüren oder Spendengelder ${ }^{107}$, so wurde aber in nicht wenigen Fällen ebenso Privateigentum eingezogen. Teilweise war auch aus diesem Grunde eine Weiterführung der bisherigen Erwerbstätigkeit nicht möglich, etwa wenn die Staatspolizei bei Händlern die Einziehung von Personen- bzw. Lastkraftwagen oder

103 Vgl. Zürcher, Kreuzzug, S. 117, 129.

104 AfW HH, 280891, Bl. 18, Dorothea G., Erklärung vom 2.2.1954.

105 Knöller: Erinnerungen, S. 19.

106 Das am 14.7.1933 erlassene Gesetz über die Einziehung volks- und staatsfeindlichen Vermögens (RGBl. 1933 I, S. 479) bestimmte, daß die Vorschriften des Gesetzes über die Einziehung kommunistischen Vermögens vom 26.5.1933 (RGBl. 1933 I, S. 293) auch auf das Vermögen der Sozialdemokratischen Partei Deutschlands sowie auf solches, das ,nach Feststellung des Reichsministers des Innern“ zur Förderung „volks- und staatsfeindlicher Bestrebungen“ bestimmt war, Anwendung finden konnten. Damit konnte per einfacher polizeilicher Verfügung auch das Vermögen der IBV-Gruppen als zu „,volks- und staatsfeindlichen Bestrebungen dienend" deklariert werden.

107 Vgl. Billstein, Krefeld, S. 304. 
Motorrädern verfügte ${ }^{108}$. Selbst Fahrräder wurden in Einzelfällen konfisziert, um den Handlungsspielraum der Zeugen Jehovas einzuschränken ${ }^{109}$. Derartige Einziehungen waren häufig von anderen Maßnahmen begleitet. So wurde einem Kaufmann nicht nur sein Leichtmotorrad weggenommen, sondern auch der Führerschein einbehalten, ,da anzunehmen ist, daß er diesen für seine illegale Betätigung benutzt" 110 . Einem Berufskraftfahrer entzog die Gestapo die Fahrerlaubnis, so daß der 50jährige Mann sich fernerhin ,mit Pferd und Wagen abquälen"111 mußte.

Die Eingriffe in die persönliche Existenz umfaßten nahezu alle Lebensbereiche. Beispielsweise wurde Ende des Jahres 1933 dem in Pölitz (Pommern) ansässigen Bibelforscher Reinhard Lemke eine ihm bereits mit Bescheid des dortigen Magistrats vom 1. Juni 1933 zugesprochene Siedlerstelle in einer vorstädtischen Kleinsiedlung auf Betreiben des Bürgermeisters wieder aberkannt, da Lemke sich an der am 12. November durchgeführten Volksabstimmung nicht beteiligt hatte ${ }^{112}$. Bei dem Widerruf der Magistratsentscheidung konnte sich der Bürgermeister auf eine Verfügung des Stettiner Regierungspräsidenten vom 16. Mai 1933 berufen, nach der für eine Vergabe von Siedlerstellen nur solche Personen in Frage kämen, von denen nach ihrer politischen Einstellung anzunehmen sei, „daß sie sich jederzeit für den nationalsozialistischen Staat einsetzen würden"113.

Der um sein Siedlungshäuschen geprellte Mann führte einen zähen Kampf um sein Recht. So wandte er sich in zwei Schreiben an den Reichsminister des Innern, in denen er ,entschiedenen Einspruch“ gegen eine Maßnahme erhob, ,die jeder juristischen Grundlage entbehre"114. Gleichzeitig wies er darauf hin - und er tat dies wahrscheinlich nicht (nur) aus taktischen Gesichtspunkten, sondern weil es seiner Überzeugung wie der der meisten Zeugen Jehovas entsprach -, daß er nicht etwa ,aus der Absicht der Opposition heraus“ der Aufforderung zur Wahlteilnahme nicht nachgekommen sei. Vielmehr würde ihm sein religiöser Glaube überhaupt jede politische Betätigung verbieten, was der Bittsteller noch mit dem Hinweis unterstrich, daß er ,in den vergangenen 14 Jahren der Nachkriegszeit" aus denselben Gründen sich ,unter einer marxistischen Regierung ebenfalls von jeder Politik ferngehalten“ habe. Um der Treue zu seinem Herrn und Heiland willen müsse er „,unter allen Umständen" an diesem Grundsatz festhalten.

Zunächst schien Lemke mit seinem Einspruch sogar Erfolg zu haben. Am 22. Januar 1934 ersuchte der Staatssekretär im Reichsinnenministerium Hans Pfundtner den Preußischen Ministerpräsidenten, dafür Sorge zu tragen „daß die Maßnahmen gegen den Gesuchsteller wegen seiner Nicht-Teilnahme an der Reichs-

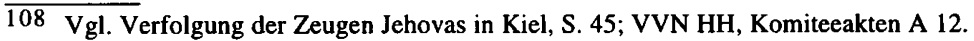

109 Vgl. Kühl, Friedrichstadt, S. 181.

110 SLG HH, SH SG 11 Son KMs 149/36, Bl. 34, Aktenvermerk der Kieler Staatspolizeistelle vom 3.9.1936. Vgl. auch Hamburger Tageblatt, 13.8.1937 („Staatsfeinde nicht ans Steuer“).

111 VVN HH, Komiteeakten J 5, Otto J., Lebenslauf vom 18.3.1946.

112 Der folgende Vorgang ist ausführlich dokumentiert in: Pommern 1934/35/Quellen, S. 409413; vgl. auch die erläuternden Ausführungen im Begleitband Pommern 1934/35/Darstellung, S. 161f.

113 Zit. in: Geheimes Staatspolizeiamt, Bericht vom 15.10.1934 an den Preußischen Ministerpräsidenten, abgedruckt in: Pommern 1934/35/Quellen, S. 409.

114 Reinhard Lemke, Schreiben vom 15.1.1934 an den RMdI, abgedruckt in: ebenda, S. 410. 
tagswahl und Volksabstimmung am 12. November 1933 alsbald aufgehoben werden"115. Doch nachdem der Bürgermeister in einer längeren Stellungnahme von dem staatsabträglichen Tun jenes „,böswilligen Nicht-Wählers“, der seine Handlungsweise zwei Tage vor der Wahl mit den anderen ortsansässigen Bibelforschern abgesprochen habe, Bericht erstattet hatte und der Regierungspräsident dieser Darstellung beipflichtete, erfolgte mit Datum vom 10. April 1934 ein abschlägiger Bescheid.

Nicht nur bereits erteilte Zusagen wurden widerrufen, sondern es konnte auch vorkommen,daß Familien, die sich zu den Zeugen Jehovas bekannten, aus ihren Siedlungshäusern vertrieben wurden. In der oberbayerischen Stadt Miesbach erlitten drei Familien 1937 dieses Schicksal ${ }^{116}$. Bereits im Frühjahr des Vorjahres hatte die dortige Kreisgeschäftsstelle der NSDAP für die Entfernung des Ehepaares Steppe von ihrer Siedlerstelle plädiert, da Herr Steppe ,durch seine aktive Tätigkeit für die verbotene und staatsfeindliche Sekte der Bibelforscher gezeigt hat, daß er gegensätzlich zur Idee des Führers eingestellt ist" 117 . Da die Stadtverwaltung diesen Gesuchen von sich aus nicht nachkam, wandte sich das Gauheimstättenamt der DAF am 23. April 1937 mit einer förmlichen Aufforderung an die Stadt, daß bei ,all den beteiligten Stellen Übereinstimmung“ herrsche, daß die drei Bibelforscherfamilien ,von ihrer Siedlerstelle wegen ihres Verhaltens entfernt werden müssen“. Nun reagierte die Stadtverwaltung von Miesbach umgehend. Fünf Tage später erhielten die drei Familien die Mitteilung, daß ihre Verträge zum 1. Juni 1937 gekündigt seien und sie ihre Siedlungshäuser bis dahin zu räumen hätten. Für den Fall der Nichterfüllung wurde die Zwangsräumung angeordnet. Die Siedlerstellen wurden ,bewährten Gliedern“ der „Volksgemeinschaft“ übertragen; eine davon erhielt der „Kreisgruppenführer des Deutschen Siedlerbundes“.

Häufig wurden Zeugen Jehovas sogar die Renten und Pensionen gekürzt oder auch gestrichen ${ }^{118}$. Dem Hamburger Seemann Alfred Knegendorf, der aufgrund eines Berufsunfalles $100 \%$ erwerbsunfähig war, wurde die Unfallrente entzogen $^{119}$. Das Verfahren war durch die Gestapo eingeleitet worden, als diese darauf aufmerksam wurde, daß der inzwischen ins Ausland verzogene Knegendorf, gegen den in Hamburg ein Strafverfahren wegen Betätigung als Bibelforscher lief, weiterhin Zahlungen aus seiner Unfallrente bezog. Mit Schreiben vom 30. August 1937 beantragte die Staatspolizeistelle Hamburg bei der See-Berufsgenossenschaft unter Berufung auf ein an alle Versicherungsträger gerichtetes Rundschreiben des Reichsministers des Innern vom 2. Juli 1937 die „Sperrung der Rente für Knegendorf"120. Am 27. April 1938 verfügte der Reichs- und Preußische Arbeitsminister,

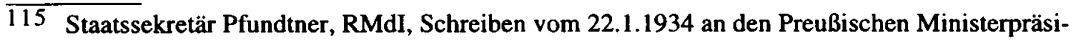
denten, abgedruckt in: ebenda, S. 411.

116 Vgl. United States Court of Restitution Appeals, S. 697-700, Court of Restitution Appeals (US-Zone), Entscheidung vom 13.11.1952.

117 Ebenda, S. 698.

118 Vgl. Zürcher, Kreuzzug, S. 91.

119 Vgl. Garbe, Gott mehr gehorchen, S. 187, S. 215, Anm. 106.

120 SLG HH, HSG 11 Js. Sond. 1675/36, BI. 12, Geheime Staatspolizei Hamburg, Schreiben vom 30.8.1937.
} 
daß die Unfallrente „bis auf weiteres ruht“, da Alfred Knegendorf ,sich nach dem 30. Januar 1933 in staatsfeindlichem Sinne gegen Deutschland betätigt" habe ${ }^{121}$.

Im Fall eines Eisenbahners, der zum 1. November 1934 in den Ruhestand versetzt und bis dahin beurlaubt worden war, wurde die Pensionierung aufgehoben, da er die von ihm noch geforderte Ableistung des mit Gesetz vom 20. August 1934 eingeführten neuen, auf die Person Hitlers zu entrichtenden Diensteides abgelehnt hatte. Im Disziplinarverfahren wurde auf Dienstentlassung ohne Übergangsgeld erkannt ${ }^{122}$. Aber auch Pensionären, von denen der Treueid auf Hitler nicht mehr zu fordern war, da sie vor Erlaß des „Gesetzes über die Vereidigung der Beamten“ in den Ruhestand getreten waren, entzog der Reichsdienststrafhof das laufende Ruhegehalt, so in einem Fall aufgrund einer wegen Bezugs des „Wachtturms“ ausgesprochenen gerichtlichen Verurteilung ${ }^{123}$. Einem Pensionär aus Bad Lippspringe, der den „Hitler-Gruß“ nicht erwiderte, wurde das Ruhegehalt gekürzt ${ }^{124}$, und im Falle eines bereits dienstentlassenen Beamten wurde diesem, da er sich in der Folge weiter für die IBV betätigte, auch noch der ihm bei seiner Entlassung bewilligte Unterhaltsbetrag entzogen ${ }^{125}$.

Zumindest in einem Urteil vom 29. November 1939 folgte das Reichsarbeitsgericht der vom Reichsdienststrafhof eingeschlagenen Linie jedoch nicht. In dieser Entscheidung verpflichteten die Arbeitsrichter den Reichsbund der Deutschen Beamten, einem der NSDAP angeschlossenen Berufsverband, als Rechtsnachfolger zur Weiterzahlung des Ruhegehaltes an einen bis 1933 beim Deutschen Beamtenbund beschäftigten Bibelforscher. Diesem war das Ruhegehalt gestrichen worden, nachdem er wegen Zuwiderhandlung gegen das IBV-Verbot zu einem Jahr und neun Monaten Gefängnis verurteilt worden war. Der Reichsbund hatte geitend gemacht, daß ihm als einem der Partei angeschlossenen Verband nicht zugemutet werden könne, Zahlungen an einen wegen volks- und staatsfeindlicher Aktivitäten Bestraften zu leisten. Im Gegensatz zu beiden Vorinstanzen erklärte das Reichsarbeitsgericht, daß dem Reichsbund der Deutschen Beamten in diesem Fall kein Leistungsverweigerungsrecht zustehe, da die Betätigung für die verbotene Bibelforschervereinigung keine Verletzung der „Treuepflicht“ dem Reichsbund gegenüber darstelle. Der vom Kläger aufgrund des Ruhegehaltsversprechens eingeforderte vermögensrechtliche Anspruch könne demzufolge nicht in Frage gestellt werden. In diesem, sich von anderen richterlichen Entscheidungen absetzenden Urteil herrschte die Sprache des „Normenstaates“126: „Die wegen einer Straftat gegen Volk, Staat und Partei Verurteilten stehen nicht außerhalb des bürgerlichen Rechts.“127

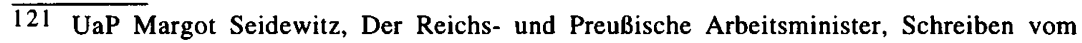
27.4.1938.

122 Vgl. Echterhölter, Recht, S. 199.

123 DV 18 (1941), S. 184, Reichsdienststrafhof, III D 64.39, Entscheidung vom 9.7.1940.

124 Vgl. Der Wachtturm, 1.9.1985, S. 12.

125 Vgl. Echterhölter, Recht, S. 196f.

126 Nach der Analyse von Ernst Fraenkel, die er mit seinem zuerst 1941 in New York erschienenen Buch „Der Doppelstaat" vorlegte, gab es im „Dritten Reich“ ein Nebeneinander von Maßnahmen- und Normenstaat. Der nationalsozialistische „Doppelstaat" hat danach bestimmte Bereiche, zum Beispiel das privatrechtliche Vertragswesen, weiterhin der formalen Rationalität des Rechtes unterworfen und in diesen Bereichen (zumindest in den ersten Jahren der nationalsozialistischen Herrschaft) Formelemente traditioneller Rechtsstaatlichkeit aufrecht- 
Für jene Zeugen Jehovas, die entlassen oder auf andere Weise ihrer Erwerbsgrundlage beraubt worden waren, gestaltete sich nicht nur die Suche nach einer neuen Beschäftigungs- und Verdienstmöglichkeit als sehr schwierig, sondern überdies wurden die ihnen gesetzlich zustehenden Leistungen stark eingeschränkt. Zunächst bekamen die Gekündigten eine sechswöchige Sperrfrist auferlegt, während der sie keine Unterstützungszahlungen erhielten. Erschienen sie auf den Arbeitsämtern, so wurde ihnen beispielsweise vorgehalten, daß sie wegen ihrer ,verstockten Haltung" schließlich selbst schuld am Verlust ihres Arbeitsplatzes seien ${ }^{128}$, daß sie zunächst einmal in die „Deutsche Arbeitsfront“ einzutreten hätten, bevor sie irgendwelche Ansprüche stellen könnten ${ }^{129}$, daß man schon Arbeit habe, ,,aber nicht für Sie"130, oder einfach flapsige Bemerkungen wie „erst kommen unsere Parteigenossen, dann kommt ihr noch lange nicht" ${ }^{\text {"131. }}$.

Ein Zeuge Jehovas berichtete davon, daß ihm der Abteilungsleiter beim Arbeitsamt nach einer einstündigen Belehrung erklärt habe, er könne weder eine Meldekarte erhalten noch Unterstützung gewährt bekommen; er solle sich doch von seinem Gott Jehova zu essen geben lassen. Da der Mann sich mit dieser Auskunft nicht zufriedengab und unter Hinweis darauf, daß die ihm als Kündigungsgrund genannte Nicht-Teilnahme an Wahlen schließlich nicht verboten sei und er folglich keine strafbare Handlung begangen habe, auf seinem Recht beharrte, ließ ihn der Arbeitsamtsbedienstete kurzerhand von der Gestapo verhaften ${ }^{132}$. Wenn Zeugen Jehovas überhaupt vermittelt wurden, so bekamen sie minderqualifizierte, schlecht bezahlte Tätigkeiten zugewiesen. Die auf die Fürsorge Angewiesenen wurden zu Pflichtarbeiten herangezogen; dort bedurfte man ihrer Arbeitsleistung schon. Seit 1936/37 wurde von den Arbeitsämtern prinzipiell erklärt, daß Bibelforscher aufgrund der von ihnen praktizierten Grußverweigerung als nicht vermittelbar gelten und ihnen deshalb die Unterstützung grundsätzlich verweigert werden müsse ${ }^{133}$.

Diese Regelung war zwischen Arbeitsministerium, Innenministerium und Gestapo vereinbart worden. Am 2. Februar 1936 hatte der Reichs- und Preußische Arbeitsminister angeordnet, daß Angehörigen der IBV die Anerkennung als Wohl-

erhalten, während andere gesellschaftliche Sphären, insbesondere jene, die mit der Verfolgung von Regimegegnern zu tun hatten, aus der Bindung an ein normatives System gelöst und damit zu rechtsfreien Räumen erklärt wurden. Mit Fraenkels Theorieansatz läßt sich $\mathrm{m}$. E. die disparate Rechtsprechung in Bibelforscherverfahren zumindest teilweise deuten. DR 10 (1940), S. 516f., Reichsarbeitsgericht, 88/39, Urteil vom 29.11.1939.

128 So im Fall einer Stationsschwester, der am 10.11.1934 von der Verwaltung des Altonaer Krankenhauses wegen Nicht-Erweisung des „Hitler-Grußes“ gekündigt worden war (AfW HH, 260488, Bl. 1).

129 So im Fall einer 37jährigen Hamburger Kontoristin, die 1935 entlassen worden war (VVN HH, Komiteeakten O 4). Vgl. auch Jahrbuch 1974, S. 117.

130 So im Fall eines aus dem Postdienst entlassenen Boten, dem zugleich verwehrt wurde, sich als Zeitungsauslieferer selbständig zu machen (VVN HH, Komiteeakten B 30).

131 So im Fall eines 32jährigen Schlossers, der 1934 entlassen worden war und nach seinen Worten allein schon deshalb bei dem Sachbearbeiter in Ungnade gefallen war, weil er beim Eintreten nicht mit „Heil Hitler" gegrüßt habe (VVN HH, Komiteeakten H 34).

132 Vgl. Zürcher, Kreuzzug, S. 91. Ein ähnlicher Vorgang führte in Hamburg zu einen Strafverfahren nach dem Heimtückegesetz wegen „Verächtlichmachung der Reichsregierung“ (SLG HH, HSG 11 Js. Sond. 1545/34).

133 Vgl. Zürcher, Kreuzzug, S. 88. 
fahrtserwerbslose $\mathrm{zu}$ versagen sei ${ }^{134}$. Im Jahr darauf wurde bei Zeugen Jehovas ein Anspruch auf Unterstützung nach dem Arbeitsvermittlungs- und Arbeitslosenversicherungsgesetz (AVAVG) und damit ein Anspruch auf Arbeitslosenversicherung und Arbeitsvermittlung generell und grundsätzlich verneint. In einem Schriftsatz des Präsidenten des Landesarbeitsamtes Rheinland vom 8. August 1937 heißt es hierzu:

„Nach einem Schreiben des Herm Reichs- u. Preußischen Ministers des Innern vom 14.5.1937 [...], dem der Herr Reichs- u. Preußische Arbeitsminister zugestimmt hat, sind die Angehörigen der ,Ernsten Bibelforscher' asoziale Elemente, die dem Arbeitseinsatz nicht zur Verfügung stehen. Infolgedessen ist ihnen die Anerkennung als Wohlfahrtserwerbslose grundsätzlich und ausnahmslos zu versagen. Aus dem gleichen Grunde muß aber auch Arbeitslosigkeit gemäß § 89a AVAVG verneint werden. Denn wer dem Arbeitseinsatz nicht zur Verfügung steht, kann auch nicht als arbeitslos bezeichnet werden. Etwaige Unterstützungsanträge von Angehörigen der ,Ernsten Bibelforscher' sind daher gemäß § 89a AVAVG durch einspruchsfähigen Bescheid zurückzuweisen. “135

Daraufhin wandten sich Vorstände von Arbeitsämtern an die Gestapo und baten um Bekanntgabe der Namen der Zeugen Jehovas aus ihrem Amtsbereich, um sie von der Arbeitsvermittlung ausschließen zu können. Die Staatspolizeistelle Regensburg, die mit Rundschreiben vom 7. Februar 1938 die oberpfälzischen Polizeibehörden anwies, den Arbeitsämtern die Namen ,zur vertraulichen dienstlichen Information zur Kenntnis zu geben“, ermahnte die Polizeibehörden jedoch zu einer eher zurückhaltenden Meldepraxis: „Ich bitte jedoch nur diejenigen Personen in die Liste aufzunehmen, die ohne Zweifel auf Grund ihrer bisherigen Tätigkeit sich als besonders aktive Bibelforscher betätigt haben."136

Den Fürsorgeträgern - zumeist die Stadt- und Landkreise - kam diese Entwicklung nicht zupaß, da auf sie durch die für Bibelforscher angeordnete NichtLeistung von Erwerbslosenunterstützung zusätzliche Kosten zukamen. Auf ihre Nöte reagierte der Reichsführer-SS mit den folgenden Ausführungen:

„Wenn ich auch nicht verkenne, daß die Ablehnung der Anerkennung als Wohlfahrtserwerbslose zunächst dem Fürsorgeverband eine Mehrbelastung einbringen wird, so kann der Fürsorgeverband andererseits eine Verringerung der Kosten dadurch erwirken, daß er seine Leistungen auf das gesetzlich zulässige Mindestmaß wegen der staatsfeindlichen Einstellung der Unterhaltsbedürftigen herabsetzt. Diese Mindestbelastung muß aber vom politischen Standpunkt aus getragen werden. Sie ist wesentlich geringer als der Kostenaufwand, der bis jetzt für die Niederhaltung einer wirtschaftlich ungeschwächten Kampforganisation fortlaufend ausgeworfen werden mußte."137

134 BA, Sammlung Schumacher/267 I, zitiert im RdS der Staatspolizeistelle Regensburg vom 7.2.1938.

135 Der Präsident des Landesarbeitsamtes Rheinland, Schreiben vom 8.8.1937 an den Vorsitzenden des Arbeitsamtes Wuppertal, abgedruckt in: Duisburg im Nationalsozialismus, S. 108.

136 BA, Sammlung Schumacher/267 I, Staatspolizeistelle Regensburg, RdS vom 7.2.1938.

137 Zit. in: RuPrMdI, Schreiben vom 30.5.1938 an den Regierungspräsidenten in Düsseldorf, Duisburg im Nationalsozialismus, S. 108. Das Schreiben des RFSS trägt vermutlich das Datum vom 8.4.1937, vgl. die entsprechende Erwähnung in BA, Sammlung Schumacher/267 I, Staatspolizeistelle Regensburg, RdS vom 7.2.1938. 
Auch der Reichs- und Preußische Minister des Innern befand, daß die Fürsorgeverbände wohl kaum sich den aus Gründen der Staatsräson zu leistenden Mehraufwendungen entziehen könnten, gab aber ebenfalls den Rat, die Kosten dadurch zu drosseln, daß die Fürsorgeverbände ,,mit den schärfsten Mitteln“ der Fürsorgepflichtverordnung vorgehen, $d$. h. soweit wie möglich eine Leistungsentrichtung abzuwehren versuchen ${ }^{138}$.

Während die Fürsorgeverbände und kommunalen Verwaltungsspitzen sich um die für sie entstehenden Mehrkosten sorgten, stürzten die von ihnen in die Wege geleiteten administrativen Maßnahmen die Zeugen Jehovas in bitterste Not. Erst mit Kriegsbeginn trat für die Zeugen Jehovas - soweit sie noch in „Freiheit" waren eine leichte Besserung der Situation ein, da infolge des Arbeitskräftemangels die Restriktionen bei der Arbeitsvermittlung aufgegeben wurden.

Das Vorgehen der Behörden bezweckte eine wirtschaftliche Ausblutung, die die Betroffenen vor die Alternative stellte, entweder ihre Haltung und damit ihren Glauben aufzugeben oder über kurz oder lang materiell zugrunde zu gehen. War erst einmal eine Entlassung vom angestammten Arbeitsplatz erfolgt, so wurde in aller Regel eine neue Arbeitszuweisung abgelehnt. Das Ausweichen auf anderweitige Beschäftigungen war ebenso nahezu unmöglich: Die Erlaubnis zur Ausübung einer selbständigen beruflichen Tätigkeit wurde vielfach verwehrt; Wandergewerbescheine wurden grundsätzlich nicht mehr an Bibelforscher ausgehändigt. Da keine Wohlfahrtserwerbslosenunterstützung gezahlt wurde und ihnen ihre Rechte aus der Arbeitslosenversicherung genommen waren, blieben nur die kargen Mindestsätze der Fürsorgeverbände. Wer von den Zeugen Jehovas nicht auf Ersparnisse, veräußerbares Eigentum oder auf unterstützungsbereite und -fähige Verwandte zurückgreifen konnte, war zu einem Leben in äußerster Armut verurteilt.

Die Wachtturm Bibel- und Traktat-Gesellschaft versuchte nach dem Krieg, die Maßnahmen zu registrieren, die im „Dritten Reich“ zur wirtschaftlichen Existenzvernichtung der Zeugen Jehovas ergriffen worden waren. Die - unvollständige Bilanz sieht demnach so aus:

„Während Hitlers Herrschaft hatten 1.687 ihre Stellung verloren, $284 \mathrm{ihr}$ Geschäft und 735 ihre Wohnung, und 457 war die Ausübung ihres Berufs verboten worden. In 129 Fällen wurden Grundstücke beschlagnahmt, 829 Rentnern wurde die Unterstützung entzogen, und 329 weitere erlitten sonstige Vermögensnachteile."139

$\overline{138 \text { RuPrM }} d I$, Schreiben vom 30.5.1938 an den Regierungspräsidenten in Düsseldorf, Duisburg im Nationalsozialismus, S. 108.

139 Jahrbuch 1974, S. 212. 


\section{Die Ausweitung der Verfolgung: Kinder aus Bibelforscher- Familien als Objekte staatlicher Zwangsmaßnahmen}

Die Probleme, die sich den ihren Glauben weiterhin praktizierenden Zeugen Jehovas im nationalsozialistischen Weltanschauungsstaat stellten, beschränkten sich nicht auf Konflikte bei Verweigerung staatlicher Forderungen und auf materielle Aspekte, sondern gefährdeten auch den Bestand von Familien, bezogen selbst die Kinder mit ein und waren geeignet, Beziehungen zu zerrütten. Vor allem in glaubensverschiedenen Ehen, in denen einer der Partner sich nicht zu den Zeugen Jehovas bekannte und den Bibelforscherglauben für sich ablehnte, kam es nicht selten zu schwerwiegenden Konflikten über die Betätigung für die IBV, die damit zusammenhängende Inkaufnahme des Verfolgungsrisikos und die dadurch auf die Familien zukommenden Belastungen. In zahlreichen Fällen wurden die nicht den Bibelforschern angehörigen Ehepartner von Partei- und Behördenstellen oder von Verwandten bedrängt, die Ehe aufzulösen ${ }^{140}$. Gaben diese dem Drängen nach, wurden die Ehen auch dann aufgehoben, wenn die sich zu den Zeugen Jehovas bekennenden Partner nicht in die Scheidung einwilligten.

Grundlegende Bedeutung kam dabei einer Entscheidung des Landgerichts Rudolstadt vom 11. Januar $1937 \mathrm{zu}$. In diesem Verfahren gestand das Gericht einem Beamten, dessen Frau trotz Verbot ihres Ehemannes an Bibelforscherversammlungen teilnahm, einen Ehescheidungsanspruch gemäß § 1568 BGB zu. In den Urteilsgründen hielt das Gericht „,es mit dem Wesen der Ehe in Deutschland für unvereinbar, daß eine Beamtenfrau bewußt gegen den Willen und die Überzeugung ihres Mannes eine politische Ansicht beibehält, die im Gegensatz zum Staate und zur nationalsozialistischen Weltanschauung steht: sie bereitet ihm durch eine solche Einstellung untragbare materielle und seelische Schwierigkeiten, kann seine Stellung im öffentlichen Leben völlig untergraben und bringt ihn in schweren inneren Widerstreit"141. Die Frau habe sich mit ihrem Bekenntnis zur Bibelforscherlehre „,aus der Volksgemeinschaft ausgeschlossen und durch ein solches Verhalten eine tiefe Zerrüttung des ehelichen Lebens verschuldet“. Eine Ehepartnerin, die sich so verhalte, zerrütte eine Ehe so stark, „daß dem anderen Ehegatten die Fortsetzung der Ehe nicht mehr zugemutet werden" könne. Dieses Urteil wurde über die Parteidienststellen bekanntgegeben, weil es über den Einzelfall hinaus als richtungsweisend für die Ausrichtung des Ehelebens im nationalsozialistischen Deutschland eingeschätzt wurde: Es enthalte, wie man parteioffiziell befand, „Richtlinien für jede Ehe von Volksgenossen“142.

Vielfache Schwierigkeiten wurden auch den Kindern von Zeugen Jehovas bereitet, die im nationalsozialistischen Deutschland nicht nur Mitbetroffene der gegen ihre Eltern gerichteten Repressionen waren, sondern oftmals selbst zu Objekten

140 Vgl. Jahrbuch 1974, S. 212. Nach den Aufzeichnungen der WTG wurden neben 108 auf Antrag des Ehepartners aufgelösten Ehen auch 30 Ehen „,von Amts wegen“ geschieden.

141 JW 66 (1937), S. 1308f., Landgericht Rudolstadt, I R 63/36, Urteil vom 11.1.1937.

142 BA, Sammlung Schumacher/267 I, Kommentierung zu einer bei der NSDAP-Kreisleitung Rosenheim am 4.5.1938 eingegangenen Urteilsabschrift. 
staatlicher Zwangsmaßnahmen wurden. Die Probleme begannen, als bald nach der Machtübernahme die politischen Veränderungen im Schulalltag spürbar wurden. Die zunehmende Orientierung an nationalsozialistischen Grundsätzen erfaßte über die Lehrinhalte und die Umstrukturierung des Fächerkanons hinaus auch die gesamten äußeren Unterrichtsbedingungen ${ }^{143}$. Tragendes Prinzip wurde der sogenannte „Gemeinschaftsgedanke“: Nicht mehr die „Einzelpersönlichkeit“ stand im Zentrum, sondern die Einordnung des Schülers in das „Volksganze“ bestimmte den schulischen Erziehungsauftrag. Neben die Vermittlung von Kenntnissen und Fertigkeiten rückte eine soldatisch straff ausgerichtete Formationserziehung, eine „Formung“ des Heranwachsenden zu einem funktionierenden Glied im „Führer-Staat“. Der Unterricht wurde damit zur „Schulung“ im Sinne des Nationalsozialismus.

Die Erziehung zur „Volksgemeinschaft“, die Propagierung der Überlegenheit der „germanischen Rasse“ oder die Anleitung zur „Wehrfähigkeit" fanden aber nicht nur durch Lehrervortrag und Schulbuch Eingang in die Klassenzimmer, sondern auch über auf die affektive Ebene gerichtete Handlungen, insbesondere über Rituale mit politischer Symbolik. Augenfälligster Ausdruck und Grundlage des NS-Kultes war auch in der Schule der dem „Führer“ zu erweisende „Gruß“. Von den Schulbehörden war angeordnet worden, daß zu Beginn und zum Schluß des Unterrichtes und bei jedem Lehrerwechsel der „Deutsche Gruß“ zu erfolgen habe ${ }^{144}$. Damit dies auch im militärischen Stakkato wunschgemäß ablief, erging die behördliche Empfehlung: „Zur angemessenen Erweisung des Hitler-Grußes ist dieser im Turnunterricht zu üben." 145

Die Landesunterrichtsbehörde in Hamburg verfügte am 1. Juli 1933, daß in den Schulen an jedem Montagmorgen vor Beginn des Unterrichts in Gegenwart aller Lehrer und Schüler ein Flaggenappell stattzufinden habe, damit die heranwachsende Jugend zum rechten „Stolz auf ihr Vaterland“ finde ${ }^{146}$. Während des Hissens der Hakenkreuzfahne hatten die Schüler die ersten Strophen des Deutschlandliedes und des Horst-Wessel-Liedes zu singen. Anfang 1934 wurde die Durchführung dieser Zeremonie auf den ersten Schultag nach und den letzten Schultag vor den Ferien beschränkt ${ }^{147}$. Ansonsten wurde die „Feierpraxis“ an den Schulen aber stark ausgeweitet. An bestimmten „Gedenktagen“, etwa aus Anlaß von Hitlers Geburtstag oder in Erinnerung an die beim Hitler-Putsch des Jahres 1923 ums Leben gekommenen „Gefallenen der Bewegung“, fanden alljährlich aufwendige Schulfeiern statt. In den mit Hakenkreuzfahnen und Hitler-Bildern geschmückten Schulaulen waren die Schülerinnen und Schüler jedoch nicht nur Adressaten von Ansprachen und Festprogrammen, vielmehr wurde von jedem Anwesenden durch

$\overline{143}$ Zu den Veränderungen im Schul- bzw. Unterrichtsalltag im Zuge der nationalsozialistischen Machtkonsolidierung vgl. Breyvogel/Lohmann, Schulalltag, S. 199-221. Hinsichtlich der Auswirkungen auf die Unterrichtsinhalte vgl. Flessau, Schule; Rossmeissl, Erziehung.

144 Eine entsprechende Bestimmung wurde für Preußen mit den ,Leitgedanken zur Schulordnung“ vom 20. Januar 1934 verbindlich. Vgl. Zentralblatt für die gesamte Unterrichts-Verwaltung in Preußen 76 (1934), S. 128.

145 Anordnung der Hamburger Landesunterrichtsbehörde vom 11.8.1933, zit. nach Lehberger, Umbau, S. 20.

146 Vgl. Lehberger, Umbau, S. 19.

147 Vgl. Zentralblatt für die gesamte Unterrichts-Verwaltung in Preußen 76 (1934), S. 128, Leitgedanken zur Schulordnung vom 20.1.1934. 
die zahlreichen proklamatorischen Elemente (Lieder, gemeinsame Gedichtsrezitationen, Gelöbnis, „Gruß“ und andere „Ehrerweisungen“) das aktive Bekenntnis zum Nationalsozialismus und seinem „Führer" gefordert ${ }^{148}$. Bei diesen Schulveranstaltungen galt grundsätzlich die Anwesenheitspflicht. Ähnlich verhielt es sich, wenn die Schüler zu bestimmten Aufgaben, zum Beispiel den zahlreichen Straßenund Haussammlungen für das Winterhilfswerk, herangezogen wurden. Oftmals mußten auch die Reden Hitlers oder anderer führender NS-Politiker über Rundfunk im Gemeinschaftsempfang gehört werden.

Diese Ideologisierung und Ritualisierung der schulischen Erziehung mußte die Kinder, die im Elternhaus im Gedankengut der Bibelforscherlehre aufwuchsen, in fortwährende Konfliktsituationen bringen. In ihrer Sozialisation waren sie mit der Unbedingtheit des göttlichen Gebotes konfrontiert; nun trat ihnen eine Schule gegenüber, die von ihnen ein offenes weltliches Bekenntnis verlangte. Für viele der älteren Schülerinnen und Schüler bedurfte es zur Entscheidung, wie sie sich angesichts dieser Herausforderung verhalten sollten, keiner unmittelbaren Einwirkung aus dem Elternhaus. Mit der Belehrung über die Treue zum biblischen Gesetz als Voraussetzung für die Heilszuversicht und der Warnung vor dem Götzendienst groß geworden, empfanden sie die zum Teil religiös verbrämten nationalsozialistischen Konformitätsrituale für sich selbst als Gotteslästerung, als Abfall von Gott. Neben der starken Verankerung im Bibelforscherglauben wird ihr Verhalten dabei auch von dem Wunsch bestimmt worden sein, es den Eltern gleichzutun, vor ihnen Achtung und Anerkennung zu finden. Die jüngeren Kinder verstanden den Konflikt wohl kaum, aber sie spürten ihn sehr deutlich. Sie gerieten zwischen die Autoritäten von Schule und Elternhaus. Die Vorhaltungen und die Schläge der Lehrer einerseits und die Fürsorge und der Schutz des Elternhauses andererseits führten sie dann aber doch sehr bald gefühlsmäßig zu einem ähnlichen Verhalten, wie es ihre älteren Geschwister zeigten.

Welchen Belastungen die Kinder von Zeugen Jehovas im Schulalltag ausgesetzt waren, verdeutlichen die folgenden Berichte. Helmut Knöller besuchte in Stuttgart eine Handelsschule: „Wenn der Lehrer das Schulzimmer betrat, war es für die Schüler Vorschrift, aufzustehen, laut mit ,Heil Hitler' zu grüßen und die rechte Hand vorzustrecken. Dies machte ich nicht mit. Natürlich schaute der Lehrer nur auf mich, und dann gab es oft Szenen wie diese: ,Knöller, kommen Sie mal raus! Warum grüßen Sie nicht mit >Heil Hitler<?" - ,Das ist gegen mein Gewissen, Herr Lehrer. ' - ,Was, Sie Schwein, Sie! Gehen Sie bloß weiter weg von mir, Sie stinken ja. Noch weiter! Pfui, so ein Volksverräter."'149 Der 1922 geborene KarlHeinz Zietlow erinnert sich an seine Schulzeit in Hamburg: „Ich kam 1929 in die Volksschule. Es lief alles ganz normal, bis das ,Tausendjährige Reich' ausgerufen wurde und der Gruß in der Schule nicht mehr, guten Morgen', sondern ,Heil Hitler' lautete. Ich war vom Vater so geprägt worden, daß ich in der Schule nicht den Arm hob und auch nicht mit ,Heil Hitler' grüßte. [...] Wenn mein Klassenlehrer Aufsicht hatte und ich ging an ihm vorbei und sagte, guten Morgen', wurde

148 Vgl. zur Funktion der Gedenkfeiern im Schulalltag des „Dritten Reiches“ Müller, W., Feierpraxis, S. 34ff.; Rossmeissl, Erziehung, S. 89ff.

149 Der Bericht von Helmut Knöller ist wiedergegeben im Jahrbuch 1974, S. $117 f$. 
ich von ihm zurückgeschickt. Dann mußte ich nochmals an ihm vorbeigehen, denn er wollte wissen, was ich nun sagen würde. Wenn ich das zweite Mal ,guten Morgen' sagte, dann brüllte er mich an. Manchmal passierte es, daß ich von ihm an den Kopf geschlagen wurde." 150

Von Lehrern, die die Kinder von Zeugen Jehovas immer wieder neu auf die Probe zu stellten versuchten, ist in Erinnerungsschreiben oftmals die Rede. Elise Kühnle, die in einem kleinen schwäbischen Ort zur Schule ging, berichtet davon, $\mathrm{da}$ sie extra nur ins Zimmer des Oberlehrers beordert worden sei, um sie beim Eintreten in Verlegenheit zu bringen. Der Lehrer habe geschrien und getobt, weil sie ohne „Gruß“ in sein Zimmer eingetreten war: „Das war so ein starker Schreier. Und der hat furchtbar gebrüllt. Ich bin damals sieben Jahre alt gewesen. Und wenn ein Lehrer einen dann so anschreit ..."151 Häufig blieb es nicht bei verbalen Wutausbrüchen. In den Akten finden sich dann Feststellungen wie: „Die Kinder Alfred und Friedrich [...] haben trotz mehrfacher Verwarnung und Bestrafung durch den Schulleiter den Deutschen Gruß und das Singen der Nationallieder verweigert." 152 Hinter derartigen „Bestrafungen“ verbargen sich zum Teil schwere körperliche Mißhandlungen ${ }^{153}$.

Hinzu kamen Versuche psychischer Einwirkung durch massive Drohungen. Dies zeigt der Fall eines 10jährigen Jungen, der sich in einer Schulstunde weigerte, ein Gedicht vorzutragen, in dem der nationalsozialistische Staat verherrlicht wurde. Nach dem Bericht seiner Mutter ließ der Lehrer daraufhin den Jungen von zwei Mitschülern „wie einen Gefangenen“ abführen ${ }^{154}$. Er wurde zum Schulleiter gebracht. Da der Junge sich auch gegenüber dem Rektor sperrte, das Gedicht aufzusagen, habe dieser ihm gedroht, seine Finger so lange zu schlagen, „bis sie blau angeschwollen“ wären. Außerdem habe er den 10jährigen befragt, ob er denn später auch den Militärdienst verweigern wolle, was dieser frei heraus bejaht haben soll. Daraufhin habe der Schulleiter den Klassenlehrer aufgefordert, den Knaben ,wie üblich" zu züchtigen. Der Rektor habe auch erklärt, wenn der Junge seine Haltung nicht aufzugeben bereit sei, werde er sich dafür einsetzen, daß er seinen Vater, der zu jener Zeit eine dreijährige Gefängnisstrafe wegen Betätigung für die IBV verbüßte, nie wiedersehen werde. Entlassen wurde der derart malträtierte Junge mit der Bemerkung, daß man nunmehr gewillt sei, die Polizei zu benachrichtigen, damit er umgehend in eine Erziehungsanstalt eingeliefert werde.

Oftmals wurden von den Lehrern auch die Mitschüler aufgestachelt und auf ihre den „Hitler-Gruß“ verweigernden Klassenkameraden gehetzt: „Da ist die ganze Klasse auf sie losgegangen. Sie haben sie umringt und auf sie losgeschlagen. Die

150 EB Karl-Heinz Zietlow, 25.1.1986.

151 EB Elise Kühnle, 23.11.1987.

152 ZJJ 28 (1937), S. 281.

153 In den aus Deutschland herausgeschmuggelten Berichten, die in der 1938 vom Zentraleuropäischen Büro der Zeugen Jehovas in der Schweiz herausgegebenen Dokumentation „Kreuzzug gegen das Christentum" abgedruckt sind, wurde verschiedentlich von Mißhandlungen, die Bibelforscherkindern durch Lehrer wegen der Verweigerung des „Hitler-Grußes“ o. ä. zugefügt wurden, berichtet. Vgl. Zürcher, Kreuzzug, S. 159, 162, 164f., $167 f$. 
Lehrer haben gemeint, das wäre ja noch schöner. Die ganze Schule ist bereit, ,Heil Hitler' zu sagen, nur die beiden Kinder nicht. Das darf es nicht geben!"155

Die Mobilisierung von Haßgefühlen wurde dadurch begünstigt, daß die Kinder von Zeugen Jehovas fast immer vollständig isoliert waren ${ }^{156}$. Auch außerhalb der Schule bestanden kaum freundschaftliche Bande zu Kindern anderen Glaubens. Die Erfahrung, von den Klassenkameraden als ,absonderliche Außenseiter" behandelt zu werden, schmerzte oftmals mehr als die Schläge der Lehrer.

Noch ganz unter diesem Eindruck steht eine zeitgenössische Schilderung aus dem Jahre 1937. Der zwölfjährige Willi Seitz aus Karlsruhe faßte seine Schulerlebnisse in die folgenden Worte: „Was ich bis jetzt [...] alles durchgemacht habe, kann ich fast nicht schreiben. In der Schule wurde ich von meinen Mitschülern geschlagen; bei Ausflügen, sofern ich dabei war, mußte ich allein gehen, durfte auch mit anderen Schulkameraden, soweit sie noch für mich waren, nicht sprechen. Mit anderen Worten: Ich wurde gehaßt und verspottet gleich einem räudigen Hunde."157

Unter diesen Umständen wurde der Schulbesuch zu einer fortwährenden schweren Belastung, zu einer sich Tag für Tag wiederholenden Demütigung: „Jeden Tag gingen wir, die Jüngsten der Familie, mit Herzklopfen in die Schule. Die Lehrer verlangten von uns, die Fahne zu grüßen, Nazilieder zu singen und mit erhobenem Arm ,Heil Hitler' zu sagen. Weil wir uns weigerten, wurden wir zum Gegenstand des Gespötts. "158 Solche Situationen waren geeignet, die Kräfte der Kinder zu überfordern. Ihnen war bewußt, daß ein Nachgeben in der Grußfrage die Bedrohung in der Schule minderte. Im Unterschied zu jüdischen Schülern bestand auch durchaus die Möglichkeit, durch eigenes Tun die prekäre Lage abzuändern. Wenn der Lehrer oder die Lehrerin morgens den Klassenraum betraten, hätte manchmal schon das alleinige Mitheben des Armes und das wortlose Bewegen der Lippen ihnen allerlei Schwierigkeiten ersparen können. Welche inneren Kämpfe diese ständigen Anfechtungen bei den Kindern auszulösen vermochten, läßt der Bericht von Horst Henschel erahnen: „In der Schule wurde jeden Tag der Hitlergruß verlangt, den ich verweigerte, wofür ich Schläge bekam. Trotzdem war es jedesmal ein Grund zur Freude, wenn ich, gestärkt durch meine Eltern, treu geblieben war. Doch zwischendurch gab es auch immer wieder Gelegenheiten, wo ich entweder nach körperlichen Strafen oder in schwierigen Situationen doch ,Heil Hitler!' sagte. Ich weiß, daß ich dann immer mit Tränen in den Augen nach Hause kam, wie wir dann gemeinsam zu Jehova beteten und ich dann wieder die Kraft hatte, den An-

155 EB Elise Kühnle, 23.11.1987. Frau Kühnle berichtet hier über ein Vorkommnis, das ihrer Schwester widerfuhr. Bei Zürcher ist der Fall eines Kindes geschildert, das von Mitschülern durch heftige Fußtritte auf Geheiß des Lehrers schwer mißhandelt worden sei. Dem Vater sei es trotz intensiver Suche nicht gelungen, einen Arzt zu finden, der bereit gewesen wäre, die Schäden zu attestieren. Vgl. Zürcher, Kreuzzug, S. 167f.

$156 \mathrm{Vgl}$. auch die veröffentlichte Schilderung von Günther Pape über seine Schulerlebnisse während der NS-Zeit, Pape, Zeuge Jehovas, S. 9-12.

157 Willi Seitz schrieb seinen Bericht nieder, nachdem er am 22.1.1937 aus der Schule verwiesen worden war und im benachbarten Ausland Aufnahme gefunden hatte. Vgl. EB Willi Seitz; Zürcher, Kreuzzug, S. 164.

158 Magdalena Reuter: Die Liebe meiner Familie zu Gott trotz Gefängnis und Tod, in: Der Wachtturm, 1.9.1985, S. 10-15 (12). 
griffen des Feindes für die nächste Zeit zu widerstehen, bis mir dann erneut eine solche oder ähnliche Sache passierte." 159

Besondere Herausforderungen stellten für die Kinder von Zeugen Jehovas die Gedenkfeiern, Flaggenappelle und Aufmärsche dar ${ }^{160}$. Für sie galt die nationalsozialistische Losung „Jede Feierstunde ist Bekenntnis“161 unter umgekehrten Vorzeichen. Kam es im Klassenzimmer noch darauf an, was der einzelne Lehrer sehen wollte oder auch nicht, unter den Augen der versammelten Lehrerschaft und der Schulleitung traf es nun auch die Schüler, deren Lehrer keine überzeugten Nationalsozialisten waren. Die Hoffnung, sich in den hinteren Reihen verbergen zu können oder in der großen Masse nicht aufzufallen, erwies sich als trügerisch. Statt dessen wurde mit besonderer Aufmerksamkeit verfolgt, wie sich die „kleinen Bibelforscher“ denn verhielten: „Bei Hitlers Geburtstag, da war immer Fahnenhissen und Hitler-Lieder singen. Alle Schüler mußten antreten. Und da ist der Rektor durchgelaufen durch die Reihen, bis er mich gefunden hat." 162 Blieb der Betreffende bei seiner Weigerung, so wurde er oftmals nach vorne geholt. Dann mußte er sich beispielsweise unter den Flaggenmast stellen, so daß alle Schüler den „Volksverräter" sehen konnten 163 .

Die demonstrative Auseinandersetzung mit dem NS-Kult wurde also keineswegs von vornherein gesucht. Vielmehr versuchten die Kinder von Zeugen Jehovas den Konflikten, soweit es irgend möglich war, auszuweichen. Als Beispiel dafür kann der folgende Bericht des 1922 geborenen Bruno Knöller gelten: „Ich bin dann in der Schule beim Fahnengruß aufgefallen. Die Fahne wurde aufgezogen, das war ja eine heilige Zeremonie, die Schüler mußten antreten, und es mußte die Hand erhoben werden zum Flaggengruß beim Singen der Nationalhymne und des HorstWessel-Liedes. Mir war es immer wieder gelungen, diese Zeremonie zu umgehen. Ich habe mich verdrückt, bin solange in die Toilette gegangen, aber irgendwie ist das beobachtet worden. Dann hat mich ein Lehrer gezwungen, mit hinauszugehen, und dann bin ich aufgefallen. Es gab eine Lehrerkonferenz, ich wurde vorgeladen und gefragt, warum ich den Fahnengruß verweigere." 164 Bruno Knöller war auf diese Situation gut vorbereitet. In der Familie sei sehr häufig darüber gesprochen worden, weshalb Zeugen Jehovas ,die Fahne nicht grüßen. Wir können sie nicht grüßen, das ist für uns biblisch gesehen ein Akt der Verehrung einem toten Tuch gegenüber, also Götzendienst. [...] Das gehört einfach mit dazu, wenn Gott für uns unser Herrscher sein soll, dann können wir uns nicht vor den Symbolen der Nationalsozialisten niederbücken. Aber auch da hat unser Vater immer zur Vorsicht gemahnt. Wenn wir dem aus dem Weg gehen können, sollen wir dem auch aus

159 Der Bericht von Horst Henschel ist wiedergegeben im Jahrbuch 1974, S. 122.

160 Bei diesen Gemeinschaftsveranstaltungen waren nur Schüler mit ausländischer Staatsangehörigkeit von der Teilnahmepflicht entbunden; die Anwesenheit jüdischer Schüler war dagegen von vornherein unerwünscht bzw. per Anweisung verboten (vgl. Müller, W., Feierpraxis, S. 46). Wenn die Kinder von Zeugen Jehovas den nationalsozialistischen Schulfeiern einfach fernblieben, wurde gegen die Eltern auch mit der Verhängung von Geldstrafen vorgegangen. Vgl. DJ 99 (1937), S. 1857, Amtsgericht Waldenburg, VIII. 195, Beschluß vom 2.9.1937.

162 Klauß, Feierstunden, S. 7.

162 EB Elise Kühnle, 23.11.1987.

163 Vgl. Garbe, Gott mehr gehorchen, S. 192.

164 Knöller, Erinnerungen, S. 19. 
dem Weg gehen. Das haben wir auch so gehalten. Aber in der Schule konnte man dem dann ja nicht mehr aus dem Weg gehen." 165

\section{Schulverweise}

Das Verhalten der Schüler zog auch auf administrativer Ebene Folgen nach sich. Schon im Laufe des Jahres 1933 kam es zu zahlreichen Schulverweisen. Im September 1933 mußte beispielsweise ein 14jähriger Schüler die Oberrealschule in Hamburg-Eilbek verlassen, weil er sich ,weigerte, den durch die Schulverwaltung geforderten Hitlergruß anzuwenden" ${ }^{166}$. Für die Wiederaufnahme an einer anderen Schule wurde das Leisten des „Deutschen Grußes“ zur Bedingung gemacht.

Derartige Entfernungen bedeuteten fast immer das Ende der weiteren schulischen Qualifikation. Nur in Ausnahmefällen gelang die Aufnahme in anderen Schulen; die finanziellen Möglichkeiten ließen auch nur selten den Besuch der in den ersten Jahren des NS-Regimes nicht vollkommen der Parteikontrolle unterworfenen Privatschulen $\mathrm{zu}^{167}$. Im März 1935 verfügte das Reichserziehungsministerium Richtlinien über die „Schülerauslese an den Höheren Schulen“, die unter Punkt IV, 2 bestimmten: „Schüler, die durch ihr Verhalten in und außer der Schule die Volksgemeinschaft oder den Staat wiederholt schädigen, sind von der Schule zu verweisen." 168 Nach den vorliegenden Berichten wurde zuweilen selbst die Ausstellung eines Abgangszeugnisses abgelehnt.

Die zwangsweise Beendigung der schulischen Ausbildung konnte auch eine Verweigerung der beruflichen Ausbildung nach sich ziehen. So bewirkte der Schuldirektor im Fall von Helmut Knöller, der 1934 der Handelsschule verwiesen wurde, daß über die „,Deutsche Arbeitsfront“ in seinem Ausbildungsbetrieb nachgefragt wurde, wie es dort um seine „Grußbereitschaft" bestellt sei. Daraufhin erfolgte die Entlassung auch aus der Lehrstelle. Der Vater des Jungen, der als ehemaliger SPD-Gemeinderat im Umgang mit Behörden vertraut war, nahm das Vorgehen gegen seinen Sohn nicht widerspruchslos hin. Er klagte mit tatkräftiger Unterstützung eines Rechtsanwaltes, der von dem Fall gehört hatte und sich für die Rechtsvertretung aus eigenem Antrieb angeboten haben soll, vor dem Arbeitsgericht. Doch die Bemühungen blieben erfolglos: „Es wurde ihm abgesprochen, in Deutschland überhaupt noch eine Lehr- oder Arbeitsstelle zu bekommen. Er habe sich durch sein Verhalten der Volksgemeinschaft selbst entzogen, so wurde das Urteil begründet."169

Durch Denunziationen von Lehrern und entsprechende Mitteilungen der Schulbehörden war mit erheblicher Verzögerung auch die Gestapo auf die Grußverweigerungen in den Schulen aufmerksam geworden. Daraufhin sah das Geheime Staatspolizeiamt in Berlin sich zu einem Rundschreiben an die Staatspolizeistellen

\footnotetext{
$\overline{165}$ EB Bruno Knöller, 23.11.1987.

166 AfW HH, 070319, Bl. 38, Bescheinigung der Oberschule in Eilbek vom 19.6.1946.

167 Die Schulwahl war für Zeugen Jehovas auch insofern eingeschränkt, als sie zumeist den Besuch einer Schule in kirchlicher Trägerschaft ablehnten.

168 Reichsministerium für Wissenschaft, Erziehung und Volksbildung, Erlaß vom 27.3.1935, zit. nach Benze, Erziehung, S. 13.

169 Knöller, Erinnerungen, S. 20.
} 
veranlaßt. Mit Datum vom 8. August 1934 teilte das Gestapa mit: „In letzter Zeit mehren sich die Fälle, wo die verbotenen ,Internationalen Bibelforscher " wieder in Erscheinung treten. Insbesondere haben sie es verstanden, auch auf die Schuljugend Einfluß zu gewinnen. Es ist ein Fall bekanntgeworden, wo ein 13jähriger Schüler das Singen des Horst-Wessel-Liedes und den deutschen Gruß mit der Begründung verweigert hat, er sei als Bibelforscher international und kenne nur einen Führer, Jehova'. Die Eltern dieses Knaben sind eifrige Anhänger der Bibelforscher-Sekte." 170 Innerhalb von zwei Wochen sollten die Staatspolizeistellen darüber Bericht erstatten, ob in ihrem Bezirk Fälle ,staatsfeindlichen Verhaltens oder sittlicher und staatspolitischer Gefährdung der Jugend seitens der Anhänger der ,Internationalen Bibelforscher-Vereinigung ' bekanntgeworden sind“.

In diesem Rundschreiben spiegelt sich der seinerzeitige Informationsstand der größten Gestapo-Stelle im Reich wider: Obwohl es in den vorausgegangenen Monaten an den Schulen zu Hunderten derartiger Vorkommnisse gekommen war, steht ein - keineswegs außergewöhnlicher - Einzelfall im Mittelpunkt des Schreibens. Da das Rundschreiben außerdem von der Einschätzung auszugehen scheint, die IBV beabsichtige auch über den Bereich der eigenen Glaubensangehörigen hinaus Einfluß auf „die Schuljugend“ zu nehmen, belegt es zugleich die mangelnde Sachkenntnis der Gestapo.

Erst aufgrund der in der folgenden Zeit in Berlin eingegangenen Informationen gelangten die zuständigen Beamten im Sachgebiet „Sekten“ zu einer realistischeren Lagebeurteilung. Ihnen wurde deutlich, daß die Grußverweigerungen in der Schule vorrangig nicht Resultat einer gezielten Kampagne der IBV waren, sondern in der familiären Situation ihren Ursprung hatten. Den auslösenden Faktor für die Konflikte sah man nun - vom Grundsatz her zutreffend - darin, daß die Kinder zwischen die unterschiedlichen Ansprüche von Elternhaus und Schule gerieten. In einer internen Gestapo-Denkschrift heißt es dazu: „Auch die Kinder versuchen die Bibelforscher schon mit ihren Irrlehren zu verseuchen. Immer wieder kommt es vor, daß Kinder in der Schule den deutschen Gruß verweigern, weil ,unsere Eltern uns gesagt haben, wir dürfen das nicht tun, denn die Bibel verbietet es.' In welche Gewissenskonflikte diese Kinder geraten, die in der Schule im Sinne des Nationalsozialismus erzogen werden und zu Hause nur die internationalen projüdischen Parolen der Eltern hören, bedarf keiner weiteren Ausführung." 171

Zu diesem Zeitpunkt galt die Kampfansage der Gestapo den Kindern selbst noch nicht. Darauf deutet auch ein „Schutzhaft-Erlaß“ vom 21. März 1936 hin: „Es häufen sich die Fälle, daß bei der Festnahme von Bibelforschern beide Elternteile zu gleicher Zeit in Schutzhaft genommen werden. Die Kinder fallen dadurch in den meisten Fällen der öffentlichen Wohlfahrt zur Last. Um die Kinder vor schweren

170 BA, R 58/405, Bl. 3, Geheimes Staatspolizeiamt, RdS vom 8.8.1934, in Abschrift als RdV der Staatspolizeistelle für den Regierungsbezirk Köln vom 13.8.1934.

171 IfZ, MA 554, 936279-87 (82), Denkschrift „Die Internationale Bibelforscher-Vereinigung“, als Anlage zum RdS der Staatspolizeileitstelle München vom 24.12.1936. 
seelischen und wirtschaftlichen Schäden zu bewahren, ersuche ich, von der gleichzeitigen Inschutzhaftnahme beider Eltern nach Möglichkeit abzusehen."172

Ob die Äußerung, daß die Kinder, ,in den meisten Fällen der öffentlichen Wohlfahrt zur Last" fielen, zutreffend ist, kann allerdings bezweifelt werden. Nach den Berichten von Zeugen Jehovas übernahmen, wenn beide Elternteile gleichzeitig inhaftiert waren, in aller Regel die Großeltern, sonstige Verwandte oder Glaubensgeschwister die Versorgung und Betreuung der Kinder ${ }^{173}$, wobei die Unterbringung bei Verwandten, die sich nicht zu der Glaubensgemeinschaft bekannten, häufig zu Konflikten führte.

\section{Sorgerechtsentziehungen}

Etwa zur gleichen Zeit, als die Gestapo mit dem „Schutzhaft-Erlaß“ eine Handhabung schuf, um die Kinder von Zeugen Jehovas im Elternhaus zu belassen und damit zugleich die öffentlichen Kassen zu schonen, begannen andere Behörden mit der Trennung der Kinder von ihren Familien - einem Vorgehen, das zutreffender als Durchführung eines „staatlich organisierten Kinderraubes“174 zu beschreiben ist. Auf die Zeugen Jehovas kam damit eine weitere Form der Verfolgung zu, die viele von ihnen noch stärker belasten sollte als wirtschaftliche Existenzvernichtung, Gestapo-Überwachung oder Haftstrafen. Zunehmend bekannten sich Behördenvertreter zu der Auffassung, daß der Staat zu Zwangsmaßnahmen greifen müsse, wo Kinder ,infolge Beeinflussung durch das Elternhaus sich zu einer staatsverneinenden Anschauung bekennen und allen Versuchen, sie zu anderer Einstellung zu bringen, passiven Widerstand entgegensetzen" 175 . Die Schul- und Jugendämter hofften, durch den Einsatz ,fürsorgerischer Mittel“ den erzieherischen Einfluß der Eltern zurückdrängen beziehungsweise brechen zu können. Nur dann bestünde die Möglichkeit, die Kinder vom Gedankengut der Bibelforscher zu lösen und sie damit für die „Volksgemeinschaft“ zurückzugewinnen.

Bei ihrem Vorgehen gegen die Zeugen Jehovas benutzten die Behörden das herkömmliche fürsorgerische und rechtliche Instrumentarium. Zunächst wählten sie den Weg der „Schutzaufsicht“: Nach § 56 des Jugendwohlfahrtsgesetzes von 1922 konnte bei einer drohenden Gefährdung von Minderjährigen als vorbeugende Maß-

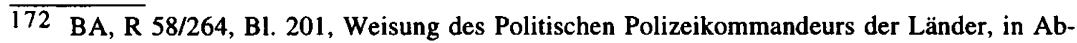
schrift als RdV der BPP vom 21.3.1936.

173 Vgl. Garbe, Gott mehr gehorchen, S. 202f.; VVN HH, Komiteeakten L 2 und M 8; EB Bruno Knöller, 23.11.1987. Die Aufnahme der Kinder von verhafteten Zeugen Jehovas durch andere Zeugen Jehovas unterstreicht das enge Zusammengehörigkeitsgefühl innerhalb der Bibelforschergemeinschaft. Selbst unter schwierigsten Bedingungen wurde versucht, Hilfe zu leisten. So versorgte z. B. eine Bauersfrau in Gruibingen (Schwäbische Alb), deren Mann wegen Kriegsdienstverweigerung erschossen worden war, neben ihren zwei eigenen Kindern noch drei weitere einer Glaubensschwester aus Augsburg, deren Mann aus dem gleichen Grunde hingerichtet worden war (EB Elise Kühnle, 23.11.1987).

174 Diese Formulierung ist Michael H. Kater entlehnt. Vgl. Kater, Bibelforscher, S. 200. Der Begriff des „Kinderraubes“ wurde allerdings auch bereits während der NS-Zeit von den Zeugen Jehovas selbst benutzt. Vgl. Zürcher, Kreuzzug, S. 154; ZJJ 28 (1936/37), S. 281, Landgericht Hamburg, 1. T 284/36, Urteil vom 5.6.1936.

175 Sächsisches Ministerium für Volksbildung, RdErl. an die Bezirksschulämter vom 13.11. 1936, betreffend „Kinder aus Bibelforscherkreisen“, zit. nach Zürcher, Kreuzzug, S. 157. 
nahme die Schutzaufsicht durch das Jugendamt wahrgenommen werden ${ }^{176}$. Dadurch sollten die Sorgeberechtigten bei der Erziehungsarbeit unterstuitzt und beaufsichtigt werden. In der Praxis bedeutete die Schutzaufsicht eine Überwachung der elterlichen Erziehung durch die Jugendämter beziehungsweise deren Fürsorger/innen, die als umfassende Kontrolle auch der sozialen und politischen Disziplinierung diente ${ }^{177}$. Für die NS-Zeit kann grundsätzlich festgestellt werden, daß ,Schutzaufsicht" und „Öffentliche Erziehung“ nicht nur als jugendfürsorgerische Maßnahmen bei gefährdeten Kindern aus zerrütteten Familien eingesetzt wurden, sondern auch als Strafmittel gegen unangepaßte und den Nationalsozialismus ablehnende Jugendliche ${ }^{178}$.

Die Zeugen Jehovas wehrten sich in der Regel nachdrücklich gegen den Versuch der Jugendämter, bei ihnen die „Schutzaufsicht“ auszuüben ${ }^{179}$. Wenn die Eltern ihre Zustimmung verweigerten, konnte das Jugendamt beim Vormundschaftsgericht Antrag auf Anordnung der Schutzaufsicht über die Kinder stellen. War aber erst einmal der Weg zu den Gerichten beschritten, so beließen es die Jugendämter nicht beim Antrag auf Verhängung von Schutzaufsicht, sondern stellten zugleich Antrag auf Entzug des Sorgerechtes und Anordnung einer Amtsvormundschaft. Nach den Bestimmungen des Bürgerlichen Gesetzbuches kann Eltern durch gerichtlichen Beschluß das Sorgerecht für ihre Kinder bei „Gefährdung des Kindeswohls“ aberkannt werden ( $\$ 1666$ BGB). Die Jugendämter beriefen sich auf diese Bestimmung und erklärten, daß durch die Erziehung eines Kindes im Gedankengut der Bibelforscher die Gefahr einer ,geistigen oder sittlichen Verwahrlosung“ gegeben sei. Die Rechtsprechung der Vormundschaftsgerichte folgte dieser Argumentation. Für die Ausrichtung an den Zielvorgaben des NS-Staates bedurfte es auf dem Gebiet des Familien- und Jugendrechtes keiner neuen Gesetzesbestimmungen; auch mit einer an nationalsozialistischen Rechtsvorstellungen orientierten Auslegung des alten BGB gelangte man zu den gewünschten Resultaten.

Die ersten Gerichtsentscheidungen über die Frage, ob Bibelforschern das Recht der Personensorge für ihre Kinder abzuerkennen sei, ergingen - soweit bisher bekannt ist - im Frühjahr 1936. Mit Beschluß vom 12. März 1936 wurde auf Antrag des Hamburger Jugendamtes vom dortigen Amtsgericht dem Ehepaar Z. das Sorgerecht für ihre Kinder einschließlich der Vertretungsbefugnis entzogen. Für die beiden zwölf- und dreizehnjährigen Söhne wurde das Jugendamt zum „Pfleger“ be-

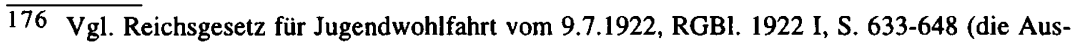
führungen zur „Schutzaufsicht“ finden sich in den §§ 56-61). Zu den rechtlichen Rahmenbedingungen der Jugendfürsorge im Nationalsozialismus vgl. Hasenclever, Jugendhilfe, S. $127 \mathrm{ff}$;; Kraus, Fürsorgeerziehung, S. 161ff.

177 Neben Behördenbediensteten übernahmen auch Angehörige der NS-Frauenschaft oder NSVMitglieder Überwachungsaufgaben. Die unangemeldeten Kontrollen fanden in der Regel wöchentlich statt, und bei geringsten Verdachtsmomenten wurden polizeiliche Hausdurchsuchungen initiiert. Die NSV mit ihrem direkten Zugriff auf die einzelnen Familien der „Volksgenossen“ wurde von den Nationalsozialisten zielstrebig als „Träger der Ermittlungshilfe“, d. h. als Spitzelorganisation, eingesetzt. Vgl. Ermittlungshilfe, S. 19ff.

178 Vgl. Otto/Sünker, Soziale Arbeit.

179 Die sogenannte formlose Schutzaufsicht gemäß $\S 60$ Abs. 3 JWG, die das Jugendamt aus eigenem Ermessen ohne gerichtliche Anordnung ausüben konnte, setzte das Einverständnis der Erziehungsberechtigten voraus. 
stellt. Der Vater legte gegen das Urteil Beschwerde ein. Das Berufungsverfahren fand am 5. Juni 1936 vor dem Landgericht Hamburg statt. Der Urteilsspruch dieses Gerichtes wurde anscheinend für so wegweisend gehalten, daß eine Veröffentlichung in der juristischen Fachpresse erfolgte ${ }^{180}$.

In der Verhandlung vor dem Landgericht war der Vertreter des Jugendamtes die treibende Kraft. Mit Nachdruck plädierte er für die Aufrechterhaltung der Sorgerechtsentziehung, wobei er zur Bekräftigung auf die zwischenzeitlich gemachten Erfahrungen verwies. Er erklärte, „daß auch im Waisenhaus alle Versuche, den Alfred zum Erweisen des deutschen Grußes zu veranlassen, vergeblich gewesen seien. Da die Einstellung der Kinder schon sehr tief eingewurzelt sei, müßten diese den Eltern unbedingt entzogen werden, um sie zu brauchbaren Mitgliedern der Volksgemeinschaft zu erziehen."181

Mit nur wenigen Worten geht das Urteil auf die Beweggründe der Eltern ein, wobei auf die Vorinstanz Bezug genommen wird: „In der Verhandlung vor dem Amtsgericht hat der Vater erklärt, er erziehe seine Kinder im Sinne der heiligen Schrift und er könne die Kinder nicht anhalten, den Deutschen Gruß zu erwidern, da das Heil nur von Gott, nicht aber von einem Menschen kommen könne. Auf die Frage, ob er gegen den Nationalsozialismus eingenommen sei, hat er die Antwort verweigert." 182

Unerschrocken gab der Vater sich auch in der Verhandlung vor dem Landgericht. Er bezeichnete die Entziehung des Sorgerechts für seine Kinder als „Kinderraub und Christenverfolgung“. Weiter vermerkt das Urteil: „Auf die Frage, ob er nicht bereit sei, die Kinder im Sinne des heutigen Deutschlands zu erziehen, erklärte er, Jehova-Gott belehre seine Kinder. Weitere Antworten wolle er auf diese Frage nicht geben." 183

Die Einlassungen des Zeugen Jehovas waren nicht dazu angetan, die Hamburger Richter zu beeindrucken. Das Landgericht bestätigte die Entscheidung der Vorinstanz. Da die Eltern ,,auf dem Boden der Anschauungen einer internationalen Religionsgemeinschaft" stehen und es ablehnten, ihre Kinder ,im Sinne des heutigen Staates“ zu erziehen, sei ,das geistige Wohl der Kinder auf das schwerste gefährdet, denn durch abwegige Beeinflussung im Elternhaus werden sie seit Jahren in geistige Bahnen gelenkt, die ihnen das Leben in der Volksgemeinschaft des heutigen Staates fast unmöglich machen“. Kriterium für die Sorgerechtsentziehung war damit ausschließlich das nationalsozialistische Interesse an „Eingliederung in die Ideenwelt des völkischen Staates", nicht das vermeintliche und vorgeschobene „Wohl der Kinder“. Die „Hanseatische Rechts- und Gerichts-Zeitschrift“ faßte den

$\overline{180}$ Ausführliche Urteilsauszüge sind veröffentlicht in: HRGZ 19 (1936), Sp. 353f., und in: ZJJ 28 (1937), S. 281 . Die Textfassungen weichen z. T. voneinander ab.

181 ZJJ 28 (1936/37), S. 281, Landgericht Hamburg, 1. T 284/36, Urteil vom 5.6.1936 (die zitierte Passage, die die tragende Rolle des Hamburger Behördenvertreters unterstreicht, ist in der Hanseatischen Rechts- und Gerichts-Zeitschrift nicht wiedergegeben worden). Nach einer Notiz bei Zürcher, die sich aufgrund der genannten Angaben mit ziemlicher Sicherheit auf diesen Fall bezieht, sind die beiden Jungen im Waisenhaus vom Schulleiter mit Schlägen malträtiert worden. Vgl. Zürcher, Kreuzzug, S. 162.

182 Hier zitiert nach HRGZ 19 (1936), Sp. 353. Die Eltern waren im Oktober 1935 vom HSG zu je zwei Monaten Gefängnis wegen Betätigung für die verbotene IBV verurteilt worden.

183 ZJJ 28 (1936/37), S. 281. 
Urteilstenor in den knappen Leitsatz: „Den Eltern ist das Sorgerecht zu entziehen, wenn sie ihre Kinder durch Erziehung zu frömmelndem Fanatismus den Ideen des nationalsozialistischen Staates bewußt entfremden." 184

Sorgerechtsentziehungen wurden nicht nur durch Jugendämter oder Schulleitungen betrieben, sondern zuweilen auch von Elternteilen, die nicht den Zeugen Jehovas angehörten. Dafür ist der folgende Fall ein Beispiel, das zugleich dokumentiert, daß die „Fürsorger" eines Jugendamtes durchaus unterschiedlich ihren Einfluß geltend machen konnten.

Anfang Februar 1936 beantragte ein Mann beim Vormundschaftsgericht in Hamburg, seiner früheren Ehefrau das ihr nach der 1931 erfolgten Ehescheidung zugesprochene Sorgerecht für die beiden der Ehe entstammenden Kinder wieder abzuerkennen. Er begründete sein Verlangen damit, daß seine geschiedene Frau die Kinder nicht im Sinne des Dritten Reiches erziehen würde. Das Jugendamt stellte daraufhin Ermittlungen an. Dabei blieb dem Amt die Zugehörigkeit der Mutter zu der verbotenen IBV nicht verborgen. Doch zunächst befand das Jugendamt, daß von einer Sorgerechtsentziehung Abstand genommen werden könne, da „die Mutter im übrigen charakterlich und sittlich eine einwandfreie Frau ist, die gut für ihre beiden Kinder sorgt und in einem besonders innigen Verhältnis zu ihnen steht" 185 .

Das Vormundschaftsgericht setzte aufgrund dieses Jugendamtvotums mit Beschluß vom 10. März 1936 die Entscheidung über den Antrag des Vaters für vorerst ein halbes Jahr aus. Während dieser ,Bewährungsfrist ' überprüfte das Jugendamt fortwährend, ob die Mutter nunmehr den Weg ,zu einer staatsbejahenden Auffassung“ einschlug. Die 31 jährige Frau ließ sich jedoch von ihrem Weg nicht abbringen. Weiterhin weigerte sie sich, ihre beiden zehn- und elfjährigen Söhne zum „Jungvolk“ zu geben, so daß die Hoffnungen des Amtes, „die Mutter in günstigem Sinn beeinflussen zu können“, sich alsbald als trügerisch erwiesen. Daraufhin wurde mit Beschluß vom 18. September 1936 die Schutzaufsicht über die Kinder angeordnet. Ein weiteres halbes Jahr später erfolgte die Anordnung der Sorgerechtsentziehung. Da die Mutter ,vollkommen in den Ideen der ,Zeugen Jehovas“

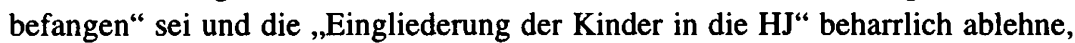
stand für das Amtsgericht fest, „daß es im Interesse der Kinder geboten ist, daß die Mutter das Sorgerecht für die Kinder nicht mehr ausübt" 186.

Die oben zitierte Wertung des Jugendamtes über die Unbescholtenheit der Mutter fand jedoch auch in das Urteil des Amtsgerichtes Eingang ${ }^{187}$. Damit stellt es ein

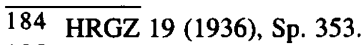

185 VVN HH, Komiteeakten S 37, Amtsgericht Hamburg, 116 VIII S 86.

186 Ebenda, Amtsgericht Hamburg, Beschluß vom 12.3.1937.

187 Die Übernahme ins Urteil kam nach Angabe der Mutter durch den Einspruch des anwesenden Vertreters des Jugendamtes zustande. Jener Beamte habe ein Jahr lang, zuletzt im Rahmen der verhängten Schutzaufsicht, zu kontrollieren gehabt, ob sie ihre Kinder gegen den Staat beeinflusse. Dadurch sei er mit den Familienverhältnissen gut vertraut gewesen. Während der Gerichtsverhandlung habe der Beamte den Amtsrichter deshalb gebeten, im Urteil ausdrücklich zu vermerken, daß es sich bei der Mutter um eine charakterlich einwandfreie Frau handele. Der Richter vermochte zuerst diesem Wunsch nicht nachzukommen, weil er ansonsten ein „Schandurteil“" fällen würde. Aber der Vertreter des Jugendamtes habe auf einem entsprechenden Vermerk bestanden, weil er „die Wegnahme der Kinder nicht verantworten“" wollte (EB Ella S., 29.1.1985, 14.2.1986). Es ist nicht auszuschließen, daß das Bild des Jugendamtsbeamten von Frau S. in ihrer Erinnerung überzeichnet bzw. idealisiert wird. Da der amtsge- 
bemerkenswertes Dokument dar: So unterstrich das Gericht ausdrücklich, daß es sich um eine für ihre Kinder treusorgende Mutter handele, gleichzeitig erklärte es aber, „daß die Mutter für die Erziehung der Kinder im heutigen [!] Staat ungeeignet" 188 sei.

In argumentative Verlegenheit gerieten die Vormundschaftsrichter in „Bibelforscherfällen" anscheinend des öfteren. In aller Regel stellten sich ihnen Familienverhältnisse dar, die dem bürgerlichen Ideal einer geordneten Lebensführung entsprachen und die sich von daher nur schwer in Einklang mit landläufigen Vorstellungen von einem kindeswohlgefährdenden Milieu bringen ließen. In einem am 7. März 1937 ergangenen Beschluß eines Vormundschaftsgerichtes heißt es beispielsweise: „Die Fürsorgerinnen haben übereinstimmend bekundet, daß ... [das Mädchen] einen besonders wohlerzogenen Eindruck mache, und daß man auch von ihr in der Schule sowie im Erziehungsheim [...] nur das Beste gehört habe." 189 Trotzdem müsse die Sorgerechtsentziehung angeordnet werden, da der nationalsozialistische Staat es nicht zulassen könne, wenn Eltern, ,die auf einem ihm feindlichen Boden stehen, deutsche Kinder erziehen, und zwar auch dann nicht, wenn es die eigenen sind".

In einem Urteil aus der zweiten Hälfte des Jahres 1937 wurde zwar von ,religiösem Fanatismus" und ,der abnormalen Veranlagung" gesprochen, doch andererseits gelangte das Gericht bei der Persönlichkeitsbeschreibung des Kindes zu ausgesprochen positiven Werturteilen: „Abgesehen von dieser Verweigerung des Deutschen Grußes, wird ihre Führung in der Schule als tadellos bezeichnet; sie ist geistig über Durchschnitt entwickelt und steht mit den Leistungen an der Spitze der Klasse. Sie zeichnet sich durch Fleiß, Aufmerksamkeit und Strebsamkeit in der Schule aus. Sie besitzt reiche Phantasie und eine besondere Gabe für bildhaftes Gestalten. Auch die äußere Erscheinung des Kindes ist in höchstem Maße sympathisch. [...] Das Kind zeigt eben eine geistige Reife, die erheblich über dem Durchschnitt der Kinder dieses Alters steht." 190 Nachdem sich im Vergleich zu den zwanziger Jahren ,die Rechtsanschauung grundlegend geändert" habe, gelte aber, daß ein Kind, welches dem Staat die ,äußere Anerkennung versagt, in der Regel trotz seiner moralischen Qualität als verwahrlost bezeichnet werden" müsse. Den Formulierungen ist unschwer anzumerken, daß der Amtsgerichtsrat in diesem Fall in einen Widerspruch geriet. Zwischen seinem eigenen Werturteil und dem von ihm erwarteten Handeln bestand eine deutliche Kluft.

richtliche Beschluß aus dem Jahre 1937 im Wortlaut vorliegt, kann am Sachverhalt selbst jedoch nicht gezweifelt werden.

188 VVN HH, Komiteeakten S 37, Amtsgericht Hamburg, Beschluß vom 12.3.1937. Die beiden zehn- und elfjährigen Söhne kamen nach der Sorgerechtsentziehung in verschiedene Pflegestellen in NS-Familien, wurden gegen Kriegsende Soldaten und gerieten anschließend in Kriegsgefangenschaft. Die aufgezwungene Trennung von ihrer Mutter währte insgesamt annähernd zehn Jahre.

189 Zit. nach Zürcher, Kreuzzug, S. 155. Die im Jahr 1938 im Europa-Verlag in deutscher und französischer Sprache erschienene Veröffentlichung von Franz Zürcher, einem leitenden Mitarbeiter des „Zentraleuropäischen Büros“ der Zeugen Jehovas in Bern, verzichtete bei der Wiedergabe von Dokumenten in der Regel auf die Nennung von Personen- und Ortsnamen, um die Betreffenden in Deutschland nicht zusätzlichen Gefahren auszusetzen. Aus diesem Grund kann nicht angegeben werden, von welchem Amtsgericht dieser Beschluß gefaßt wurde.

190 Zit. nach Zürcher, Kreuzzug, S. 160f. 
Mitte 1937 schaltete sich die Gestapo in das behördliche Vorgehen gegen die Kinder von Zeugen Jehovas ein. War bisher in Einzelfällen von den örtlichen Jugendämtern eine Trennung der Kinder von ihren Eltern erwirkt worden, so strebte man nunmehr im Berliner Geheimen Staatspolizeiamt eine flächendeckende Lösung an. Mit Runderlaß vom 21. Juni 1937 wurden die Staatspolizeistellen aufgefordert, in dieser Frage tätig zu werden:

„Um die Verbreitung der Lehre der IBV unter der Jugend zu verhindern, ist es erforderlich, die Kinder der bereits in Erscheinung getretenen Bibelforscher dem Einfluß ihrer Eltern zu entziehen. $\mathrm{Zu}$ diesem Zweck ersuche ich, bei den zuständigen Amtsgerichten darauf hinzuwirken, daß denjenigen Anhängern der IBV, die durch ihre illegale Betätigung und ihr Bekenntnis zur Lehre der IBV das geistige Wohl ihrer Kinder gefährden, das Personenfürsorgerecht gemäß 1666 BGB entzogen wird."191

Zur Präzisierung verwies das Gestapa auf eine im Vormonat ergangene Gerichtsentscheidung:

„Das Amtsgericht in Zwickau hat bereits durch Beschluß vom 4. Mai 1937 in einem Falle dem Vater das Personenfürsorgerecht für seinen Sohn gemäß § 1666 BGB mit der Begründung entzogen, daB er das Wohl seines Kindes durch die Erziehung im Sinne der Bibelforscherlehre gefährde. Für den Sohn selbst, der bereits unter dem Einfluß dieser Lehre stand, wurde durch Beschluß vom 13. März 1937 gemäß § 63, Absatz 1, Ziffer II RJWG Fürsorgeerziehung angeordnet (Aktz. d. Amtsgerichts Zwickau 56 XII S 226/36). Auf diese Entscheidung sind die jeweils zuständigen Gerichte hinzuweisen. Von jedem Fall der Entziehung des Personenfürsorgerechts gemäß $§ 1666$ oder der Anordnung der Fürsorgeerziehung wegen Betätigung für die illegale IBV ist zu berichten.“

In den folgenden Wochen blieben die Gestapo-Stellen nicht untätig. Am 2. Juli 1937 ordnete die Staatspolizeileitstelle München das Entsprechende für ihren Bezirk an ${ }^{192}$, vier Tage später wies die Stuttgarter Staatspolizeileitstelle die Landräte „zur Veranlassung des Erforderlichen" an, wobei ausdrücklich darauf hingewiesen wurde, daß der Erlaß „zur Weitergabe an die Ortspolizeibehörden nicht bestimmt“ sei $^{193}$. Die Sorge der württembergischen Kollegen teilte Dr. Geschke, der Leiter der Kieler Staatspolizeistelle, jedoch nicht. Er hielt es anscheinend nicht für notwendig, die unteren Dienststellen von einem derart offenkundigen Einwirkungsversuch der Gestapo auf die Rechtsprechung von Zivilgerichten nichts wissen zu lassen. Im Regierungsbezirk Schleswig wurde der Erlaß auch an die Ortspolizeibehörden weitergegeben ${ }^{194}$.

Die örtlichen Polizeistellen überprüften daraufhin, ob die von ihnen überwachten Zeugen Jehovas minderjährige Kinder hatten und ob beziehungsweise inwieweit

191 UaP J. E. Straßer (Sammlung zur historischen Dokumentation), Gestapa, RdErl. vom 21.6.1937, in Abschrift als RdV der Staatspolizeileitstelle Stuttgart vom 6.7.1937.

192 IfZ, MA 554, 936263, Staatspolizeileitstelle München, RdErl, vom 2.7.1937.

193 UaP J. E. Straßer (Sammlung zur historischen Dokumentation), Staatspolizeileitstelle Stuttgart, RdV vom 6.7.1937.

194 Staatspolizeistelle Kiel, Erlaß vom 14.7.1937, in Abschrift als RdV des Schleswiger Landrates vom 16.7.1937 an die Ortspolizeibehörden im Kreise, abgedruckt in: Kühl, Friedrichstadt, S. 185. 
diese im Sinne der Bibelforscherlehre erzogen wurden. So berichtete beispielsweise die Städtische Polizei in Eutin mit Schreiben vom 30. Juli 1937, daß die 1920 geborene Elfriede O. „vollkommen nach den Grundsätzen der IBV“ erzogen worden sei. Der Bericht schloß mit dem Satz: „Inwieweit ein Vorgehen gegen Elfriede $O$. notwendig ist, kann von hier aus nicht beurteilt werden.“195

\section{Erziehungspflichten}

Das bereits erwähnte Urteil des Zwickauer Amtsgerichtes vom 13. März 1937, auf das der Gestapa-Erlaß vom 21. Juni 1937 Bezug nimmt, ist insofern bemerkenswert, als es den Übergang zu einer weiteren Ausweitung der Rechtsprechung gegen Bibelforscher markiert: Es ordnete das äußerste der gesetzlich möglichen Zwangsmittel an. Nach Schutzaufsichten und Sorgerechtsentziehungen folgte nunmehr der Griff zur Anordnung der „Fürsorgeerziehung“. § 62 des Jugendwohlfahrtsgesetzes sah zur „Verhütung oder Beseitigung der Verwahrlosung“ als letztes staatliches Erziehungsmittel die Einweisung in die „Fürsorgeerziehung“" vor ${ }^{196}$.

Gegen den Beschluß des Amtsgerichtes in Zwickau auf Anordnung der ,Fürsorgeerziehung " wurde vor dem Landgericht Zwickau Beschwerde erhoben. Da das in diesem Berufungsverfahren ausgesprochene Urteil in der ,Juristischen Wochenschrift" dokumentiert wurde, sind von daher auch nähere Ausführungen zu dem im Gestapa-Erlaß erwähnten Fall möglich.

Das Zwickauer Gericht hatte die sogenannte ,heilende“ Fürsorgeerziehung ,zur Beseitigung der geistigen und sittlichen Verwahrlosung “ über den 17 jährigen Herbert S. verhängt. Der Jugendliche galt deshalb als „verwahrlost“, weil er sich vorbehaltlos zu den Lehren der Zeugen Jehovas bekannte. Nach Ansicht des Gerichtes war diese Haltung ausschließlich darauf zurückzuführen, daß er im Elternhaus ,eine falsche Lebensausrichtung erhalten“ hatte. Dort habe er vollkommen ,,im Banne der Anschauungen jener ,Ernsten Bibelforscher" " gestanden:

„Die Mutter und ihre Umgebung ist diesen Gedankengängen derart blind unterworfen, daß man auch vor Konflikten mit der staatlichen Ordnung nicht zurückschreckt; so bekennt sich die Mutter zu Grundsätzen der ,Ernsten Bibelforscher", wie etwa dem ,Gott mehr gehorchen als den Menschen " und ,wenn sie hinter Schloß und Riegel komme“; der eine Stiefbruder des Herbert S. ist sogar wegen Heeresdienstverweigerung - einer bei Bibelforschern vielfach zu beobachtenden Auswirkung ihrer staatsfeindlichen Einstellung - bestraft worden. In diesem lebensfremden und zersetzenden Geiste hat die Mutter nun auch ihren jüngsten Sohn Herbert erzogen; dieser verweigert unter Berufung auf Bibelerkenntnisse und trotz aller Vorstellungen und Strafen den Deutschen Gruß starr und ist bereits jetzt - nach dem Vorbilde seines nächstälteren Stiefbruders - zur Heeresdienstverweigerung sowie auch zur Arbeitsdienstverweigerung entschlossen. [...] Es ist gar kein Zweifel, $\mathrm{da} B$ der Junge ein Produkt seiner Umwelt und der abwegigen, unzulänglichen Erziehung seiner Mutter ist; es ist höchste Zeit, ihn dieser Umwelt - die keinerlei Einsicht erhoffen läßt - zu

195 Städtische Polizei in Eutin, Schreiben vom 30.7.1937, zit. nach Stokes, Eutin, S. 710.

196 In den folgenden Jahren wurde die Fürsorgeerziehung zumeist unmittelbar im Zusammenhang mit der Sorgerechtsentziehung angeordnet. Die Schutzaufsicht fand dagegen bei Zeugen Jehovas nur noch selten Anwendung. 
entziehen. Die Voraussetzungen des § 63 Abs. 1 Ziff. 2 RJug WohlfG für die Anordnung einer heilenden Fürsorgeerziehung sind sonach erfüllt.“"197

Über den Einzelfall hinaus, der wohl - aufgrund der in ihm zum Ausdruck kommenden „Radikalität“ der Bibelforscherlehre - dem Gericht als besonders geeignet erscheinen mußte, zum Mittel der „Fürsorgeerziehung “ zu greifen, verdienen in erster Linie die allgemeinen rechtlichen Erwägungen Beachtung. Nach dieser Entscheidung waren die Merkmale einer Verwahrlosung bereits dann erfüllt, wenn „ein den allgemeinen Erziehungszielen (vgl. § 1 RJugWohlfG sowie Ges. über die Hitlerjugend v. 1. Dez. 1936) entgegengesetzter Entwicklungsprozeß" festgestellt werden könne. Damit wurde nicht nur erneut vom Vorrang des staatlichen Erziehungsanspruches vor dem elterlichen Erziehungsrecht ausgegangen, sondern darüber hinaus wurden durch die Berufung auf das Hitlerjugendgesetz die Prinzipien nationalsozialistischer Jugendführung in den Rang ,allgemeiner Erziehungsziele“ erhoben ${ }^{198}$. Fürderhin waren erzieherische Zwangsmaßnahmen folglich immer dann zu ergreifen, wenn die elterliche Erziehung im Widerspruch zu den im Gesetz über die Hitler-Jugend festgelegten Zielen stand.

Mit dem am 1. Dezember 1936 verkündeten Hitlerjugendgesetz war die HitlerJugend gemeinsam mit Schule und Elternhaus zum Träger der Erziehung der deutschen Jugend erklärt worden. Paragraph 2 bestimmte: „Die gesamte deutsche Jugend ist außer in Elternhaus und Schule in der Hitlerjugend körperlich, geistig und sittlich im Geiste des Nationalsozialismus zum Dienst am Volk und zur Volksgemeinschaft zu erziehen." 199 Das Gesetz erhob zugleich den vormaligen Parteijugendverband in den Status einer Staatsjugend. Für die zwischen zehn und achtzehn Jahre alten Kinder und Jugendlichen bestand damit de facto die Verpflichtung zur Mitgliedschaft in der Hitler-Jugend ${ }^{200}$, obwohl die gesetzlichen Voraussetzungen für eine „Jugenddienstpflicht" erst 1939 geschaffen wurden ${ }^{201}$. Doch schon ab Ende 1936 nahmen die Nötigungen zum Beitritt stark zu. So waren zum Zeitpunkt der offiziellen Einführung der Jugenddienstpflicht Anfang 1939 bereits über $98 \%$ der 10- bis 18jährigen in der Hitler-Jugend organisiert ${ }^{202}$.

Die Weigerung der Zeugen Jehovas, ihre Kinder in die Hitler-Jugend zu geben, rückte in den Sorgerechtsverfahren zunehmend in den Mittelpunkt. Das im Bürgerlichen Gesetzbuch festgeschriebene Elternrecht ${ }^{203}$ auf Kindererziehung fand nach Ansicht der Gerichte immer dann seine Grenze, wenn die Eltern dieses nicht im

$\overline{197}$ JW 67 (1938), S. 2145, Landgericht Zwickau, 5 T 179/37, Beschluß vom 14.4.1937.

198 Vgl. Fraenkel, Doppelstaat, S. 86.

199 Gesetz über die Hitler-Jugend vom 1.12.1936, RGBI. 1936 I, S. 993.

200 Vgl. Stachura, Jugenderziehung, S. 233.

201 Die 2. DVO zum Gesetz über die Hitler-Jugend (Jugenddienstverordnung) vom 25.3.1939 bestimmte im § 1: „Der Dienst in der Hitler-Jugend ist Ehrendienst am Deutschen Volke. Alle Jugendlichen vom 10. bis zum vollendeten 18. Lebensjahr sind verpflichtet, in der HitlerJugend Dienst zu tun“" (RGBl. 1939 I, S. 710).

202 Nach den bei Klönne, Jugend, S. 34, wiedergegebenen absoluten Zahlen waren Anfang 1939 von 8,87 Millionen zehn- bis achtzehnjährigen 8,7 Millionen in der Hitler-Jugend Mitglied.

203 Gegen die $\S \S 1626,1631$ Abs. 1 BGB, nach denen das Recht auf Kindererziehung grundsätzlich den Eltern zusteht, wurde während des „Dritten Reiches“ von den Vormundschaftsgerichten durch die Voranstellung des staatlichen Erziehungsanspruches vor dem Elternrecht fortwährend verstoßen. 
Sinne des NS-Staates ausübten. Mit der Zuweisung der alleinigen Definitionsgewalt über alle substantiellen Fragen von Erziehung an den Weltanschauungsstaat erkannte die Justiz dem Elternhaus nur noch die Funktion eines Erfüllungsgehilfen $\mathrm{zu}^{204}$. Der Leiter des Deutschen Zentralinstituts für Erziehung und Unterricht, Ministerialrat Dr. Rudolf Benze, faßte diesen Sachverhalt in die folgenden Worte:

„Alle Erziehungsarbeit in der Familie muß sich bewußt sein, daß sie ein Glied in der nationalsozialistischen Gesamterziehung des deutschen Volkes ist und den Treuhändern des deutschen Volkes - NSDAP und Staat - verantwortlich ist. Beide greifen jedoch im allgemeinen nicht in die Familienerziehung ein, es sei denn, daß die Eltern durch grobe Verstöße gegen ihre Pflichten als Erzieher und Volksgenossen die Kinder gesundheitlich, politisch oder sozial gefährden."205

Das, was man den Zeugen Jehovas vorwarf, war nicht mangelnde Fürsorge für ihre Kinder, sondern „Pflichtversäumnisse“ gegenüber dem Staat. Dabei handelte es sich bei der Grußverweigerung, bei der Ablehnung des Flaggenappells oder - zumindestens bis 1939 - beim Nicht-Beitritt zur Hitler-Jugend nicht um Handlungen, die gesetzlich unter Strafe standen. Vor den Vormundschaftsgerichten wurde in den Bibelforscherverfahren vielmehr über eine (ablehnende) „Haltung“ und damit über eine (feindliche) „Gesinnung“ gerichtet. Insofern können diese Verfahren als Beleg dafür gelten, inwieweit nationalsozialistisches Rechtsdenken während des „Dritten Reiches“ auch außerhalb der Strafgerichtsbarkeit zur Anwendung gelangte.

Beispielsweise entzog das Amtsgericht Wilster (Schleswig-Holstein) mit Beschluß vom 26. Februar 1938 den Eheleuten B. das Sorgerecht, obwohl ihre Kinder ,nach den Aussagen der Lehrer [...] in der Schule keinen Widerstand gezeigt, sondern sich am Singen nationalsozialistischer Lieder beteiligt und immer mit dem deutschen Gruß gegrüßt“ hatten, also mithin die Merkmale einer „Verwahrlosung" nicht gegeben waren. Doch auch in diesem Fall wurden die Eltern eines Verstoßes gegen die ihnen obliegenden Erziehungspflichten für schuldig befunden, denn sie verwehrten ihren Kindern den Eintritt in die Hitler-Jugend. Damit stellten die Eltern sich aber dem entgegen, daß ,die Jugend [...] im nationalsozialistischen Staat außer in Elternhaus und Schule auch in der Hitler-Jugend zu erziehen" sei. Unter Bezugnahme auf das Hitlerjugendgesetz erklärte das Amtsgericht: „Das Ziel dieser nationalsozialistischen Erziehung kann nur erreicht werden, wenn alle drei Erziehungsstätten planmäßig zusammenarbeiten. Versagt das Elternhaus in der Arbeit für dieses Erziehungsziel oder versucht es die Arbeit der beiden anderen Erziehungsstätten zu verhindern oder zu stören, so bedarf es einer verstärkten Einflußnahme dieser Stellen auf den Jugendlichen."206 Da die Kinder aber aufgrund des elterlichen Verbots nicht gleichzeitig ,,von der Hitlerjugend betreut und weiter erzogen werden“ könnten, unterlägen sie - vor allem nach Wegfall des Schulbesuchs - allein dem Einfluß der Eltern. Dadurch bestünde „die große Gefahr, daß die Kinder für die Bestrebungen der IBV gewonnen werden und dem

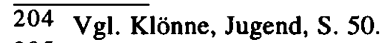

205 Benze, Erziehung, S. 15; zum nationalsozialistischen „Erziehungsstaat“ und seiner Programmatik vgl. Herrmann, U., Formung des Volksgenossen.

206 JW 67 (1938), S. 1264, Amtsgericht Wilster, VIII B 229/38, Beschluß vom 26.2.1938. 
Staat verloren gehen“. Hierin sah das Gericht jene „erhebliche geistige Gefährdung der Kinder", die den Sorgerechtsentzug nach § 1666 BGB erforderlich mache ${ }^{207}$.

Nicht immer haben Vormundschaftsgerichte in Bibelforscherverfahren so geurteilt. Es sind bis hinein in die Kriegsjahre in Einzelfällen Urteile ergangen, in denen die Anordnung der Sorgerechtsentziehung abgelehnt wurde. Das Amtsgericht in Calw hielt es in einer Entscheidung aus dem Jahr 1938 für nicht erforderlich, im Falle eines 13jährigen Jungen, der den Beitritt in die Hitler-Jugend ablehnte, Zwangsmaßnahmen zu verhängen ${ }^{208}$. Im Fall eines gleichaltrigen Mädchens wurde die Anordnung der „Fürsorgeerziehung“ als „weder zweckentsprechend noch zulässig“ bezeichnet, da die in $§ 63$ Jugendwohlfahrtsgesetz ${ }^{209}$ geforderte „Aussicht auf Erfolg“" nicht vorausgesetzt werden könne. Wie ein vom Gericht eingeholtes amtsärztliches Gutachten belege, müsse von einer derart gefestigten inneren Überzeugung bei dem Mädchen ausgegangen werden, daß es nach Ansicht des Gerichtes ,,zu keiner Änderung seiner Stellungnahme durch Fürsorgeerziehung zu bewegen" sein werde ${ }^{210}$.

Auch das Amtsgericht in Schwäbisch-Gmünd lehnte 1937 die Einweisung von Bibelforscherkindern in die „Fürsorgeerziehung“ ab. Da dieser Fall zu einem obergerichtlichen Grundsatzurteil führte, soll auf ihn etwas ausführlicher eingegangen werden. Das Verfahren richtete sich gegen die Landwirtseheleute Karl und Christine Uhlmann, die sich 1932 als Zeugen Jehovas hatten taufen lassen. Ihnen sollte das Sorgerecht für die 1924 geborene Tochter Ida und die viereinhalb Jahre jüngere Elise abgesprochen werden. In Gang gesetzt wurde das Verfahren vom Rektor der Volksschule in Alfdorf, der es anscheinend nicht verwinden konnte, daß die beiden Mädchen beharrlich den „Hitler-Gruß“ verweigerten und auch durch Schläge nicht zu einer Änderung ihrer Haltung zu bewegen waren. Über das Jugendamt wurde am 22. April 1937 beim Amtsgericht in Schwäbisch-Gmünd wegen „Gefahr im Verzuge“ gemäß § 67 JWG ein Eilantrag auf Anordnung der vorläufigen „Fürsorgeerziehung“ gestellt.

An die Gerichtsverhandlung kann sich Elise Kühnle, geborene Uhlmann, die damals acht Jahre alt war, nur noch schwach erinnern: „Der Amtsrichter, das war ein alter Mann, der hat das sehr neutral beurteilt. Der hat uns Kinder - jedes einzelne für sich - ausgefragt. Was er gefragt hat, daß weiß ich natürlich nicht mehr. Auf jeden Fall hat er ein gutes Urteil über uns abgegeben. Er hat geschrieben, er sehe keinen Grund dafür, daß wir Zwangserziehung nötig hätten; wir

$\overline{207}$ Zum Zeitpunkt der Gerichtsverhandlung befanden sich beide Elternteile wegen Betätigung für die IBV in Haft. Die Mutter kam am 5.5.38 wieder frei; der Vater starb am 24.2.1940 im KZ Sachsenhausen. Vgl. VVN HH, Komiteeakten B 28; Möller, Steinburg, S. 217.

208 EB Bruno Knöller, 23.11.1987; EB Egon Knöller, 30.4.1983.

209 Diese Vorschrift, die erst nachträglich bei der Neufassung des $\S 63$ im Jahre 1932 Aufnahme in das Jugendwohlfahrtgesetz gefunden hatte, bestimmte, daß die Fürsorgeerziehung nicht angeordnet werden dürfe, ,wenn sie offenbar keine Aussicht auf Erfolg bietet“. Die Neufassung des $\S 63$ erfolgte durch die VO des Reichspräsidenten über Jugendwohlfahrt vom 4.11.1932 (RGB1. 1932 I, S. 522f.). Die Gesetzesnovellierung stand im Zusammenhang mit dem Sparkurs der Reichsregierung: Ihr Zweck war nicht pädagogischer, sondern fiskalischer Natur.

210 Zit. nach Zürcher, Kreuzzug, S. 161; die Entscheidung erging in der zweiten Hälfte des Jahres 1937. 
seien gut erzogene Kinder. Aber die Lehrer haben keine Ruhe gelassen. Die haben das weiterbetrieben." 211

Gegen das Urteil des Amtsgerichtes legte das Jugendamt sofortige Beschwerde ein. Das Landgericht Ellwangen hob daraufhin die amtsgerichtliche Entscheidung auf und ordnete die „vorbeugende Fürsorgeerziehung“ an. Herr Uhlmann legte nun seinerseits sofortige weitere Beschwerde ein und rief das Revisionsgericht an, wodurch der Vollzug der „Fürsorgeerziehung“ vorläufig ausgesetzt wurde. Die Zeugen Jehovas sahen die Erziehung ihrer Kinder „zur Achtung vor Gottes Geboten“ als ihre „selbstverständliche Pflicht, die sie als Eltern vor Gott haben, und wovon sie keine politische oder staatliche Einrichtung entbinden" 212 könne.

Am 3. Dezember 1937 fand die Revisionsverhandlung vor dem Oberlandesgericht München statt. Zunächst prüften die Richter des verhandelnden 8. Zivilsenates, ob im vorliegenden Fall ein Mißbrauch des elterlichen Sorgerechtes gegeben sei. Das Vorliegen eines schuldhaften Verhaltens wurde bejaht. Dieses liege in dem Bekenntnis zur Lehre der Bibelforscher, denn deren Anschauungen seien ,in hohem Grade volkszersetzend und staatsgefährlich". Dazu führte das Gericht im einzelnen aus:

„Bei dieser Sachlage steht außer Zweifel, daß ein deutsches Kind in seinem geistigen (sittlichen) Wohl schwer gefährdet wird, wenn es in den Anschauungen der Ernsten Bibelforscher erzogen wird. Eine Erziehung in diesen Grundsätzen führt dazu, daß das Kind seinem Vaterland und seinem Volk entfremdet wird, daß es zur Mißachtung und Unbotmäßigkeit gegenüber den staatlichen Anordnungen und Maßnahmen geneigt gemacht wird und daß es die Fähigkeit verliert, dereinst ein brauchbares Mitglied der Volksgemeinschaft zu werden und seine Pflichten gegenüber Staat und Gemeinschaft zu erfüllen. [...] Eine solche Erziehung, die ein noch unreifes, urteilsloses Kind durch Einprägung staatsfeindlicher Lehren für sein späteres Leben in einen sein Wohlergehen und Fortkommen aufs schwerste gefährdenden Gegensatz zu Staat und Volksgemeinschaft zu bringen vermag, verstößt so offensichtlich gegen Vernunft und staatliche Ordnung, daß der Erziehungsberechtigte trotz religiöser Bedenken bei pflichtgemäßer Überlegung dies unmöglich übersehen kann und daß besonders dann, wenn er trotz Vorhalts und Belehrung über das Verkehrte seiner Handlungsweise auf ihr beharrt, ohne weiteres angenommen werden muß, er handle wider bessere Einsicht, sein Sorgerechtsmißbrauch sei also schuldhaft. Mit der Berufung auf seine religiöse Überzeugung vermag der sorgeberechtigte Elternteil sein Verschulden nicht auszuräumen. Es geht hier nicht darum, ob die Eltern für ihre Person irgendwelchen als religiös bezeichneten Lehren anhängen dürfen, sondern nur darum, welche Erziehungspflichten ihnen gegenüber ihrem minderjährigen Kind obliegen und ob die Art ihrer Erziehung mit den Interessen des Kindes vereinbar ist. [...] Ein Kind, bei dem die oben geschilderten Folgen einer derartigen Erziehung eintreten, sinkt damit in einen Zustand herab, in dem es in erheblichem Grad derjenigen sittlichen Eigenschaften ermangelt, die bei einem Kind unter sonst gleichen Verhältnissen als Ergebnis einer ordnungsgemäßen Erziehung vorausgesetzt werden müssen, und ist sonach als sittlich verwahrlost zu erachten. Bei Anwendung dieser Grundsätze ist nach dem vom LG. für erwiesen gehaltenen Sachverhalt die

211 EB Elise Kühnle, 23.11.1987.

212 Zürcher, Kreuzzug, S. 154. 
Folgerung gerechtfertigt, $[\ldots]$ daß die beiden Kinder infolgedessen im Elternhaus der Gefahr der sittlichen Verwahrlosung ausgesetzt sind.“213

Die Revision wurde in der Grundsatzfrage verworfen, da das Landgericht „ohne Rechtsverstoß annehmen [konnte], daß die beiden Kinder zur Hintanhaltung der drohenden Verwahrlosung aus dem Elternhaus entfernt und anderweitig untergebracht werden müssen“. Das Instanzurteil wurde nur insofern beanstandet, als es die Frage nicht hinreichend geklärt hatte, ob es dafür der Anordnung der vorbeugenden ,Fürsorgeerziehung“ bedurfte.

Soweit die rechtlichen Erwägungen des Oberlandesgerichtes. Sie sind in sich konsistent und unterscheiden sich insofern von manch anderem Urteil. Doch woran zeigte sich im Konkreten der Mangel an ,sittlichen Eigenschaften“, worin äußerte sich im Verhalten der Kinder jene konstatierte „Verwahrlosung“? Diese Fragen können anhand der Ausführungen des Gerichtes beantwortet werden, da die Richter über die Rechtsfrage hinaus auch zur „Tatfrage“ ausführlich Stellung genommen haben. So berichteten sie über das schulische Verhalten der Kinder:

„Hiernach haben die zwei Kinder bei der Feier des Tages der nationalen Arbeit unentschuldigt gefehlt, obwohl sie als Schülerinnen zur Teilnahme an der Feier verpflichtet waren. Sie haben ferner schon seit längerer Zeit die Erweisung des deutschen Grußes in der Schule mit dem bei den Bibelforschern üblichen Hinweis auf eine Bibelstelle verweigert. Ida hat die Frage eines Lehrers, ob sie sich hinter den Führer stelle, ausdrücklich verneint. Elise hat es ständig abgelehnt, das HorstWessel-Lied zu singen und im Zeichenunterricht ein Hakenkreuz zu zeichnen. Ermahnungen und Schulstrafen waren bei beiden Kindern ohne Erfolg." 214

Über dieses obergerichtliche Urteil wurde in zahlreichen juristischen Fachzeitschriften berichtet ${ }^{215}$. Die von Reinhard Heydrich als Chef der Sicherheitspolizei herausgegebene Zeitschrift „Kriminalistik“ unterstrich die ,,allgemeine Bedeutung“ der Entscheidung ${ }^{216}$; der Reichsminister des Innern ließ wegen ihrer ,grundsätzlichen Bedeutung“" einen Urteilsauszug auch in der Tagespresse veröffentlichen ${ }^{217}$.

Nach erneuter Verhandlung vor dem Landgericht, dem vom Oberlandesgericht die Prüfung der Frage auferlegt worden war, ob in diesem Fall anstatt der ,Fürsorgeerziehung" nicht eine anderweitige Unterbringung ohne Inanspruchnahme öffentlicher Mittel erfolgen könne, standen der Wegnahme der Kinder keine juristischen Hindernisse mehr entgegen. Am 5. Mai 1938 kamen Ida und Elise von zu Hause fort $^{218}$. Zunächst wurden die beiden Kinder vom Jugendamt in die Obhut von zwei

$\overline{213}$ DJ 100 (1938), S. 954f,, OLG München, 8 WX 478/37, Urteil vom 3.12.1937.

214 Ebenda, S. 955.

215 Umfangreiche Auszüge aus der Urteilsschrift veröffentlichten die vom RMM als „Amtliches Blatt der deutschen Rechtspflege“ herausgegebene „Deutsche Justiz“, die „Höchstrichterliche Rechtsprechung" und das Ministerialblatt des RMdI. Vgl. DJ 100 (1938), S. 954f.; HRR 14 (1938), 545; RMBliV 99 (1938), Sp. 317-320.

216 Kriminalistik, 12 (1938), S. 68.

217 IfZ, MA 603, 20198; die Verlautbarung des RMdI trug die bezeichnende Überschrift „, Keine Kindererziehung durch ,Ernste Bibelforscher" ".

218 Die Kinder wurden von Polizeibeamten und zwei Diakonissen aus Stuttgart abgeholt. Dieses verursachte großes Aufsehen im Ort. Elise Kühnle berichtet: „Eines Tages ist in Alfdorf vor der Schule ein Auto vorgefahren. [...] Wir haben uns gewehrt, in dieses Auto reinzugehen. 
Bauernfamilien gegeben. Die Mädchen mußten dort nicht nur den Trennungsschmerz und Heimweh verkraften, auf sie kamen auch neue Belastungen zu. Elise Kühnle berichtet davon, daß es sich bei der „Pflegefamilie“, in der sie untergebracht worden war, um „ganz arge Nazis“ gehandelt habe: „Das war meine schlimmste Zeit. Die Frau hat mir jeden Abend einen Vortrag über den Hitler gehalten. Die war ganz pflichtbewußt. Sie hat mich also soweit bringen wollen, daß ich „Heil Hitler“ sage. Das hat sie als ihre Aufgabe angesehen.“ In der dortigen Schule sei es ihr ähnlich ergangen. Die Lehrer hätten mit allen Mitteln versucht, eine Änderung ihres Verhaltens zu erzwingen. Wegen ihrer Renitenz seien Strafarbeiten an der Tagesordnung gewesen. Diese Situation empfand die 9jährige als vollkommen unerträglich. Nach ungefähr sechs Wochen riß sie aus und ging zunächst zu Fuß zu einer $15 \mathrm{~km}$ entfernt wohnenden Tante. Von dort gelangte sie zu ihren Eltern. Auch ihre Schwester entwich der Obhut ihrer „Pflegefamilie“; sie fuhr mit einem Fahrrad heim zu den Eltern. „Wir haben natürlich gewußt, das kann nicht gut gehen.“

Nach einiger Zeit wurden die Kinder erneut abgeholt. Dieses Mal erfolgte die Einweisung in ein bei Crailsheim gelegenes Kinderheim, in dem hauptsächlich „schwererziehbare Kinder“ untergebracht waren. Elise Kühnle berichtet: „Der Rektor war uns gegenüber nicht schlecht gesonnen. Er hat uns - vielleicht alle sechs bis acht Wochen - in sein Amtszimmer kommen lassen, um uns nationalsozialistischen Unterricht zu erteilen. Er hat sogar gesagt: Wir würden prima Nationalsozialisten abgeben, solche täte der Führer brauchen. Wir sollten bloß halt ,Heil Hitler ${ }^{*}$ sagen.“ Zum Kinderheim, das unter evangelischer Trägerschaft stand, gehörte auch eine feste Pfarrstelle. Die Erinnerungen, die Elise Kühnle an den Anstaltsgeistlichen hat, unterscheiden sich von den anderen Eindrücken: „Aber der Pfarrer dort, das war ein netter Mensch. Der war uns sehr gut gesonnen. Der hat zu meiner Mutter gesagt, daß er uns nicht bedauert, sondern er würde uns beneiden, daß wir so standhaft seien. Der ist sogar gekommen und hat sich dann um mich gekümmert. [...] Von ihm gab es keinen Druck, sondern im Gegenteil, er hat uns eher gestützt.“

Im Januar 1942 wurde Elise aus dem Erziehungsheim entlassen. Über ihre dreieinhalbjährige Heimzeit urteilt sie im Rückblick: „Als Kind vergißt man sich ja. Wir sind unter den vielen Kindern gewesen, haben unseren geregelten Tagesablauf gehabt. Und die Erzieherinnen, die haben uns besser behandelt als die anderen Kinder, weil wir ja nicht schwererziehbar waren, sie hatten also mit uns nicht so große Probleme. Es war verhältnismäßig schon zu ertragen. Aber unsere Mutter, die zu Hause war und die ganze Landwirtschaft hat schaffen müssen, und der Vater im $\mathrm{KZ}$, und die dauernde Einsamkeit, für die war es am allerschlimmsten."219

Das hat natürlich Tränen und einen Kampf gegeben, bis wir überhaupt eingestiegen sind. Aber wir sind denen natürlich nicht gewachsen gewesen. Polizei und Lehrer waren dabei, die haben uns mit Gewalt in das Auto reingezerrt." (EB Kühnle, 23.11.1987) Die folgenden Ausführungen beruhen ebenfalls auf diesem Erinnerungsbericht.

219 Die Verhaftung des Vaters war im Spätherbst 1938 erfolgt; die Gestapo hielt ihn im KZ Welzheim gefangen. An den Haftfolgen ist er im Januar 1951 verstorben.

In den vorliegenden Berichten anderer Betroffener, die als Kinder von Zeugen Jehovas in Erziehungsheimen untergebracht waren, ist von vergleichsweise ähnlich positiven Erfahrungen nicht die Rede. Vielmehr erinnern sie sich - wie es eine Zeugin Jehovas, die im Juli 1943 in die Wessenbergische Erziehungsanstalt in Konstanz eingeliefert wurde, formulierte - „der 
Nachdem den Untergerichten durch Entscheidungen wie die des Oberlandesgerichts München im zuvor geschilderten Fall klare Leitlinien für die Rechtsprechung in Bibelforscherverfahren an die Hand gegeben worden waren, waren die justitiellen Voraussetzungen für einen umfassenden „Kinderraub“ gegeben. Damit hatten sich die NS-Behörden die Möglichkeit verschafft, auf höchst wirkungsvolle Weise gegen eine ausgegrenzte Gruppe in ihrer Gesamtheit vorzugehen, die anders als die Juden oder die Sinti und Roma nicht unter Ausnahmerecht gestellt war: Wer sich nach 1937/38 noch als Bibelforscher betätigte, mußte nicht nur mit einer strafgerichtlichen Verurteilung zu einer Gefängnisstrafe oder mit der staatspolizeilichen Einweisung in ein Konzentrationslager rechnen, sondern generell auch mit der Wegnahme der Kinder.

Die Amtsgerichte benötigten zur Begründung eines Sorgerechtsentzugs jetzt nur noch wenige Sätze, wobei folgender - gewissermaßen standardisierter - Aufbau sich herausbildete:

1. „Die Eltern bekennen sich zur Lehre der Bibelforscher, die jede staatliche Autorität leugnet."

2. „Durch die Erziehung im Sinne dieser Lehre bringen sie ihr Kind in scharfen Gegensatz zur Volksgemeinschaft und gefährden so sein Wohl.“

3. „Den Eltern war daher die Sorge für die Person des Kindes zu entziehen - § 1666 BGB - und insoweit Pflegschaft anzuordnen."220

Sorgerechtsentziehungen wurden im ,Dritten Reich“ auch gegen andere Regimegegner ausgesprochen, allerdings fehlte jener Automatismus, wie er bei den Verfahren gegen Zeugen Jehovas zugrunde gelegt wurde: „Bibelforscher gleich Gefährdung des Kindeswohls“. So hatte das Amtsgericht Berlin-Lichterfelde bereits in einem Urteil aus dem Jahr 1935 festgestellt, daß ,kommunistische und atheistische Erziehung" einen Grund für die Entziehung des Sorgerechts bieten könne. Bezeichnenderweise war in diesem Fall gerade der Mangel an religiöser Erziehung als Beleg für eine Verletzung der elterlichen Erziehungspflichten herangezogen worden: „Wie er [der Vater] selbst angibt, ist er Dissident und hat sein Kind bisher weder taufen noch sonst kirchlich erziehen lassen. Hierin liegt aber ein schwerer Verstoß gegen seine Erziehungspflichten. Denn es ist als ein allgemeiner Grundsatz anzuerkennen, daß der Gewalthaber nicht das Recht hat, das Kind ohne jede religiöse Anweisung und Erziehung zu lassen. [...] Der Gewalthaber vernachlässigt das Kind und ruft dessen sittliche Gefährdung hervor, wenn er den deutschen Anschauungen zuwider das Kind von jedem religiösen Einfluß fernhält und es in atheistischem Sinne erzieht." 221

Andere vormundschaftsgerichtliche Verfahren richteten sich beispielsweise gegen eine Frau, die wegen ,außerehelicher Beziehungen zu einem Juden“ der Kin-

eisigen und rauhen Atmosphäre“, die ihnen in der Heimerziehung entgegenschlug (Der Wachtturm, 1.1.1979, S. 22f.).

220 Diese drei Sätze umfassen den vollständigen Wortlaut eines vormundschaftsgerichtlichen Beschlusses. Vgl. UaP J. E. Straßer, Amtsgericht Leipzig, 18 X Gro 7/38, 14.4.1938.

221 ZJJ 27 (1935/36), S. 232, Amtsgericht Berlin-Lichterfelde, 6 X 126, Urteil vom 15.4.1935. 
dererziehung für ,nicht würdig“ befunden wurde ${ }^{222}$, oder gegen eine Mutter, die ihre Kinder in einem katholischen Kloster erziehen lassen wollte ${ }^{223}$.

Die Ausdehnung derartiger Entscheidungen zu einem generellen Vorgehen gegen andere Gegnergruppen in ihrer Gesamtheit, also zum Beispiel gegen Kommunisten, Sozialdemokraten, Katholische Aktion oder Bekennende Kirche, ist nicht bekannt geworden. Im Fall der - relativ kleinen - Gruppe der Bibelforscher war die Wegnahme ihrer Kinder ein wichtiges Instrument im Arsenal der Verfolgungsmaßnahmen. Nach den Erhebungen der Wachtturm Bibel- und Traktat-Gesellschaft sind in mindestens 860 Fällen Kinder ihren Eltern fortgenommen worden. Es kann davon ausgegangen werden, daß die Zahl der betroffenen Kinder noch deutlich höher liegt ${ }^{224}$.

\section{Druckmittel und gelenkte Justiz}

Die Wegnahme der Kinder wurde als Druckmittel eingesetzt, um auf diese Weise Zeugen Jehovas zur Aufgabe ihres Widerstandes zu bewegen. In nicht wenigen Fällen erwies sich die Androhung eines Sorgerechtsentzuges dabei als ein äußerst wirkungsvolles Instrument. So gaben selbst Zeugen Jehovas, die sich durch mehrere Haftstrafen nicht von einer weiteren Betätigung für die IBV hatten abschrecken lassen, diesem Druck nach. Aus Sorge um ihre Kinder und um den Bestand der Familie stellten sie entweder ihre Aktivitäten ganz ein oder gingen zumindest bei ihren Kindern Kompromisse ein. In den Berichten finden sich dann zuweilen Äußerungen wie diese: „Man bedrohte uns, das jüngste Kind zu nehmen, wenn sie nicht in den B.D.M. eintrat. Wir mußten also passen; sie ist wenig hingegangen und blieb somit uns." 225

Die glaubhafte Lossagung von der Bibelforschervereinigung konnte dazu führen, daß Kinder, die bereits in die „Fürsorgeerziehung“ eingewiesen worden waren, wieder an ihre Familien zurückgegeben wurden. So bekam ein Zeuge Jehovas, der 1940 im Gefängnis Wolfenbüttel die „Verpflichtungserklärung“ unterschrieben hat und sich nach der Haftentlassung nicht mehr für die IBV betätigte, nach einiger Zeit sein Kind zurück ${ }^{226}$.

Häufig endeten derartige Einwirkungsversuche aber auch erfolglos, so zum Beispiel im Fall des Buchdruckermeisters Rolf Appel aus Süderbrarup (Schleswig). Dieser hatte zum 3. März 1941 die Einberufung zur Wehrmacht erhalten. Der Familienvater kam dem Gestellungsbefehl nicht nach, sondern teilte der betreffenden Einheit in Lübeck, bei der er zum Dienstantritt erscheinen sollte, schriftlich mit, daß er den Waffendienst mit seinem Glauben nicht vereinbaren könne. Wenige Tage

222 ZJJ 28 (1936/37), S. 139f., Landgericht Torgau, 6 T 527/35, Beschluß vom 27.11.1935.

223 DR 7 (1937), S. 466, Amtsgericht Frankfurt/Main-Höchst, Beschluß vom 4.5.1937.

224 Vgl. Der Wachtturm, 1.5.1976, S. 274; Jahrbuch 1974, S. 125. Auch im Jahrbuch der Zeugen Jehovas wird ausdrücklich darauf hingewiesen, daß ,die genaue Zahl noch wesentlich höher liegen mag“ (ebenda). Zur Art der von der WTG zusammengetragenen Angaben, den Umständen ihrer Erhebung und den dadurch bedingten „Lücken“ siehe S. 493, Anm. 11.

225 VVN HH, Komiteeakten B 10, Lebenslauf des B. vom 23.4.1946. Ausweislich der ProzeBunterlagen (SLG HH, HSG 44/38) zeigte der Vater des Mädchens sich ansonsten trotz Berufsverbotes und mehrjähriger Gefängnisstrafen unbeugsam.

VVN HH, Komiteeakten Z 4; AfW HH, 310300. 
später erschien die Feldgendarmerie in dem kleinen schleswig-holsteinischen Ort und verhaftete Rolf Appel. Er wurde nach Lübeck gebracht, wo nach Angaben seiner Frau ,ein höherer Offizier lange Zeit väterlich auf ihn einsprach und ihm empfahl, doch erst einmal die Uniform anzuziehen“227. Seine Ehefrau erhielt am 30. Juni vom Bürgermeister die Aufforderung, die vier Kinder der Familie am 3. Juli 1941 im Gemeindebüro um 10 Uhr ,abzuliefern“228.

Die Kinder wurden in zwei verschiedene Erziehungsheime eingewiesen, wobei die Wegnahme der 9, 10, 14 und 15 Jahre alten Kinder unter Mitwirkung von Polizeibeamten geschah. Außerdem wurde der Ehefrau zur gleichen Zeit der Geschäftsbetrieb untersagt, und man nötigte sie zum Zwangsverkauf der kleinen Buchdruckerei und des Wohnhauses weit unter Wert. Der Personenwagen der Familie wurde ebenfalls beschlagnahmt.

Währenddessen saß Rolf Appel auf Anordnung des Reichskriegsgerichtes in Berlin in Untersuchungshaft. Dort wurde er fortwährend von den behördlichen Maßnahmen gegen seine Familie unterrichtet. Marie Appel, die ihren Mann einige Male in Berlin im Gefängnis besuchen konnte, folgerte daraus: „Man hoffte, daß er dadurch weich werden würde. In Verbindung damit machte man ihm täglich die größten Vorwürfe, wie unehrlich und gewissenlos er handele, indem er seine Familie im Stich ließe." 229

Rolf Appel ließ sich von seinem Entschluß auch durch die gegen seine Familie getroffenen Maßnahmen nicht abbringen. Am 29. August 1941 wurde der 39jähige daraufhin vom Reichskriegsgericht ,wegen Zersetzung der Wehrkraft (Wehrdienstverweigerung)“ zum Tode verurteilt. Sechs Wochen später ist das Urteil im Zuchthaus Brandenburg-Görden vollstreckt worden 230 .

Zumindest einmal war die Frage des vormundschaftsrechtlichen Vorgehens gegen die Zeugen Jehovas auch Gesprächsgegenstand im Reichsjustizministerium. Die zur Belehrung der Richterschaft und zur Anweisung der Rechtsprechungsorgane vom Reichsminister der Justiz seit Oktober 1942 herausgegebenen „Richterbriefe" griffen das Thema in der Nummer 3 im Dezember 1942 auf 231.

Nach seinem im August des Jahres erfolgten Amtsantritt versuchte der neue Minister Otto Georg Thierack mit allen Mitteln der „Justizkrise“ Herr zu werden, die durch eine am 26. April 1942 vor dem Reichstag gehaltene Rede Hitlers ausgelöst wurde, in der der ,Führer und oberste Gerichtsherr“ die deutsche Richterschaft

227 Zit. nach: Philipsen, Für den Glauben in den Tod, S. 41.

228 Der Bürgermeister von Süderbrarup, Schreiben vom 30.6.1941, abgedruckt in: Verfolgung der Zeugen Jehovas in Kiel, S. 50. Das Amtsgericht in Kappeln hatte mit BeschluB vom 18.6.1941 die vorläufige Fürsorgeerziehung angeordnet.

229 Der Erinnerungsbericht von Marie Appel ist unter der Überschrift „Eltern und Kinder setzen Jehova an die erste Stelle" wiedergegeben im Jahrbuch 1974, S. 187-190 (188). Vgl. zum Schicksal der Familie Appel den Aufsatz von Philipsen, Für den Glauben in den Tod; sowie Imberger, Widerstand, S. 370-373.

230 Vgl. Ehrenbuch Brandenburg-Görden, Band 2, S. 52; Bescheinigung des Oberreichskriegsanwalts, St.P.L. (RKA) I 175/41, vom 15.10.1941, abgedruckt in: Verfolgung der Zeugen Jehovas in Kiel, S. 49. Der älteste Sohn der Familie Appel wurde 1944 ebenfalls hingerichtet (siehe S. 364, Anm. 179).

231 BA, R 22/4002, Bl. 12, Richterbriefe, Mitteilungen des RJM, Nr. 3 vom 1.12.1942, Fallbeispiel Nr. 14 (dokumentiert in: Richterbriefe, S. 48-51). Die folgende Darstellung beruht - soweit nicht anders ausgewiesen - auf dieser Quelle. 
wegen ihrer vorgeblichen Nachsichtigkeit scharf gescholten hatte ${ }^{232}$. Die „Richterbriefe" gehörten zu jenem Bündel von Maßnahmen, das Thierack ergriffen hatte, um durch erhöhte Einwirkung auf die Justizorgane zu Gerichtsentscheidungen zu gelangen, die geeignet waren, bei den Parteispitzen jeden Zweifel an einer entschlossenen und ,schlagkräftigen“ Judikatur zu beseitigen.

In den mit dem Vermerk ,vertraulich“ versehenen Richterbriefen wurden einzelne Gerichtsentscheidungen kommentiert, die aus Sicht der Staats- und Parteiführung Fehlurteile waren. Auf diese Weise sollte den Richtern - wie Thierack ihnen gegenüber ausdrücklich erklärte - eine „Anschauung davon [gegeben werden], wie sich die Justizführung nationalsozialistische Rechtsanwendung denkt"233. Der Justizminister verband damit die Erwartung, daß sich das „Richterkorps“ fortan nicht mehr „sklavisch der Krücken des Gesetzes bedienen“ werde, womit zur Rechtsbeugung aufgefordert und damit die Bindung der Rechtsprechung an das Gesetz faktisch aufgehoben wurde.

Die Aufnahme einer abschlägigen Entscheidung, die zur Frage von Sorgerechtsentzug bei Bibelforschern ergangen war, in die dritte Ausgabe der „Richterbriefe“ scheint darauf hinzudeuten, daß nach Ansicht des Justizministeriums auch auf diesem Gebiet die Notwendigkeit zu einer solchen ,Lenkungsmaßnahme“ bestand 234 . Dem dort dargestellten Fall lag folgende Begebenheit zugrunde: Ein elfjähriges Mädchen war in der Schule dadurch aufgefallen, daß es unter Berufung auf seine religiöse Überzeugung fortgesetzt den „Deutschen Gruß“ verweigerte und sich bei „Fragen, die den Führer betreffen, [...] völlig uninteressiert“ zeigte. Da die Eltern das Verhalten des Kindes ausdrücklich billigten und es trotz „Belehrung“ durch die Schulleitung ,hartnäckig“ ablehnten, ,auf das Kind im gegenteiligen Sinne einzuwirken", beantragte das Jugendamt die Sorgerechtsentziehung für das elfjährige Mädchen und gleichzeitig - sozusagen präventiv - für deren noch nicht eingeschulte sechsjährige kleine Schwester. Das Amtsgericht Oberhausen lehnte mit Beschluß vom 21. März 1942 diesen Antrag jedoch ab und ordnete statt dessen, lediglich' die Schutzaufsicht an 235 .

Obwohl dieses Urteil in der Berufungsinstanz aufgehoben worden war - und somit das von den NS-Behörden angestrebte Ziel der Sorgerechtsentziehung über

232 Die Reichstagsrede vom 26.4.1942, in der Hitler drohte, „Richter, die ersichtlich das Gebot der Stunde nicht erkennen“, ihres Amtes zu entheben, wurde durch Abdruck im „Völkischen Beobachter" vom 27.4.1942 der Öffentlichkeit bekanntgegeben. Die Rede ist beispielsweise abgedruckt in: Staff, Justiz, S. 95-99.

233 Erklärung Thieracks vom 1.10.1942 anläßlich der Einführung der Richterbriefe, zit. nach Staff, Justiz, S. 68.

234 Zur Frage der Auswahl der in den „Richterbriefen“ angeprangerten Urteile hatte Thierack erklärt: „Diese Richterbriefe werden namentlich Entscheidungen enthalten, die mir nach Ergebnis oder Begründung besonders hervorhebenswert erscheinen. An diesen Entscheidungen möchte ich aufzeigen, wie eine bessere Entscheidung hätte gefunden werden können und müssen" (zit. nach Staff, Justiz, S. 68).

235 Vgl. Richterbriefe, S. 49. Vermutlich handelt es sich um den Fall der 1931 geborenen Margot M. aus Oberhausen, die 1942, nachdem das Sorgerecht ihren Eltern entzogen worden war, in ein Erziehungsheim eingeliefert wurde. Außerdem habe man ihr verboten, ,eine ordentliche Lehre durchzuführen“. Ihr Schicksal ist kurz erwähnt in: Wir „Hoch- und Landesverräter", S. 291. 
beide Kinder erreicht wurde -, fand der Fall Eingang in den „Richterbriefen“ ${ }^{236}$. Denn die Begründung, mit der das Oberhausener Amtsgericht das Begehren des Jugendamtes abgewiesen hatte, scheint den höchsten Justizstellen ausreichend Anlaß für eine Belehrung der Richterschaft gegeben zu haben.

Der Vormundschaftsrichter hatte sein Urteil zum einen darauf gestützt, daß die Eltern nach Lage der Dinge nicht mit hinreichender Sicherheit als Gegner des nationalsozialistischen Staates bezeichnet werden könnten. Nach seinen Feststellungen standen die Eltern der NS-Bewegung lediglich ,nicht sympathisch gegenüber und seien auch nicht gesonnen, sie zu fördern“. Doch solange die Eltern nicht mit den Strafgesetzen in Konflikt gerieten, böte diese Einstellung allein keinen ausreichenden Grund für den Entzug des Sorgerechtes. Zum anderen war der Richter zu dem Eindruck gelangt, daß die Erziehung der Kinder, von dem beanstandeten Verhalten in der Schule abgesehen, keinen Grund zum Einschreiten biete. Da von den Eltern aber zu verlangen sei, „daß sie der nationalsozialistischen Erziehung durch die Schule wenigstens nicht entgegenwirken“, sei eine weitere Beobachtung geboten. Aus diesem Grunde erfolgte die Verfügung der Schutzaufsicht, während die Sorgerechtsentziehung für vorläufig nicht erforderlich betrachtet wurde. Bei dieser Entscheidung ließ der Richter sich auch davon leiten, daß die Eltern nach seinem persönlichen Eindruck ,charakterlich durchaus zuverlässige Menschen“ seien.

Auf derartige Ausführungen mußte nach Ansicht der Justizoberen mit einer massiven Urteilsschelte reagiert werden. In der mit den Richterbriefen der gesamten richterlichen Beamtenschaft zur Kenntnis gegebenen Stellungnahme des Reichsministers der Justiz wurde dem Vormundschaftsrichter entgegengehalten, er habe ,die Grundsätze nationalsozialistischer Jugenderziehung verkannt“. Wie die amtliche Stellungnahme betonte, gehöre zu den Erziehungspflichten auch die ,rechtzeitige Vermittlung der Achtung und Ehrfurcht vor den Symbolen des Staates und der Bewegung". Von den Eltern fordere der Staat in diesem Sinne eine aktive Mitarbeit. In Richtung auf das inkriminierte Urteil heißt es weiter: ,Zurückhaltende Neutralität ist hier ebenso schädlich wie eine Bekämpfung der nationalsozialistischen Idee.“ Der Vormundschaftsrichter habe nicht erkannt, daß bereits „Gleichgültigkeit bei der Erziehung zum vaterlandsbewußten Volksgenossen“ eine schwere „Pflichtverletzung“ seitens der Eltern darstelle.

Insbesondere die begriffliche Trennung zwischen Gegner und Nicht-Förderer der nationalsozialistischen Bewegung, die in den Urteilsgründen Eingang gefunden hatte, rief im Justizministerium erbitterten Widerspruch hervor. Mit unmißverständlicher Deutlichkeit stellte das Ministerium klar: „Wer aus religiösem Irrglauben beharrlich den Deutschen Gruß verweigert, wer sich ohne Grund von dem großen

$\overline{236}$ Bei Weinkauff, Justiz, S. 165, ist dagegen zu lesen: „Der Richterbrief 3 forderte (und erreichte schließlich) die Entziehung des Sorgerechtes“. Diese Wortwahl des ehemaligen BGH-Präsidenten Hermann Weinkauff suggeriert, daß die Sorgerechtsentziehung erst aufgrund der ministeriellen Intervention zustande gekommen sei. Tatsächlich hatte das Berufungsgericht bereits vor der Aufnahme des Falles in den „Richterbriefen“ das Urteil der Vorinstanz korrigiert. In derartigen ,Verschiebungen“" spiegelt sich die Gesamttendenz dieses Standardwerkes wider, das die Verantwortung für die Pervertierung der Rechtsprechung im Nationalsozialismus weitgehend den „,brutalen Terrorisierungsmethoden“ des „,Regime Thieracks" (ebenda, S. 164) zuschreiben möchte, um den Beitrag der mehrheitlich nationalkonservativen Richterschaft für den Rechtsabbau im NS-Staat zu minimieren. Vgl. Der Unrechts-Staat, S. 123ff. 
sozialen Aufbauwerk der NSV ausschließt und seine Kinder absichtlich der HJ vorenthält und allen Belehrungen unzugänglich ist, von dem kann nicht gesagt werden, $\mathrm{da} ß$ er der Bewegung nur ,nicht sympathisch ' gegenüberstehe und sie nicht fördere. Er bekämpft sie durch seinen Widerstand und ist ihr Gegner." Jene differenzierende Sicht des Vormundschaftsrichters, der sich vor seinem Urteil auch von der sonstigen elterlichen Erziehung einen Eindruck verschafft hatte, fand im Reichsjustizministerium kein Verständnis. Mit derlei Erwägungen hatte sich ein deutscher Amtsrichter nicht zu befassen. Er hatte nur zu richten. Und dafür gab ihm der Reichsminister der Justiz in den „Richterbriefen“ eine klare Weisung mit auf den Weg: „Der Vormundschaftsrichter hätte daher das Sorgerecht mit der einfachen Erwägung entziehen müssen, daß Eltern, die sich offen zu den Ideen der ,Bibelforscher' bekennen, zur Erziehung ihrer Kinder im nationalsozialistischen Sinne nicht geeignet sind.“

Ein ranghoher Mitarbeiter im Reichsjustizministerium, dessen steile Karriere ihn im Dezember 1943 auf den Posten eines Staatssekretärs führte, war bereits Jahre zuvor mit dem Vorschlag hervorgetreten, bei einem „Mißbrauch des elterlichen Erziehungsrechtes" $\mathrm{zu}$ schärferen juristischen Mitteln zu greifen. Vorangegangen war eine Entscheidung des Reichsgerichtes. In einem Urteil vom 17. Februar 1938 hatte das höchste Strafgericht erklärt, daß schon die Zusammenkunft zu einer „Familienandacht" als eine verbotene Betätigung zu gelten habe, da die Gefahr bestünde, daß auf diese Weise der zwischen den bisherigen Mitgliedern der Glaubensgemeinschaft bestandene Zusammenhang im Rahmen der Familie fortgeführt werde und diese als „Keimzelle für die künftige Wiedereröffnung der Sekte“ nutzbar gemacht werden könne ${ }^{237}$.

In einer Kommentierung des Urteils ging jener Oberstaatsanwalt Dr. Herbert Klemm, seinerzeit noch Dezernent im politischen Generalreferat und Verbindungsführer zwischen Oberster SA-Führung und Reichsjustizministerium, noch einen Schritt weiter. Er meinte das Urteil so interpretieren zu können, daß eine verbotene Betätigung regelmäßig auch dann vorliege, wenn im Rahmen einer Familie auf die der Sekte nicht angehörenden Familienmitglieder Einfluß von seiten der anderen ausgeübt würde mit dem Ziel, diese für die Sache der verbotenen Glaubensgemeinschaft zu gewinnen. Dies sei beispielsweise dann der Fall, ,wenn sektierende Eltern ihre Kinder zu den Anschauungen der verbotenen Sekte erziehen“. Klemm blieb es vorbehalten, nachdem in den vorangegangenen Jahren mit den Instrumenten des Jugend- und Familienrechtes eingeschritten worden war, nun auch den Einsatz des Strafrechtes bei dem Staat nicht genehmer Erziehung zu fordern: ,Eine solche Erziehung stellt eine mit Strafe bedrohte Tätigkeit für die verbotene Sekte dar, da sie in hohem Grade geeignet ist, zur Bildung einer ,Keimzelle für die künftige Wiedereröffnung ' beizutragen. “238 Damit plädierte Klemm für eine strafrechtliche Verfolgung der Eltern und für Gefängnisstrafen bei einer Kindererziehung im Bibelforscherglauben ${ }^{239}$.

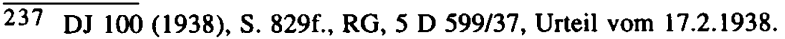

238 DJ 100 (1938), S. 830, Herbert Klemm, Urteilsanmerkung.

239 In einigen Erinnerungsberichten geben Eltern an, daß sie wegen der Erziehung ihrer Kinder gerichtlich verurteilt worden seien (vgl. Zürcher, Kreuzzug, S. 167). Die Wahrnehmung 


\section{„Pflegefamilien“, Heime und andere „Erziehungsanstalten“}

Vom weiteren Schicksal der Kinder nach erfolgter Sorgerechtsentziehung soll abschließend die Rede sein. Im Regelfall wurde von den Gerichten die Amtsvormundschaft angeordnet, teilweise wurden allerdings auch Einzelvormundschaften verfügt. Bei der Auswahl der Personen, denen die Vormundschaft und damit das Sorgerecht übertragen wurde, wird in erster Linie darauf geachtet worden sein, daß diese sich uneingeschränkt zu den nationalsozialistischen Erziehungszielen bekannten.

Die Jugendämter brachten die Kinder entweder bei „Pflegefamilien“ oder in Heimen unter. Da bei den Ämtern in der Frage der Unterbringung ,von Kindern aus politisch unzuverlässigen Familien“ keine einheitliche Auffassung bestand, verfügte das Reichsinnenministerium mit Runderlaß vom 27. Dezember 1938, daß eine „Fürsorgeerziehung“ in Anstalten ,nur dann in Betracht kommt, wenn außer oder infolge der politischen Unzuverlässigkeit der Familien Gefahr der Verwahrlosung der Kinder besteht oder Verwahrlosung bereits eingetreten ist“, während es in den meisten Fällen genügen werde, ,wenn das Jugendamt durch entsprechenden Antrag bei dem Vormundschaftsgericht einen Beschluß auf Unterbringung in einer anderen geeigneten, politisch einwandfreien Familie erwirkt" ${ }^{\prime 240}$.

$\mathrm{Zu}$ den ,politisch einwandfreien Familien“ zählten in erster Linie diejenigen von Staatsbediensteten und von Parteifunktionären. So kamen Kinder von Zeugen Jehovas beispielsweise in die Obhut der Familien eines Arbeitsamtsdirektors, eines Studienrates, eines städtischen Verwaltungsbeamten, eines Justizinspektors und eines NSDAP-Ortsgruppenleiters.

Die Wegnahme der Kinder von ihren Eltern, die jahrelange Trennung, teilweise ohne jede Kontaktmöglichkeit und Verbindung, und insbesondere die drastischen Erziehungsmaßnahmen, die häufig in den Heimen und erst recht in den NSFamilien bei dem Versuch, die Kinder in die ,nationalsozialistische Volksgemeinschaft" einzugliedern, angewandt wurden, bedeuteten persönliche Trägodien, die sich mit Worten kaum beschreiben lassen.

Das Alter der Kinder, für die „Familienunterbringung“ oder „Fürsorgeerziehung" angeordnet wurde, umfaßte vom Einschulungsalter an aufwärts alle Altersstufen von Minderjährigen ${ }^{241}$. Vielfach waren sie zu jung, um überhaupt begreifen

dieser Zeugen Jehovas kann sich dabei auf die ihnen in den Verhören oder vor Gericht gemachten Vorhaltungen stützen, und trotzdem täuscht sie, da es eine gesonderte strafrechtliche Bestimmung, die eine dem nationalsozialistischen Staat nicht genehme Kindererziehung ahndete, nicht gab. In zahlreichen Gerichtsverfahren wurde den Beschuldigten allerdings die „staatsfeindliche Erziehung“" ihrer Kinder erschwerend zur Last gelegt und konnte sich somit strafverschärfend auswirken. Auch nahm die Gestapo teilweise Zeugen Jehovas, deren Kinder in der Schule wegen Grußverweigerung o. ä. aufgefallen waren, in Schutzhaft.

240 DJ 101 (1939), S. 182, RMdI, RdErl. vom 27.12.1938. Die Düsseldorfer Staatspolizeistelle erklärte in einer Verfügung vom 30.4.1939 - unter Bezugnahme auf einen Gestapa-Erlaß vom 17. des Monats -, daß zu den ,politisch unzuverlässigen Familien“ auch die der Bibelforscher zu zählen seien (zit. nach Kater, Bibelforscher, S. 201).

241 Die Einschulung war praktisch gleichbedeutend mit der erstmaligen Konfrontation der Kinder mit den nationalsozialistischen Erziehungsansprüchen. Im Kleinkindalter blieben sie in der Obhut ihrer Familien weitgehend vor äußeren Einwirkungen verschont. Wenn sie dann jedoch als Erstkläßler auf Anweisung ihrer Eltern den „Deutschen Gruß“ verweigerten, begannen die Schwierigkeiten. In diesen Fällen drangen die Schulbehörden umgehend auf den Sorge- 
zu können, wieso sie gewaltsam von ihren Eltern getrennt wurden. So erging es beispielsweise Hans Neumann, der 1937 im Alter von sieben Jahren von zu Hause weggeholt und zuerst in ein Jugendlager und später auf einem Bauernhof untergebracht wurde. Er berichtet: „Während der ganzen Zeit hatte ich keine Ahnung, warum mir das alles widerfuhr. Meine Eltern waren sehr vorsichtig gewesen und hatten mir nicht viel erzählt [...] Daher verstand ich nicht, warum ich von ihnen getrennt worden bin. Ebensowenig verstand ich, warum der Bauer, der für mich verantwortlich war, mich immer schalt und mich einen Verbrecher nannte oder warum andere Kinder nichts mit mir zu tun haben wollten." 242

Auch wenn die Kinder ihre Lage verstandesmäßig oft noch nicht erfassen konnten, verhielten sie sich unter dem Eindruck der Trennung von ihren Eltern in ihrer neuen Umgebung häufig unzugänglich und widerspenstig. Die älteren Kinder und Jugendlichen setzten sich gegen die „Pflegeeltern“ oder die Heimerzieher zur Wehr, wenn diese - oftmals unter Anwendung körperlicher Gewalt ${ }^{243}$ - sie zum Nationalsozialismus ,bekehren' wollten ${ }^{244}$. Nicht selten führten Konflikte dazu, daß bei den Jugendämtern um anderweitige Unterbringung nachgesucht wurde. So wurde ein 17jähriger, der bei einer ,sehr nationalsozialistisch eingestellten Familie“245 einquartiert worden war, ,wegen Obdachlosigkeit“ in ein Jugendheim eingewiesen, weil - wie es in einem behördlichen Vermerk heißt - „der Quartiergeber ihn auf keinen Fall behalten wollte, da der Jugendliche sich mit den Gedankengängen der ,Ernsten Bibelforscher" befaßte und den deutschen Gruß verweigerte" 246 .

Mit Zwangsmaßnahmen erreichten die NS-Behörden, die Heime und die „Pflegefamilien" bei Bibelforscherkindern fast nie etwas. Diese waren - vielleicht mit Ausnahme der ganz Kleinen - schon so stark durch die familiäre Situation und das häusliche Bibelstudium geprägt, daß sie sich zumeist gegen alle derartigen Einwirkungsversuche sperrten. Das Kalkül der Nationalsozialisten, nach dem die

rechtsentzug. Das Amtsgericht Besigheim ordnete beispielsweise mit einer Eilentscheidung bereits fünf Tage nach Eingang eines vom Bezirksschulrat gestellten Antrags die vorläufige Fürsorgeerziehung im Fall von drei sieben- bzw. achtjährigen Kindern an. Vgl. UaP Rolf Zehender, Amtsgericht Besigheim, GR. 43-45/40, BeschluB vom 5.2.1940; Hildebrandt Hoffmann, Streiflichter, S. 43-45.

242 Hans Neumann: Meine Kindheit während des Nationalsozialismus, in: Erwachet, 22.8.1983, S. 23-27 (23).

243 Von Kindern, die sich im Erziehungsheim beharrlich weigerten, den „Hitler-Gruß“ zu erweisen, ist bekannt, daß sie zum Teil schwer mißhandelt wurden. Bei Zürcher wird beispielsweise von einem Jungen berichtet, der aus einem Heim entwich, weil er wiederholt geschlagen wurde. Vgl. Zürcher, Kreuzzug, S. 158.

244 Von einer Belastung blieben die „Fürsorgezöglinge“ allerdings verschont: Der Zwang zur Mitgliedschaft in der Hitler-Jugend entfiel, da das Gesetz bestimmte, daß Jugendliche wegen „Unwürdigkeit“" von der Zugehörigkeit zur HJ ausgeschlossen blieben, ,,solange sie behördlich verwahrt werden“ ( $\$ 3$ Abs. 2 der 2 . DVO zum Gesetz über die Hitler-Jugend, RGB1. 1939 I, S. 710).

245 So die Angabe der Schwester des Jungen in einem Interview vom 21.1.1983, zit. nach Verfolgung der Zeugen Jehovas in Kiel, S. 40. Nach ihren Angaben sei ihr Bruder (Walter Appel) von dem Quartiergeber angezeigt worden, weil er der Familie offen seine Meinung gesagt und seine Abscheu vor dem NS-Regime zu verstehen gegeben habe. Zum weiteren Schicksal des Jungen, der im Oktober 1944 wegen Verweigerung des Arbeitsdienstes hingerichtet wurde, vgl. die Schilderung bei Garbe, Gott mehr gehorchen, S. 210.

246 StA HH, Jugendbehörde I, 343b, Amt Walddörfer (Hamburg-Volksdorf), Abteilung für Jugendertüchtigung, 31.3.1944. 
Kinder nur dem „schädlichen Einfluß der Eltern“ entzogen werden müßten, um sie zu „,brauchbaren Gliedern der Volksgemeinschaft“ formen zu können, ging nicht auf. Im Gegenteil: Das Erlebnis der Trennung von den Eltern trug bei vielen Kindern und Jugendlichen noch zu einer Verhärtung ihrer Haltung bei. „Schwach zu werden" war für sie nicht nur - wie sie es gelernt hatten - ein Zeichen des Abfalls von Gott, sondern sie empfanden dies oftmals auch als einen Verrat an ihren Eltern.

In Erinnerungsberichten finden sich fast immer Hinweise darauf, daß die Kinder angesichts der übermächtigen Belastung nervlich völlig am Ende waren. Ein seinerzeit 15jähriges Mädchen, das 1941 in das Landesjugendheim Selent (Holstein) eingeliefert wurde, berichtete zum Beispiel davon, daß sie tagelang nur geweint und zunächst jede Nahrungsaufnahme verweigert habe ${ }^{247}$.

Ließ der Druck jedoch nach oder schwand nach monate- und jahrelanger Trennung die Erinnerung an die im Elternhaus erhaltene biblische Unterweisung, so konnte es dazu kommen, daß die Verweigerungshaltung aufgegeben wurde. Im Geschichtsbericht der Wachtturm-Gesellschaft heißt es dazu: „Es gab Fälle, in denen Kinder, die von den Eltern getrennt wurden, vorübergehend im Glauben schwach wurden und tatsächlich in der Gefahr standen, in das nationalsozialistische Lager abgetrieben zu werden, so, wie sich dies die Führer der ,Bewegung' gedacht hatten." 248 Nun wird man das Nachgeben der Kinder, ihre Mitwirkung bei der Hitler-Jugend oder die Bereitschaft zum Ableisten des Arbeits- und Wehrdienstes nur schwerlich als Ausdruck eines aktiven Bekenntnisses zum Nationalsozialismus werten können. Das eigentliche Problem bestand darin, daß mit einer sich auf diese Art äußernden Sinnesänderung nicht selten ein Prozeß der zunehmenden Entfremdung zwischen Eltern und Kind einsetzte, der teilweise auch über 1945 hinaus wirkte.

Wenn die Erziehungsbemühungen nicht zu den von den NS-Behörden erhofften Ergebnissen führten, reduzierte sich die „Fürsorgeerziehung“ auf eine reine Anstaltsverwahrung. Motiv der Unterbringung war damit nicht mehr die beabsichtigte „Umerziehung“, sondern der „Schutz“ der Gemeinschaft vor den ,unbelehrbaren“ Kindern der Zeugen Jehovas. Eine Aussonderung aus der „Fürsorgeerziehung" erfolgte aber zumeist nicht, obwohl diese nach den Bestimmungen des Jugendwohlfahrtsgesetzes das Vorliegen einer „Erfolgsaussicht“ voraussetzte (§63 Abs. 2 JWG). Ein Grund dafür mag sein, daß Bibelforscherkinder von den Heimleitungen als Arbeitskräfte in der Küche oder Landwirtschaft geschätzt wurden.

Der Kontakt zwischen den Eltern und den Kindern wurde von den Jugendämtern weitgehend zu unterbinden versucht. Oft wurde keine Schreiberlaubnis gewährt. Für Besuche der Eltern in den Heimen bedurfte es einer Einwilligung der Heimleitung oder des Jugendamtes. Auch diese wurde häufig verwehrt. Der Württembergische Landesfürsorgeverband lehnte 1942 im Fall einer Mutter, deren Ehemann im Januar des Jahres wegen Kriegsdienstverweigerung hingerichtet worden war, mehrere Gesuche auf Beurlaubung ihrer beiden zehn- und elfjährigen Kinder 
über die Sommerferien oder über Weihnachten ,aus erzieherischen Gründen“249 kategorisch ab.

Nach mehreren Berichten wurde der Aufenthaltsort der Kinder vor den Eltern gänzlich oder zunächst vorläufig verschwiegen. Auch der Abtransport der Kinder erfolgte zuweilen, ohne daß die Eltern von dem Termin zuvor in Kenntnis gesetzt worden waren 250 .

So erging es beispielsweise einer Mutter in Striegau (Schlesien), die mittags vergeblich auf die Rückkehr ihres 101/2jährigen Sohnes aus der Schule wartete. Als sie ihn daraufhin gesucht habe, hätten die Behörden jegliche Auskunft über den Aufenthaltsort ihres Sohnes verweigert. Erst nach einiger Zeit habe sie in Erfahrung bringen können, daß der Junge in ein Waisenhaus eingeliefert worden sei251. Ähnlich verfuhren die Behörden gegenüber einer Bibelforscherin aus Bad Lippspringe. In diesem Fall wurden drei 7, 9 und 13 Jahre alte Kinder ohne Benachrichtigung aus der Schule heraus fortgeschleppt. Ihre Tochter berichtet: „Mutter bemühte sich wochenlang, herauszufinden, wohin man die Kinder gebracht hatte. Schließlich erfuhr sie, daß sie sich in einem Erziehungsheim für sittlich verwahrloste Kinder in Dorsten befanden." 252

Um die Verbindung zu ihren Kindern nicht abbrechen zu lassen, unternahmen Eltern alle möglichen Versuche, die Kontaktverbote zu durchkreuzen. So wurden - teilweise auch unter Einschaltung einzelner Heimbediensteter - heimliche Treffen arrangiert oder Briefe geschmuggelt ${ }^{253}$.

Es gibt einzelne Hinweise darauf, daß sich Kinder und Jugendliche der „Fürsorgeerziehung" zu entziehen versuchten bzw. daß ihre Eltern sie dem behördlichen Zugriff entzogen. Aus Angst vor der drohenden Einweisung in ein Erziehungsheim - der Termin vor dem Amtsgericht war bereits anberaumt - brachte im Frühjahr 1937 der Karlsruher Franz Josef Seitz seinen zwölfjährigen Sohn Willi außer Landes, wo dieser zunächst im benachbarten Elsaß und später in der Schweiz Unterkunft fand ${ }^{254}$. Im gleichen Jahr unternahm ein Zeuge Jehovas während eines ihm zur Beerdigung seiner Ehefrau gewährten Hafturlaubes zusammen mit seinem Kind eine „dramatische Flucht in die Schweiz“, weil er nach dem Tod der Mutter mit der Wegnahme des Kindes rechnen mußte ${ }^{255}$.

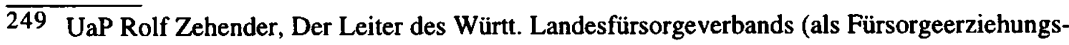
behörde), Bescheid vom 12.12.1942.

250 Vermutlich wollte man auf diese Weise verhindern, daß die Eltern, die sich massiv gegen die Anordnung der "Fürsorgeerziehung“ zur Wehr setzten, ihre Kinder vor dem Zugriff der Behörden verbargen, sie beispielsweise bei auswärtigen Glaubensgeschwistern versteckten. Ein anderer Grund ist in einem Schreiben vom Juli 1939 an die Gestapo Detmold angesprochen. Obwohl die Kreisamtsleitung der NSV bereits alle Vorbereitungen für die Unterbringung getroffen hatte, sollte dies der Mutter zunächst noch geheimgehalten werden, da man befürchtete, daß die Bibelforscherin, wenn „vorher etwas durchsickern würde, mit ihren Kindern in den Tod gehen würde“ (zit. nach Hopster/Moll, Lage, S. 37). Vgl. VVN HH, Komiteeakten A 11.

252 Bericht von Elisabeth Reuter, in: Der Wachtturm, 17, 1.9.1985, S. 12.

253 Vgl. Jahrbuch 1974, S. 18; Der Wachtturm, 1.1.1979, S. 22f.; Der Wachtturm, 1.9.1985, S. 12.

254 Vgl. EB Willi Seitz; Zürcher, Kreuzzug, S. 163f. Der Bericht ist dort unter der Überschrift „Flucht ins Ausland als einziger Ausweg" wiedergegeben.

255 Jahrbuch 1974, S. 122. 
Jugendliche, die sich in der „Fürsorgeerziehung“ den Anordnungen widersetzten, konnten schnell als schwerst- oder ,unerziehbar" eingestuft werden ${ }^{256}$. Nach einem Erlaß des Reichsministers des Innern vom 3. Oktober 1941 konnte in Fällen, in denen ,die Betreuung durch die Jugendhilfe, insbesondere auch Schutzaufsicht und Fürsorgeerziehung, versagt hat oder von vornherein erfolglos erscheint“"257, eine Überstellung an die Polizei zur weiteren „Unterbringung“ erfolgen. Auch einzelne Kinder von Bibelforschern wurden in die unmittelbar dem Reichskriminalpolizeiamt unterstellten Jugend-Konzentrationslager verschleppt ${ }^{258}$. Ob sie zu den wegen ,staatsfeindlicher Betätigung“ von der Gestapo eingelieferten Jugendlichen zählten oder ob sie wegen „Renitenz“ aus der „Fürsorgeerziehung“ in diese sogenannten ,Jugendschutzlager“ überstellt wurden, ist allerdings unbekannt.

Über das Schicksal der jungen Bibelforscher in diesen Lagern liegen nur sehr wenige Informationen vor. Vom Jugend-KZ Moringen ist bekannt, daß sich dort Bibelforscher der Arbeit in der Munitionsfabrikation widersetzten. Über derartige Verweigerungsaktionen liegen zwei Berichte ehemaliger Mithäftlinge vor. Nach den Angaben des einen Berichtes sei ein Bibelforscher, der erstmals zur Arbeit in der unterirdischen Munitionsfabrik ${ }^{259}$ eingeteilt worden war, am Eingang zum Schacht stehengeblieben und habe dort kategorisch erklärt, daß er weder ein Gewehr noch Munition je anfassen werde. Daraufhin hätten SS-Leute ihn festgehalten und ihm ins Hemd einige Granaten gesteckt. Der junge Bibelforscher habe sich gewehrt und die Granaten von sich geschmissen. „Da hat er Prügel gekriegt, bis er liegenblieb. Da dachten wir auch, der wäre tot. Aber der war zäh. [...] Der ist später wieder in die Muna gekommen. Der durfte im Arbeitsraum ausfegen, dem haben sie nie wieder Munition in die Hand gedrückt." 260

Auch der andere Bericht spricht von der unbeugsamen Haltung eines Bibelforschers, der die Arbeitsaufnahme in der Munitionsfabrik strikt ablehnte. Daraufhin habe der SS-Kommandoführer die Mithäftlinge aufgehetzt, auf den „Arbeitsverweigerer" einzuschlagen. Dieser Aufforderung seien auch Häftlinge nachgekommen, weil - wie ein Mitgefangener berichtet - ,sie ja dadurch, daß er nicht gearbeitet hat, haben mehr machen müssen. Jetzt haben die schon eine Wut gehabt auf ihn, weil sie gesagt haben: ,Der drückt sich vor der Arbeit und wir müssen das

256 Zum Selektionscharakter der Fürsorgerziehung im Nationalsozialismus vgl. Lampert, Sozialpolitik, S. 198. Danach haben die Jugendbehörden die „Eingliederungsfähigen“ in NSVJugendheimstätten, die „Halbguten“ in Erziehungsheimen und die „Schwersterziehbaren“ in den polizeilichen Jugendkonzentrationslagern untergebracht.

257 RMBliV 6 (1941), S. 1773, RMdI, RdErl. vom 3.10.1941, betr. Einweisung in das Jugendschutzlager Moringen. Dieses Lager für „männliche Minderjährige“ im Alter von 16 bis 21 Jahren war bereits ein Jahr zuvor in der südniedersächsischen Kleinstadt Moringen eingerichtet worden.

258 Für das Jugend-KZ Moringen ist belegt, daß dort eine kleinere Zahl von Bibelforschern inhaftiert waren. Vgl. Guse/Kohrs, Bewahrung, S. 145, 310f.; zu den Ergebnissen dieser nur als Maschinenschrift vorliegenden Diplomarbeit vgl. Das Jugendschutzlager Moringen; Guse/ Kohrs, Entpädagogisierung. Zur Geschichte des Lagers für „weibliche Minderjährige“, des Jugend-KZ Uckermark, von dem nicht bekannt ist, ob dort auch Kinder von Zeugen Jehovas gefangengehalten wurden, vgl. Hepp, ,Jugendschutzlager“ Uckermark.

259 In der $25 \mathrm{~km}$ entfernten „Heeresmunitionsanstalt Volpriehausen“ mußten die Häftlinge des Jugend-KZ Moringen in aufgelassenen Bergwerksstollen Zünder auf Granaten montieren. 
mitmachen!' Die haben das gar nicht verstehen können, was Bibelforscher heißt. [...] Ich weiß nur, daß sie ihn blutig geschlagen haben. Der hat dort gelegen und der hat nicht mal mehr einen Laut von sich gegeben. "261

Noch schlimmer erging es den Bibelforscherkindern, die nicht über die deutsche Staatsangehörigkeit verfügten. Am 13. Juli 1943 beantragte der Landrat des Kreises Teschen beim Landesjugendamt in Kattowitz die Einweisung eines erst 7jährigen Kindes ${ }^{262}$ in das „Polen-Jugendverwahrlager Litzmannstadt“. Der Landrat befürchtete, daß durch den Jungen, der bereits von der Schule verwiesen worden war, andere Kinder „staatsfeindlich beeinflußt werden"263. Da die Eltern als Bibelforscher die Aufnahme in die „Deutsche Volksliste“ verweigert hatten, gingen die deutschen Behörden mit rücksichtsloser Härte vor: Die 28jährige Mutter wurde „ausgesiedelt"; der Vater war bereits im Vorjahr im Alter von 32 Jahren ,verstorben“. Nun wurde das Kind in das berüchtigte Jugend-KZ Litzmannstadt (Lodz) eingeliefert. Ob es überlebte, ist nicht bekannt ${ }^{264}$.

Aber selbst in Fällen, in denen eine Wegnahme der Kinder unterblieb, weil zum einen die Eltern sich nicht mehr für die IBV in der Öffentlichkeit betätigten beziehungsweise die Gestapo davon keine Kenntnis erhielt, und weil zum anderen die Kinder in der Schule nicht wegen Grußverweigerung aufgefallen waren und ihrer „Jugenddienstpflicht“" genügten, waren diese Familien zahlreichen Benachteiligungen ausgesetzt. So wurde ihnen oftmals die gesetzliche Kinderbeihilfe ${ }^{265}$ verwehrt.

Ein Runderlaß des Reichsministers der Finanzen vom 30. Januar 1941 bestimmte, daß Kinderbeihilfe dann nicht gewährt werden dürfe, „wenn ihre Zahlung mit dem Zweck der Kinderbeihilfe nicht vereinbar sein würde“. Der Zweck wurde als „Förderung gesunder, gemeinschaftswürdiger, deutscher Familien“266 beschrieben. In den drei Monate später erlassenen Richtlinien wurden verschiedene Personengruppen benannt, denen Leistungen grundsätzlich zu versagen seien. Danach war von einer Unterstützung auszuschließen der „Haushaltsvorstand, der nach dem

$\overline{261}$ Zit. nach ebenda, S. 311. In einer anderen Veröffentlichung findet sich die Angabe, daß in der „Heeres-Muna“ Volpriehausen ein Zeuge Jehovas wegen der Weigerung, sich an der Kriegsproduktion zu beteiligen, ,zu Tode geprügelt" worden sei. Vgl. Heimatgeschichtlicher Wegweiser, Niedersachsen I, S. 38. Ob sich diese Notiz auf den hier angeführten Fall bezieht, läßt sich aufgrund der vorliegenden Berichte nicht beantworten.

262 Das RSHA hatte mit Erlaß vom 28.11.1942 das Einweisungsalter für das „Polen-Jugendverwahrlager Litzmannstadt" auf 8 bis 16 Jahre festgelegt (BA, R 22/1191); Roman Hrabar verweist darauf, daß in der Praxis auch vielfach Jugendliche unter 8 Jahren in dieses $\mathrm{KZ}$ eingeliefert wurden. Vgl. Hrabar, Osadzanie, S. 53.

263 Der Landrat des Kreises Teschen, Schreiben vom 13.7.1943, Hrabar, Osadzanie, S. 60.

264 Infolge der permanenten Unterversorgung und zahlreicher Mißhandlungen ist die Sterblichkeit im Jugend-KZ Litzmannstadt (Lodz) sehr hoch gewesen. Vgl. Hepp, „Jugendverwahrlager Litzmannstadt".

265 Die Verordnung über die Gewährung von Kinderbeihilfe an kinderreiche Familien vom 15.9.1935 (RGBl. 1935 I, S. 1160) sah zunächst nur einmalige Unterstützungszahlungen vor. Eine regelmäßige monatliche Unterstützung zum Lebensunterhalt ermöglichte die Kinderbeihilfen-Verordnung vom 9.12.1940 (RGBI. 1940 I, S. 1571f.). In der Regel wurde Kinderbeihilfe ab dem dritten Kind gewährt. Vgl. auch Lampert, Sozialpolitik, S. 195f.

266 Reichssteuerblatt 31 (1941), S. 105, Der Reichsminister der Finanzen, RdErl. vom 30.1. 1941. Nach den ein Vierteljahr später erlassenen Richtlinien war der Zweck der Kinderbeihilfe „ein bevölkerungspolitischer zur Stärkung des deutschen Volkes“. Folglich hätten „Gedanken der Wohltätigkeit und der sozialen Fürsorge [...] bei der Entscheidung über die Gewährung oder Versagung von Kinderbeihilfe auszuscheiden" (ebenda, S. 313). 
Urteil des Kreisleiters der NSDAP nicht gewillt oder nicht geeignet ist, in Treue dem Deutschen Volk und Reich zu dienen, der insbesondere die Kinder, für die er Kinderbeihilfe beansprucht, von einer Betätigung in der NSDAP oder einer ihrer Gliederungen fernhält‘"267.

$\mathrm{Daß}$ derartige Bestimmungen zuweilen auch dazu genutzt werden konnten, Antragsteller zu einem Parteibeitritt zu nötigen, zeigt der Bericht des Sohnes eines Hamburger Zeugen Jehovas: „Wir waren sieben Geschwister und sollten als kinderreiche Familie Kindergeld erhalten. Einen Monat bekamen wir es ausgezahlt. Den zweiten Monat kamen sie schon mit einem Fragebogen: Entweder das Geld weiter zu beziehen und in die Partei einzutreten. Oder auf alles zu verzichten. Meine Eltern haben sich kurz des letzteren entschlossen [... und haben] ihnen auch das Geld des ersten Monats sofort zurückgezahlt.“268

Die Unterlagen über einen aufschlußreichen Fall, in dem die Eltern beim Reichsstatthalter in Hamburg Einspruch ${ }^{269}$ gegen die Versagung der Kinderbeihilfe erhoben, sind erhalten geblieben. Die Eingabe datiert aus dem Jahr 1942. Die fünfköpfige Arbeiterfamilie war auf die Unterstützung angewiesen, da sie sich in einer wirtschaftlichen Notlage befand.

Von der Einspruchsstelle des Reichsstatthalters wurden Stellungnahmen verschiedener Behörden und Parteigliederungen darüber eingeholt, ob die Kinder ,im Sinne der heutigen Staatsauffassung erzogen werden“270. Die Schule sah ,keinen Anlaß zu irgendwelchen Klagen“, und selbst die Geheime Staatspolizei erhob gegen die Gewährung der beantragten Kinderbeihilfe „keine Bedenken“, da die Eltern ihre Mitarbeit in der IBV eingestellt hätten:

„Bei ihrer letzten Haftentlassung haben sie eine schriftliche Erklärung abgegeben, daß sie sich in Zukunft in keiner Weise mehr als Bibelforscher betätigen werden. Die Eheleute H. haben hier unter Nachüberwachung gestanden. Es konnte bisher nicht festgestellt werden, daß sie sich entgegen ihrer schriftlichen Erklärung weiterhin betätigt haben. [...] Nach hiesigen Erfahrungen haben sich die Bibelforscher, sobald sie sich erst endgültig von ihrer Irrlehre abgewandt haben, als sehr brauchbare und gewissenhafte Staatsbürger erwiesen. Nach dem Verhalten der Eheleute H. in letzter Zeit muß angenommen werden, daß sie auf dem Wege sind, sich ganz von der Bibelforscherei abzuwenden.“271

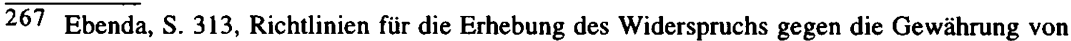
Kinderbeihilfe, gemeinsam erlassen vom Reichsminister der Finanzen, vom RMdI und vom Stellvertreter des Führers (für die Partei).

268 VVN HH, Komiteeakten G 21, Erklärung von Helmut H. vom 8.8.1946.

269 Wenn die Gewährung der gesetzlichen Kinderbeihilfe behördlicherseits verweigert wurde, konnte der Betroffene nur noch mittels einer „Eingabe“ bzw. eines „Einspruchs“ um Überprüfung der Entscheidung nachsuchen. Ein Erlaß des „Führers und Reichskanzlers“" vom 28.9.1939 (RGBl. 1939 I, S. 1535) hatte die Möglichkeit, auf dem Wege des Verwaltungsgerichtsverfahrens Abhilfe zu schaffen, auf wenige, hier nicht in Betracht kommende Ausnahmefälle beschränkt, so daß dem Betroffenen nur noch das Verfahren der einfachen Verwaltungsbeschwerde offenstand.

270 StA HH, Senatskanzlei-Präsidialabteilung, 1942 S III/1706, Der Reichsstatthalter in Hamburg, Einspruchsstelle, Schreiben vom 11.11 .1942 an den Polizeipräsidenten.

271 Ebenda, Staatspolizeileitstelle Hamburg, Schreiben vom 19.12.1942 (die Initiale wurde vom Verf. geändert). Beide Elternteile waren 1935 für mehrere Monate im KZ - der Vater in 
Die vorbehaltlose Zustimmung der Gestapo zur Gewährung der Kinderbeihilfe verblüffte die Sachbearbeiter bei der Einspruchsstelle, denn der Leiter des zuständigen NSDAP-Kreises hatte zwei Monate zuvor erklärt, daß der um Kinderbeihilfe nachsuchende Vater die nationalsozialistische Bewegung ablehne. Deshalb schrieb man erneut den Kreisleiter an, verwies auf die beigefügte Stellungnahme der Gestapo und bat um Auskunft, ob die von ihm übermittelte Feststellung ,erst in neuester Zeit getroffen worden“272 sei. In seiner Antwort erklärte der Kreisleiter des NSDAP-Kreises Hamburg 1, daß er von seiner seinerzeitigen Feststellung nicht abzurücken gedenke. Zum Beleg für die von ihm konstatierte NS-Gegnerschaft teilte er dem Reichsstatthalter die folgende Begebenheit mit:

„Die Ehefrau H. erklärte gelegentlich einer Vorladung am 13. ds. Mts., daß Gott den Krieg verurteile und sämtliche Regierungen an diesem Krieg schuld seien. Auf Befragen, ob sie und ihr Ehemann sich fürs Vaterland einsetzen würden, verneinte Frau H. dies, weil ihr Gott es verbiete. Wenn der Ehemann in den Krieg ziehen müßte, würde er sich lieber erschießen lassen.“273

Der Kreisleiter befand, daß aufgrund dieser Einstellung von ihm „die Bewilligung der Kinderbeihilfe [...] nicht befürwortet werden “ könne.

Der Reichsstatthalter und Gauleiter als oberster Dienstherr von Staatsverwaltung und Partei schloß sich dem Votum seines Kreisleiters an und lehnte die Beschwerde ab, weil die Eltern nicht gewillt seien, ,in Treue dem Deutschen Volk und Reich zu dienen“274. Außerdem hielt es Staatsrat Dr. Becker als Leiter der Einspruchsstelle für notwendig, die Gestapo unter Beifügung des Schreibens des Kreisleiters auf die wahre Haltung des Bibelforscher-Ehepaars aufmerksam zu machen ${ }^{275}$. Statt der erhofften Kinderbeihilfe gab es für Familie H. nur erneute Schwierigkeiten mit der Gestapo.

Esterwegen, die Mutter in Fuhlsbüttel. Der Mutter war 1937 das Sorgerecht über ihr ältestes Kind entzogen worden. Vgl. VVN HH, Komiteeakten; AfW HH, 160299.

272 StA HH, Senatskanzlei-Präsidialabteilung, 1942 S IIV/1706, Der Reichsstatthalter in Hamburg, Einspruchsstelle, Schreiben vom 6.1.1943 an den Kreisleiter des NSDAP-Kreises Hamburg 1.

273 Ebenda, Der Kreisleiter des NSDAP-Kreises Hamburg 1, Schreiben vom 19.2.1943.

274 StA HH, Senatskanzlei-Präsidialabteilung, 1942 S III/1706, Der Reichsstatthalter, Entscheidung vom 10.3.1943.

275 Ebenda, Der Reichsstatthalter in Hamburg, Einspruchsstelle, Schreiben vom 8.3.1943 an die Staatspolizeileitstelle Hamburg. 